OPEN ACCESS

Edited by:

Marco Faustini,

Sorbonne Universités, France

Reviewed by:

Davide Raffaele Ceratti,

Délégation lle-de-France Sud (CNRS),

France

Mateusz Odziomek,

UMR7574 Chimie de la Matière Condensée de Paris (LCMCP), France

${ }^{*}$ Correspondence:

E. D. Martínez

eduardo.martinez@cab.cnea.gov.ar

Specialty section:

This article was submitted to

Colloidal Materials and Interfaces,

a section of the journal

Frontiers in Materials

Received: 16 November 2020

Accepted: 11 January 2021

Published: 19 April 2021

Citation:

Martínez ED, Prado A, Gonzalez M, Anguiano S, Tosi L, Salazar Alarcón L

and Pastoriza H (2021) Recent

Advances on Nanocomposite Resists

With Design Functionality for

Lithographic Microfabrication.

Front. Mater. 8:629792.

doi: $10.3389 /$ fmats.2021.629792

\section{Recent Advances on Nanocomposite Resists With Design Functionality for Lithographic Microfabrication}

\author{
E. D. Martínez ${ }^{1,2,3 *}$, A. Prado ${ }^{1,3}$, M. Gonzalez $^{1,3}$, S. Anguiano ${ }^{1}$, L. Tosi ${ }^{1,2,3}$, L. Salazar Alarcón ${ }^{1,3}$ \\ and $H$. Pastoriza ${ }^{1,2,3}$
}

${ }^{1}$ Instituto de Nanociencia y Nanotecnología (INN), Centro Atómico Bariloche, Comisión Nacional de Energía Atómica (CNEA), SC. de Bariloche, Argentina, ${ }^{2}$ Consejo Nacional de Investigaciones Cientificas y Técnicas (CONICET), Buenos Aires, Argentina,

${ }^{3}$ Instituto Balseiro, Universidad Nacional de Cuyo (UNCuyo), S. C. Bariloche, Argentina

Nanocomposites formed by a phase-dispersed nanomaterial and a polymeric host matrix are highly attractive for nano- and micro-fabrication. The combination of nanoscale and bulk materials aims at achieving an effective interplay between extensive and intensive physical properties. Nanofillers display size-dependent effects, paving the way for the design of tunable functional composites. The matrix, on the other hand, can facilitate or even enhance the applicability of nanomaterials by allowing their easy processing for device manufacturing. In this article, we review the field of polymer-based nanocomposites acting as resist materials, i.e. being patternable through radiation-based lithographic methods. A comprehensive explanation of the synthesis of nanofillers, their functionalization and the physicochemical concepts behind the formulation of nanocomposites resists will be given. We will consider nanocomposites containing different types of fillers, such as metallic, magnetic, ceramic, luminescent and carbonbased nanomaterials. We will outline the role of nanofillers in modifying various properties of the polymer matrix, such as the mechanical strength, the refractive index and their performance during lithography. Also, we will discuss the lithographic techniques employed for transferring 2D patterns and 3D shapes with high spatial resolution. The capabilities of nanocomposites to act as structural and functional materials in novel devices and selected applications in photonics, electronics, magnetism and bioscience will be presented. Finally, we will conclude with a discussion of the current trends in this field and perspectives for its development in the near future.

Keywords: nanoparticles, nanotechnology, nanomaterials, electron beam lithography, photolithography, microactuators, photoresists, functional devices

\section{INTRODUCTION}

Lithography is an essential tool for nano-and micro-fabrication whose goal is to transfer a predefined pattern to a surface. To this end, the surface is coated with a polymer-based resist material sensitive to a particular form of radiation. Exposure may turn the resist more (positive-tone) or less (negativetone) soluble in certain solvents (developers). Photo-curing or photo-degradation in selected areas of the resist is achieved by two strategies: 1) through a homogeneous source of irradiation and a mask that blocks the incident radiation in selected regions or 2) through direct writing with a focused beam (maskless methods). Once developed, some regions of the substrate remain covered with the resist 
while others become exposed and, thus, are susceptible to etching or deposition of additional materials. Further details on lithography methods are given in the Appendix at the end of this article. Typically, polymeric resists are used strictly as sacrificial materials that serve as a cover or mold for the controlled deposition or etching of structural materials. Current trends attempt to shift this paradigm by employing polymer resists with enhanced functionalities, which can then act as operative components in microdevices. This is driving the development of custom-made nanocomposite materials (NCMs) to achieve particular physical and/or chemical properties. Specifically, we will refer to NCMs with lithographic capabilities as nanocomposite photoresists (NCPRs). These are typically composed of photoresists (PRs) loaded with different nanofillers (NFs), usually nanoparticles (NPs). Developing NCPRs is a current challenge that involves materials scientists, chemists, physicists, and engineers.

One of the foreseen applications of NCPRs is the development of novel microdevices. Well established technologies for microfabrication developed for the microelectronic industry are taking advantage of NCPRs, either for assisting in a fabrication process or for their integration as functional components in the final device. Regarding NCMs, many excellent reviews are available in the literature summarizing the impressive amount of work performed to improve the properties of polymers (Jordan et al., 2005; Paul and Robeson, 2008; Hanemann and Szabó, 2010; Sengupta et al., 2011; Fu et al., 2019; Chow and Mohd Ishak, 2020). Polymer based NCMs are soft-matter candidates for many applications in micro-robotics (Hines et al., 2017; Hu et al., 2018; El-Atab et al., 2020; Vieille et al., 2020). A recent review by Kuang and co-authors deals with the general topic of shape programmable materials (Kuang et al., 2020) and the complementary recent paper by Zhou et al. focuses on the different strategies for printing 3D structures using soft polymers, including NCMs (Zhou et al., 2020). Different types of magnetic NCMs containing also carbon or metal NPs within shape memory polymers, liquid crystals, elastomers, azobenzenes, hydrogels, and bio-hybrids have been used to make "smart" shape-morphing materials, as explained in the recent review by Shen and co-workers (Shen et al., 2021). In comparison, NCPRs have received considerably less attention. A pioneering work by Webb and Hatzakis (Webb and Hatzakis, 1979) in the late 70s showed the possibility of modifying poly(methyl methacrylate) (PMMA) resists for EBL with metal methacrylates. Several works published in the late 90s were devoted to enhancing the lithographic capabilities (sensitivity, contrast, etch resistance, etc.) of commercial PRs, which to some extent are patent-protected (Ishii et al., 1997; Dutoit et al., 1999; $\mathrm{Hu}$ et al., 2001). The following progress in the synthesis of nanomaterials and micro-fabrication techniques pushed forward the development of NCPRs with improved functionalities. Other NCMs used in micro-fabrication are only suitable for non-radiation lithography, such as nanoimprint and other soft lithography techniques (Qin et al., 2010) and will not be considered as NCPRs.

In this work we will focus on the development and application of NCPRs, following previous efforts on this matter (Ingrosso et al., 2010; Song et al., 2015; Brighenti et al., 2020). We review the state-of-the-art in the development of NCPRs used for nano- and micro-fabrication of functional components by lithographic techniques as outlined in Figure 1. We describe the use of NPs as filler materials in polymer solutions that are sensitive to some form of radiation (UV, X-Ray, electrons, etc.), including commercial PRs and polymer/monomer solutions produced adhoc. We summarize the developments and applications of NCPRs containing different types of nanoparticles, such as metallic, magnetic, ceramic, luminescent and carbon-based nanomaterials while describing the different strategies used to control the homogeneous dispersion of NFs and the lithographic techniques employed. Moreover, we discuss frontier approaches where hybrid organic/inorganic nanocomposites are brought together to obtain combined benefits.

\section{ANATOMY OF A NANOCOMPOSITE RESIST}

The development of composite materials has been a constant drive throughout our history. From the first mud and straw brick ever fabricated we have now progressed to the point that physical properties can be controlled down to the atomic scale. The essential goal behind composites is straightforward: to combine the properties of interest of two or more materials in the most advantageous way. In their simplest form, composites consist of a disaggregated material (filler) dispersed in a physically and chemically distinct continuous material (matrix). The interface formed between the matrix and filler determines the mechanical strength of the composite and the energy required to separate the components.

Depending on the shape and distribution of the filler particles, composite materials can display anisotropic properties which should be carefully considered when applied to the manufacturing of complex structures and devices. Moreover, important considerations must be taken into account when the filler consists of nanoscale objects. Firstly, the physical properties of the NFs depend on their size and can be anisotropic. Secondly, the reduced size of the NFs implies a high surface-to-volume ratio. Thus, the role of the interface acquires special relevance and may even dominate the properties of the compound. Finally, the methods of NF manufacture are radically different from those used for macroscopic fillers. In general, NFs are synthesized through bottom-up approaches, starting from molecular precursors to promote the controlled nucleation and growth of NPs. The particle size distribution (PSD), shape and chemical properties of the NFs can be readily controlled; however, the quantities obtainable from a single batch are small and therefore not easily scalable for industrial production. Thus, NCMs are usually reserved for specific applications where small quantities are required.

\subsection{The Host Matrix}

As we are interested in NCMs with lithographic capabilities (NCPRs), we will consider polymers as the material of choice for the matrix. However, porous inorganic materials have been 


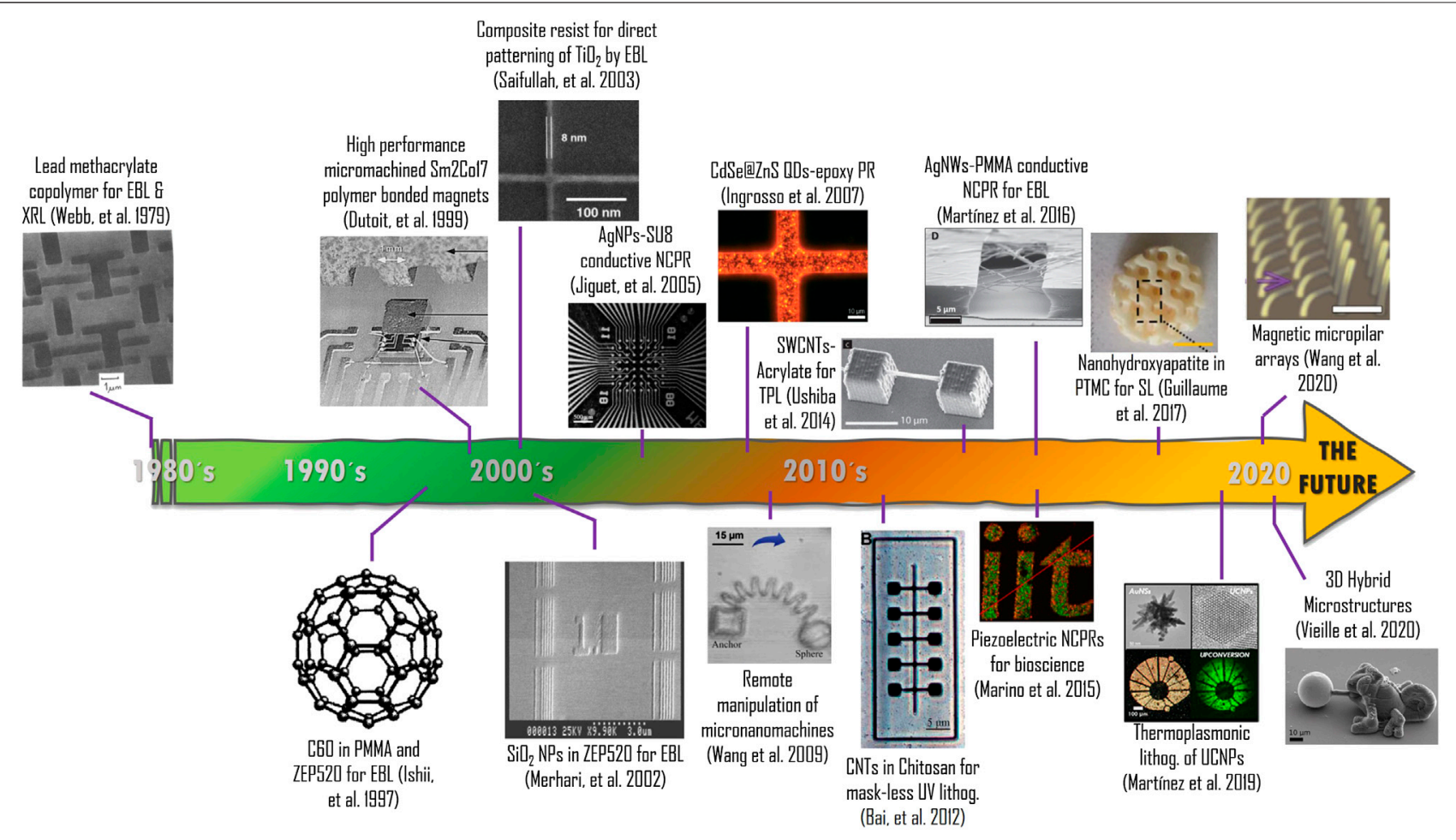

FIGURE 1 | Timeline showing progress in the field of NCPRs. Selected results involving different NCPRs and applications.

shown to be suitable candidates as well, also acting as intermediates in the photo-catalytic in-situ formation of NPs (Martínez et al., 2009; Martínez et al., 2010; Malfatti et al., 2016; Innocenzi and Malfatti, 2018). Most cases discussed in the following sections make use of photo-sensitive polymers in the form of a polymer solution. These PRs are in many cases commercially available and commonly used in microfabrication. Other radiation-sensitive polymers formulated ad-hoc have been explored as host materials for pre-synthesized NFs or for their in-situ formation using different thermal or radiation-exposure procedures. We will distinguish between these two approaches and describe selected experimental results in the following sections.

Here, we give a short description of the most popular commercial PRs employed in the formulation of NCPRs classified according to their composition. Additional details on the photochemistry of PRs can be found elsewhere (Henderson, 2012).

(1) Epoxy-based photoresists: by far, the main example is SU-8, a negative tone resist whose main component is the bisphenol A epoxy oligomer. It contains eight epoxide groups exposed for further cross-linking. Gamma (c)butyrolactone (GBL) or cyclopentanone (CPN) may constitute the solvent, depending on the formulation. SU-8 contains up to $10 \mathrm{wt} \%$ triarylsulfonium hexafluroantimonate salt, a photo-acid generator. When exposed to UV light (typically the i-line at $365 \mathrm{~nm})$, the photo-acid decomposes to form hexafluoroantimonic acid, which protonates the epoxides on the oligomer. Subsequent heating of the polymer activates the cross-linking and regenerates the acid catalyst. The high degree of cross-linking, which can be further enhanced with a final thermal treatment ("hard bake") at temperatures between $150^{\circ} \mathrm{C}$ and $200^{\circ} \mathrm{C}$, results in excellent mechanical properties (Young's modulus $E$ 4-5 GPa, glass transition temperature around $200^{\circ} \mathrm{C}$ ). This makes SU-8 the preferred choice for high aspect ratio lithography and for the fabrication of polymeric structural components (Campo and Greiner, 2007). SU-8 has been repeatedly modified for different purposes through the incorporation of molecular additives and NFs (Dutoit et al., 1999; Jiguet et al., 2004; Damean et al., 2005; Jiguet et al., 2005; Jiguet et al., 2006a; Chiamori et al., 2008; Dawan et al., 2008; Mionic et al., 2009; Fischer et al., 2015; Kandpal et al., 2015; Li et al., 2018; Nguyen et al., 2018; Perry et al., 2019).

(2) DNQ-Novolak photoresists: these are phenol-formaldehyde copolymer-based positive tone resists. The photo-active molecule diazonaphthoquinone (DNQ) acts as a dissolution inhibitor, being insoluble in basic solutions. When exposed to UV light (i-line at $365 \mathrm{~nm})$, DNQ decomposes through Wolff rearrangement and produces gaseous nitrogen and an indene carboxylic acid, which is base-soluble. Therefore, exposed areas dissolve much faster in basic developer solutions. The sensitizer concentration may be as high as $40 \mathrm{wt} \%$ of the resist. The typical solvent for Novolak 
resists is 2-methoxy-1-methylethyl acetate, also called propylene glycol methyl ether acetate (PGMEA). Novolak resins may be modified to produce an image reversal, meaning that the exposed regions remain insoluble while the unexposed ones dissolve. To achieve this, basic additives such as monazoline, imidazole, and triethylamine are included in the resist formulation. Also, additional baking steps and UV exposure are required to complete the reactions and finally obtain a negative image of the mask (Reichmanis et al., 1999). Popular negative tone resists for EBL like ma-N are also based in the Novolak chemistry. DNQNovolak based PRs have been modified with NFs in several works (Marques-Hueso et al., 2010; Abargues et al., 2013; Pudlauskaite et al., 2013).

(3) Poly(methyl methacrylate) (PMMA) is a popular polymer for EBL, x-ray lithography (XRL) and deep UV (193-254 nm) lithography. It acts as a high-resolution positive tone resist due to chain scissions upon exposure to radiation. Commercial formulations of PMMA PRs are anisole (type A) or chlorobenzene (type C) based solutions of a methyl methacrylate polymer $(495,000$ or 950,000 molecular weight) in varying concentrations (2-11 wt\%). PMMA has been modified with NFs in several works (Ishii et al., 1997; Vaudreuil et al., 2007; Persano et al., 2012; Palevicius et al., 2013; Martínez et al., 2016; Dusoe et al., 2017; Tiwale et al., 2019).

(4) ZEP520, another interesting PR for EBL, is based on the alternating copolymer poly( $\alpha$-chloroacrylate-coa-methyl styrene) which undergoes chain scission under electron-beam irradiation, therefore acting as a positive tone resist. The PR is a solution of the copolymer in anisole or o-dichlorobenzene. For NCPRs based in ZEP520 see for example (Ishii et al., 1997; Hu et al., 2001; Merhari et al., 2002).

(5) Polydimethyl siloxane (PDMS) is another largely explored material for the matrix component of NCMs because of its excellent biocompatibility, optical transparency and tunable mechanical properties. PDMS is widely used for microfluidics and microstructuring through soft-lithography methods (Qin et al., 2010; Liu and Choi, 2012; Ozhikandathil et al., 2015). Although this is not a photo-sensitive polymer, the inclusion of photo-initiators and additives in the formulation of PDMS has been reported to allow photo-patterning (Iojoiu et al., 2000; Bhagat et al., 2007; Cotton et al., 2011) enabling its use in the development of NCPRs. Different groups reported the preparation of PDMS-based nanocomposites containing $\mathrm{Au}$ NPs (Fedoruk et al., 2013; SadAbadi et al., 2013; Romanenko et al., 2020), Ag NPs (Cong and Pan, 2009), Ag nanowires (Martinez et al., 2015; Shuai et al., 2017), magnetic NFs (Chung et al., 2011) and carbon nanotubes (Khosla and Gray, 2010; Liu and Choi, 2012; Li et al., 2019a; Lee et al., 2019). PDMS nanocomposites with carbon based nanofillers was recently reviewed (Kausar, 2020).

\subsection{Nanoparticles as Filler Materials}

We shall refer as NFs to particles used as fillers with at least one dimension in the $1-100 \mathrm{~nm}$ range. A broad spectrum of NFs are of interest for specific applications, and this review is structured in relation to their different types. Silica particles, clay nanoplatelets and other ceramic NPs are employed to improve the mechanical strength of the patterned structures (Tjong, 2006; Ligon-Auer et al., 2016). Carbon based nanomaterials, such as carbon nanotubes (CNTs) and graphene are specially interesting for their mechanical (Moniruzzaman et al., 2006; Mionić et al., 2010; Sengupta et al., 2011) and electronic characteristics (Khosla and Gray, 2009; Majidian et al., 2014). Metallic nanowires (NWs) can act as electrically conductive fillers (Hu et al., 2016; Martínez et al., 2016; Zhao et al., 2017). NFs made of noble metals display plasmonic resonances (Maier and Atwater, 2005; Yu et al., 2019b) and, together with photoluminescent nanomaterials, such as quantum dots (QDs) and upconversion nanoparticles (UCNPs), may be used in NCPRs for photonic applications (Ingrosso et al., 2007; Abargues et al., 2008; Kaboli et al., 2019). Iron oxide NPs can provide magnetic properties to NCPRs for the microfabrication of magnetic actuators (Ingrosso et al., 2009; Liu and Han, 2010; Chung et al., 2011).

The morphology of NFs is also relevant in terms of their intrinsic anisotropic properties, since these can be transferred to the whole NCPR. Elongated NPs, nanorods, NWs, CNTs and others can be isotropically dispersed in the NCPRs or be aligned in a given direction for a "designed anisotropy" (Ma et al., 2014; Ushiba et al., 2014; Xiong et al., 2016). Also, the size of the NFs plays a mayor role because: 1) it determines the surface-tovolume ratio and therefore the relevance of the interface between the NFs and matrix; 2) the properties of nanoscale objects may be strongly dependent on their size, as in the case of plasmonic NPs and QDs. In this regard, many intensive physical properties may become extensive. NFs have an important influence on the optical properties of NCPRs and their response to radiation (Caseri, 2000). Depending on the filling fraction of NFs and their composition they can affect negatively to the penetration depth and resolution because of an increased absorption and scattering of UV light, producing undesired masking effects (Jiguet et al., 2004; Jiguet et al., 2005; Dawan et al., 2008). However, positive effects on lithography can also result from the incorporation of NFs. For example, NFs with atomic numbers higher than that of the polymer reduce electron scattering during EBL, thus increasing the resolution (Ishii et al., 1997; Hu et al., 2001; Merhari et al., 2002). NFs can also improve the resistance to chemical or plasma etching (Hu et al., 2001; Merhari et al., 2002; Ali et al., 2003) and increase the refractive index of polymer matrices (Bremer et al., 2009; Bae et al., 2010).

\subsection{Synthesis of Nanofillers}

A vast list of chemical recipes is available in the literature to produce common NFs with a high degree of control in terms of size, shape and composition. In the following, we present a list of the most relevant and commonly used synthesis routes. 
(1) Synthesis of plasmonic Au and Ag NPs follows classical methods from Turkevich (Turkevich et al., 1951; Kimling et al., 2006) and Brust (Brust et al., 1994), or variations of these. Briefly, noble metal-precursor salts (silver nitrate, silver acetate, tetrachloroauric(III) acid, chloro(triphenylphosphine)gold(I) and others) are submitted to a redox reaction using reducers such as sodium borohydride, ascorbic acid, sodium citrate, oleylamine and many others. Because the standard reduction potentials of $\mathrm{Ag}(\mathrm{I}), \mathrm{Au}(\mathrm{I})$ and $\mathrm{Au}(\mathrm{III})$ are positive and relatively high (above $0.7 \mathrm{~V} \mathrm{NHE}$ ), the reaction must be carefully controlled in order to avoid rapid growth and precipitation of the solid phase. For this purpose, stabilizing molecules are added, which bond to the reduced metal ions and form a capping layer protecting the nucleated NPs. This capping favors the formation of stable colloids by preventing the aggregation of NPs through either steric or electrostatic repulsion. In some cases, mild reducers can act as capping agents, for example, oleylamine and sodium citrate; in others, surfactants are used for stabilization. The synthesis of $\mathrm{Au}$ and Ag NPs can be carried out in water or in nonpolar solvents. Ligand exchange can be performed afterward, to favor the phase transfer from organic to aqueous solvents, or viceversa (Yang et al., 2011). To achieve this, thiols (Woehrle et al., 2005) and amine ligands are the preferred option.

(2) Metal chalcogenide QDs and UCNPs are typically produced by thermal decomposition of organo-metallic precursors (Mai et al., 2006; Valizadeh et al., 2012; Hu and Zhu, 2015) or by co-precipitation methods (Wang et al., 2014) using high boiling point organic solvents, high temperatures $\left(250-330^{\circ} \mathrm{C}\right)$ in an oxygen-free atmosphere.

(3) Iron-oxide-based magnetic NPs are typically produced using similar procedures through thermal decomposition of $\mathrm{Fe}$ (acetylacetonate) ${ }_{3}$ and other organo-metallic percursors. In many cases, the same solvents and surfactants employed for UCNPs and QDs are used (1-octadecene, octadecane, benzyl/phenyl ether, oleylamine, oleic acid, etc.) (Sun and Zeng, 2002). The co-precipitation method is also a conventional route for the synthesis of $\mathrm{Fe}_{3} \mathrm{O}_{4}$ and $\gamma-\mathrm{Fe}_{2} \mathrm{O}_{3} \mathrm{NPs}$ (Wu et al., 2008). This can be done in aqueous, highly basic and anaerobic conditions, from mixtures of $\mathrm{Fe}(\mathrm{II})$ and $\mathrm{Fe}(\mathrm{III})$ salt precursors.

(4) Silica NPs are synthesized through sol-gel methods in a process resembling an inorganic polymerization. A widely popular method, developed by Stöber et al. in 1968 , consists in the controlled precipitation of prehydrolized tetraethylorthosilicate (TEOS) in ethanolic solution upon the addition of ammonia (Stöber et al., 1968).

(5) Similarly, sol-gel synthesis of metallic oxide NPs makes use of metallic salts and alkoxide precursors in alcoholic solution. Because these precursors are highly sensitive to water and prone to hydrolysis reactions, stabilizing molecules are added to form metal coordinated complexes. These help to control the condensation reactions and allow fine tuning of the PSD.

All methods described above share a general synthesis rule: in order to achieve narrow PSD, i.e., monodisperse colloids, the stages of nucleation and growth must be carefully separated. Readers are encouraged to visit a review article by Park et al. with details on most of the synthesis routes for NPs of different materials (Park et al., 2007).

\subsection{Nanoparticle Surface Functionalization}

The main objective in the formulation of a NCPRs is achieving a homogeneous and stable dispersion of the NFs. Understanding what affects the distribution of the NFs in the polymer matrix is therefore mandatory, including knowledge of the acting forces and kinetics involved in the two-phase system. In terms of energy, two contributions should be considered: enthalpic and entropic. The former includes the chemical affinity, electrostatic repulsion of charged NPs and intermolecular forces between polymers; the latter takes into account the conformational state of the polymer chains, inducing their collapse, crowding and mixing. Importantly, the relative weight of these two contributions depends on the size (or equivalently the molecular weight) of the polymer chains, being the enthalpic contribution dominant for short-chain polymers (Schadler et al., 2007).

Compared to micron-sized fillers used in industrial polymer composites, NFs have a significantly larger surface-to-volume ratio and, thus, all properties related with their surface chemistry are crucial for the physico-chemical features of NCMs in general and NCPRs in particular. To give an idea of the surface areas involved, for spherical particles of $10 \mathrm{~nm}$ in diameter, each NP accounts for a surface of $3.14 \times 10^{-16} \mathrm{~m}^{2}$. In a NCM with $10 \mathrm{vol} \%$ of this NF the total interface area would amount to $6 \times 10^{7} \mathrm{~m}^{2} / \mathrm{m}^{3}$, meaning $60 \mathrm{~m}^{2}$ of surface area in a single milliliter of the NCM. Considering that the specific surface energy of inorganic materials $\left(200-1,500 \mathrm{~mJ} \mathrm{~m}^{-2}\right)$ is higher than that of polymers $\left(10-50 \mathrm{~mJ} \mathrm{~m}^{-2}\right)$, the dynamics of NCMs is strongly driven by the need to reduce this energy. One way of achieving this is by agglomeration of the NFs. To prevent this, the surface energy of the NFs must be reduced before their incorporation into the polymer matrix. This may be achieved by surface modification, i.e., through the formation of an organic capping around the NFs with a higher affinity to the solvent and polymer molecules. This way, particle-polymer enthalpic interactions can be more effective in reducing the total energy than particle-particle interactions, favoring the homogeneous dispersion of NFs in the polymer matrix and resulting in a thermodynamically stable system (Caseri, 2000; Caseri, 2006).

In general, the incorporation of NFs in NCMs can be done without solvents, for example, through melt blending and mixing. However, NCPRs have the important peculiarity that the resist always includes a solvent, i.e., a volatile liquid phase that allows the formation of films on flat surfaces via spin- or dip-coating methods. Also, different additives are present in NCPRs in order to control the sensitivity to light (or other forms of radiation) for lithography. The presence of a solvent is fundamental for 


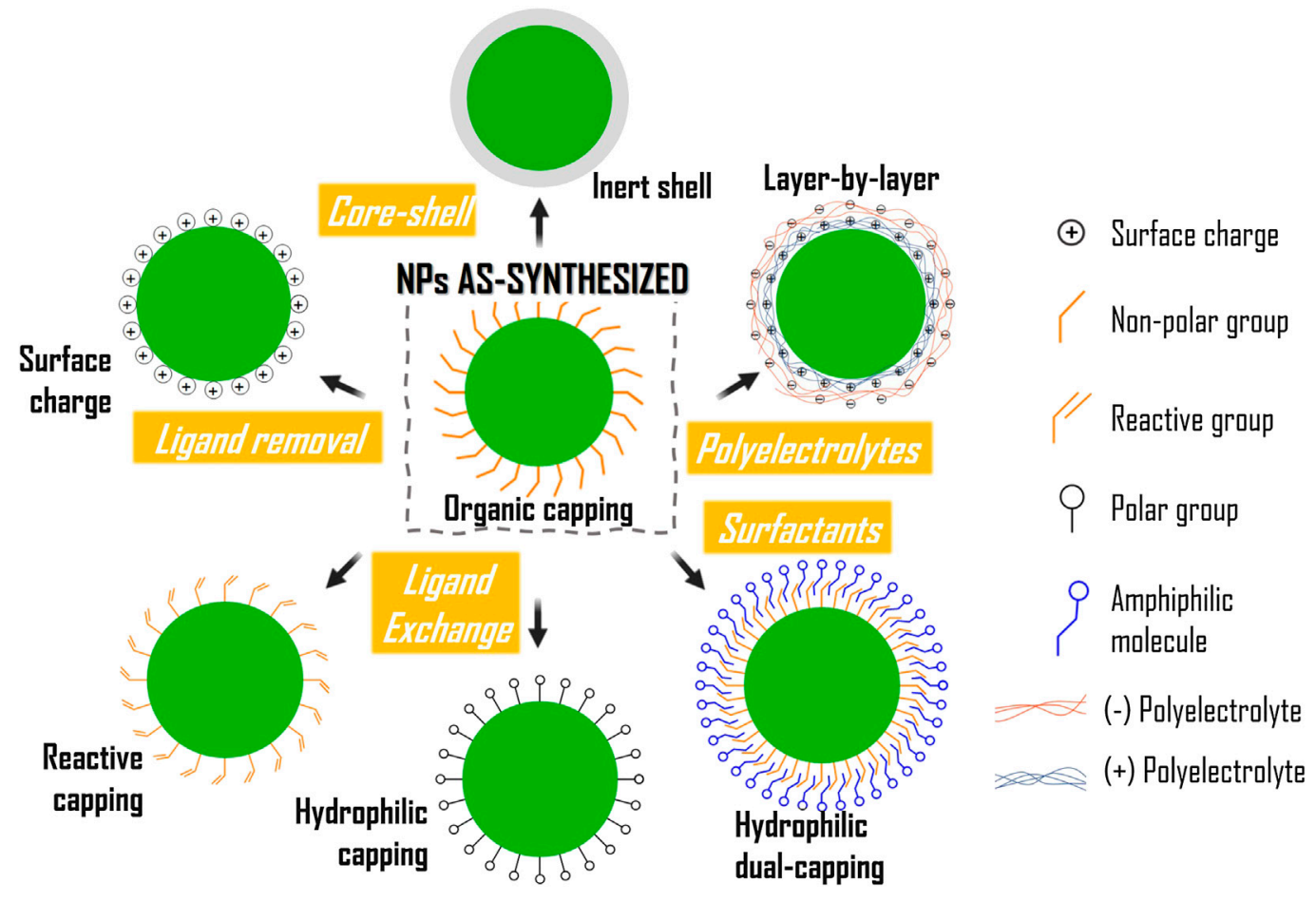

FIGURE 2 | Alternative methods for surface modification of NFs after their synthesis. The organic capping of as-made NFs can be removed or replaced by ligand exchange, the growth of an inorganic inert shell (e.g. silica), or by coating with polyelectrolytes (for aqueous colloids).

regulating the dynamics of polymers and NFs, and the rheological properties of the NCPRs before coating.

NCPRs are typically prepared by mixing a PR with NF colloids (ex-situ methods) or with a solution of the corresponding precursors (in-situ methods) in a miscible solvent (co-solvent). As a rule of thumb, the co-solvent must be able to wet the NF's surface in order to form a stable dispersion; otherwise, functionalization is required. In many works, however, commercial colloids are used as NFs without modification. This requires strong mixing strategies, such as overnight stirring or prolonged sonication in order to obtain a relatively stable colloid with a limited shelf-life (Jiguet et al., 2004; Damean et al., 2005). More recent efforts seek to incorporate covalentbonded polymer chains to the surface of NFs. This can be accomplished by two different strategies known as "graftingto" and "grafting-from" (Tsubokawa, 2007; Kumar et al., 2013). In the grafting-to approach the polymer chains of the matrix contain functional groups with a strong affinity to the surface of the NFs. During the formulation of the NCPRs the NFs anchor to the polymer chains, or their monomers/oligomers, losing their independent mobility. The main drawback of this strategy lies in the low grafting density due to steric repulsion and slow chain diffusion. In the grafting-from approach the surface of NFs is first modified with the binding of either polymer chains or initiators of the polymerization reaction. Despite the greater synthesis complexity of this approach, a higher grafting density and the possibility for an advanced chemical design are worthy advantages (Kumar et al., 2013). The use of polymer-grafted
NFs makes the role of entropic forces more relevant. The size of NFs relative to that of free polymer chains determine the depletion forces that can induce aggregation (Firestone et al., 2015). Also, as the reduced size of the NFs implies a high curvature, the molecular dynamics of the grafted polymers depart from the known behavior of grafted flat surfaces (Schadler et al., 2007).

A schematic representation of the possible modifications to the NFs after their synthesis is depicted in Figure 2. NPs can be submitted to additional treatments after synthesis in order to achieve the desired chemical interaction with the solvent or polymer matrix. Examples are ligand removal or exchange (Kong et al., 2017), phase transfer using surfactants (Wu et al., 2012), formation of polyelectrolytes multilayers (Palo et al., 2018) or the growth of a silica shell layer (Liu and Han, 2010). Ligands may be generally described as containing an anchoring group, i.e., chemical moieties that will interact with the surface of NPs, and a terminal (also called functional) group that will give the desired chemical function. While the selection of the functional group will depend on the target application (here to ensure the compatibility with the solvent or polymer resist) the selection of the anchoring group depends on the composition of the NPs. For metallic NPs (mainly Ag, Au) thiol and disulfide groups are mostly employed (Woehrle et al., 2005). Sulfur shows the highest affinity to noble metal surfaces. Amines are also common although the binding energy to metals is lower than that of tiolates (Neouze and Schubert, 2008). In particular, quaternary ammonium cations like tetraalkylammonium halides are very 
much used due to their amphiphilic properties. A weaker interacting group for metal are phosphines. For example, triphenylphosphine is usually used for protecting Au NPs. Due to their weaker interaction, phosphines may be easily replaced through ligand exchange reactions. Finally, negatively charged carboxylate groups, obtained by deprotonation of carboxylic acids, coordinate to metal surfaces. However, these are easily replaced in the presence of any of the previously mentioned groups. For metal oxide NPs, the main compounds used for surface modification are phosphonates and silanes. Modification of a metal (M) oxide surface by phosphonate groups creates $\mathrm{M}-\mathrm{O}-$ $\mathrm{P}$ bonds forming mono-, bi-, or tridentate anchoring. Silanes react with surface $-\mathrm{OH}$ groups through condensation reactions resulting in multidentate attachments. Alkoxy- and chlorosilanes that can provide a large variety of functional groups are commonly used. Interestingly, the formation of a $\mathrm{SiO}_{2}$ shell layer on different types of core-NPs is a common strategy followed by its modification with silanes (Liu and Han, 2010). In addition, carboxylic acids are able to bind to certain metal oxides, for example, iron oxide NPs coated with oleic acid. Finally, QDs are often stabilized by trioctylphosphine (TOP), or its oxide (trioctylphosphine oxide, TOPO), binding preferentially to the transition metal ions of the nanocrystals. Thiol ligands are also used for covering QDs (Lee et al., 2009) and more labile options include hexadecylamine or other amines. In all cases, by harvesting the surface charge of NPs it is possible to coat the surfae of NPs through electrostatic interaction with polyelectrolytes, which are polymers containing groups that can display a net electrical charge in aqueous solutions at a given $\mathrm{pH}$. The succesive attachment of polycations and polyanions allows the formation of multilayer coatings (Palo et al., 2018).

Interested readers are encouraged to visit review articles by Neouze (Neouze and Schubert, 2008) and Sperling (Sperling and Parak, 2010) and references therein dedicated to the issue of surface modification of NPs.

Surface chemistry design must take into account functional properties of the ligands and their interaction with the matrix polymer. Examples include alkyl chain length for steric hindrance, reactive moieties for covalent bonding to the matrix, such as in thiol-ene (Smith et al., 2017) or amineepoxy (Malekshahinezhad et al., 2020) systems, or for acting as initiators for polymerization. Ligands with polar hydrophobic/ hydrophilic terminations are required for improved stability in a given solvent. Layer-by-layer coatings are useful for controlled surface charge in aqueous-based colloids. Dense and mesoporous inorganic shells (e.g., silica) are helpful for hosting additional functionalities, while grafting molecules are needed for proceeding with grafting-to or grafting-from strategies.

\section{FORMULATION OF NANOCOMPOSITE RESISTS}

Several strategies have been followed for the inclusion of NFs into polymer matrices. In a fairly simple classification, three popular trends can be distinguished: 1) ex-situ incorporation of NFs, 2) in- situ formation of NFs and 3) post-infiltration methods. A graphic explanation of these approaches is presented in Figure 3. The first, which consists in the synthesis of NFs and the preparation of stable colloids prior to their incorporation in the polymer solution, is probably the most widely used. Typically, NFs are synthesized through bottom-up chemical routes following wellestablished protocols, as described in Section 2.3.

Ex-situ methods provide a high degree of control in the morphology and PSD of the NFs. Also, the surface chemistry of NFs can be tailored to fulfill the desired chemical interaction with the host matrix. Ligand molecules may be carefully engineered to, firstly, allow the formation of a stable colloid in a solvent compatible with the PR (the co-solvent); secondly, avoid aggregation of NFs during mixing of the colloid and PR; lastly, provide chemically reactive functional groups to act as grafting sites for covalent linking with the polymer, if desired.

In-situ methods are based in the addition of molecular precursors, and additives for controlling the growth process, into the PRs or polymer solutions used. Nucleation of the NFs is induced either through radiation exposure or during a thermal treatment after completion of the lithographic process. For example, metal cations $[\mathrm{Ag}(\mathrm{I}), \mathrm{Au}(\mathrm{III})]$ have been used to form $\mathrm{Ag}$ or $\mathrm{Au}$ NPs through chemical reduction (Abargues et al., 2010), while metal methacrylates, formed through the reaction of transition metal alkoxides and methacrylic acid, are able to form metal oxide nanostructures (Ganesan et al., 2011). This approach is specially interesting for direct one-pot NCM formation, reducing the number of processing steps. In particular, for high resolution lithography such as EBL, the use of polymer resists containing inorganic molecular precursors allows the formation of nanocomposite structures with dimensions of a few tens of nanometers, whereas NCPRs with pre-formed NFs may fail in guaranteeing the presence of NFs in such precise locations. The inclusion of molecular precursors instead of pre-synthesized NFs has a minor effect on the rheology of the PR or polymer solution, facilitating its application by spin-coating or other methods. However, in-situ methods are inferior regarding the degree of control of the morphology and PSD. Another important drawback is the presence of residual molecular precursors in the final microstructure, which may affect the long term stability of the composite.

A less frequent strategy, which we will refer to as "postinfiltration," is the inclusion of inorganic materials after completion of lithography. In one example of this approach, usually mentioned as sequential infiltration synthesis (SIS), the $\mathrm{PR}$ is submitted to an infiltration procedure with molecular precursors after deposition (can be done before or after lithography). During infiltration, the molecular precursors diffuse into the polymer and remain available for later oxidation with $\mathrm{H}_{2} \mathrm{O}$ molecules in vapor phase. For example, trimethylaluminum (TMA) has been infiltrated by atomic layer deposition (ALD) into SU-8 (Tseng et al., 2011; Dusoe et al., 2017), ZEP520 (Tseng et al., 2011) and PMMA (Tiwale et al., 2019). Further details on this method were recently reported (Waldman et al., 2019). 


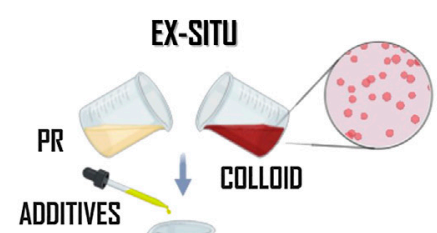

NANDCDMPUSITE PR
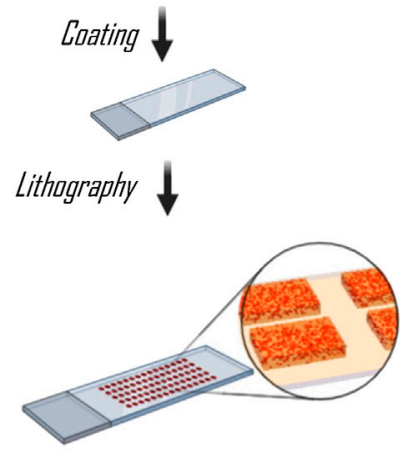

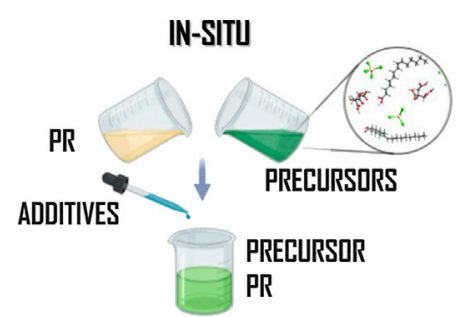

Coating
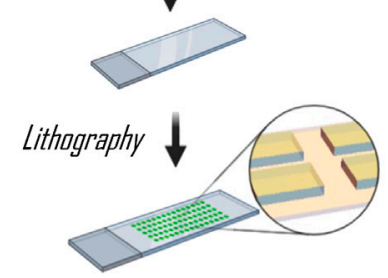

Pust-treatment $\downarrow$ (T. UV, EBL, chem. rection, etc)

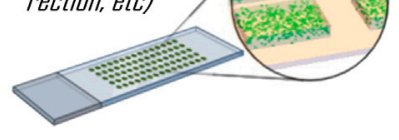

\section{POST-INFILTRATIDN}

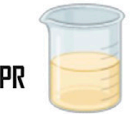

Coating $\downarrow$

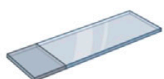

Lithography \

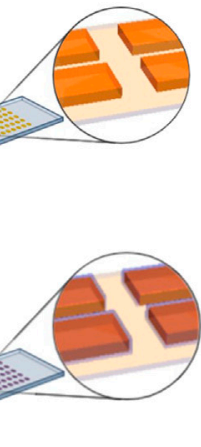

FIGURE 3 | Main strategies used for the formulation of NCPRs. Ex-situ methods are based on a mixture of a PR and a colloidal dispersion of NFs in a compatible solvent. In-situ procedures rely on molecular precursors added to the PR for the later nucleation reaction of the NFs. Post-infiltration strategies apply deposition methods before or after lithography. Created with content from BioRender.com.

\section{EXAMPLES OF NANOCOMPOSITE PHOTORESISTS AND APPLICATIONS}

While the lithographic capabilities of a NCPR are mostly determined by the polymeric matrix, its functionality arises essentially from the added fillers. Each type of NF presents specific advantages that can be exploited in the formulation of a NCPR. Metallic NFs increase electrical conductivity and can locally enhance the electromagnetic field by means of plasmonic resonances (Murray and Barnes, 2007; Gerardo et al., 2017; Jiang et al., 2018). This allows engineering of electrodes and contacts in single-step procedures, as well as sensing or heating devices. In the case of EBL, metallic NFs can also improve commercial resists, allowing their use on isolating substrates (Martínez et al., 2016). Magnetic NFs present the unique property of forming single domains, which can be readily reoriented through an external magnetic field. This may be harnessed to achieve remote magnetic control and actuation and accurate drug delivery systems, e.g., with micro swimmers (Kim et al., 2011; Suter et al., 2013; Peters et al., 2014; Peters et al., 2016; Ceylan et al., 2019; Yasa et al., 2019). Also, for many applications in micro/ nano electromechanics and microfluidics, mobile parts such as membranes (Nakahara et al., 2020), valves (Nakahara et al., 2018), blocks (Tasoglu et al., 2014) or cantilevers (Boisen et al., 2011; Suter et al., 2011a; Suter et al., 2011b; Kuo et al., 2013) are remotely controlled with static or alternating fields. Luminescent NFs (mostly QDs) are particularly useful for security and anti-counterfeit measures (Mayer et al., 2017; Kaboli et al., 2019; Mayer et al., 2019), as well as for a broad variety of photonics (Smirnova et al., 2009a) and bioscience (e.g., labeling, targeting) applications (Pregibon and Doyle, 2009; Appleyard et al., 2011 a; Appleyard et al., 2011b; Chapin and Doyle, 2011; Srinivas et al., 2011; Suh et al., 2012; Lee et al., 2014; Choi et al., 2012; Gerver et al., 2012; Zeng et al., 2020; Yang et al., 2020b), sometimes combined with magnetic NFs (Bong et al., 2010). In some cases, magnetic NFs have also been used for photonics by creating photonic crystals and shaping structural colors (Kim et al., 2009; Ge et al., 2010; Li et al., 2019b). Carbon NFs increase the electrical and thermal conductivity of the resist (Dawan et al., 2008; Potts et al., 2011; Bai et al., 2012; Majidian et al., 2014) and also find applications in sensing (Xi et al., 2013; Sun et al., 2018). Ceramic NFs may improve the mechanical properties of a composite (Jiguet et al., 2006a; Tjong, 2006; Dusoe et al., 2017), its etching resistance (Hu et al., 2001; Merhari et al., 2002; Ali et al., 2003; Tiwale et al., 2019) and increase its refractive index (Bremer et al., 2009; Bae et al., 2010). Also, NCPRs with piezoelectric NFs are investigated for applications in bio-science (Marino et al., 2015b) or as pressure sensors for robotic manipulation (Zhang et al., 2020).

In what follows, we will summarize the main results obtained so far in the formulation of NCPRs containing different types of NFs. Finally, we will briefly review some developments that rely on the in-situ formation of NFs. 


\subsection{Metallic and Plasmonic Nanofillers}

Metallic fillers are typically added in NCPRs to achieve electrical conductivity, mechanical reinforcement or plasmonic activity. In noble metal NPs, localized surface plasmon resonances depend on the composition, size, shape and dielectric environment (Maier and Atwater, 2005; Yu et al., 2019b). Under localized surface plasmon resonances a large amplification of the local electromagnetic field occurs at a short distance from the surface. For separation distances shorter than their characteristic size, plasmon modes of neighboring NPs can couple through nearfield interactions, enabling new plasmonic resonances characterized by a large electromagnetic field enhancement in the gap region, referred to as "hot-spots" (Murray and Barnes, 2007; Jiang et al., 2018). This is the basis of surface enhanced Raman scattering (Pilot et al., 2019), surface enhanced infrared absorption and other techniques for highly sensitive molecular detection. Numerous plasmon-based platforms for sensing have been devised with plasmonic NFs in a host matrix (Fan et al., 2011; Wolosiuk et al., 2014). In addition, plasmon resonances lead to electron-photon scattering and thus to heat generation, giving rise to thermoplasmonics (Baffou et al., 2013). This effect has been used to produce local heating of a thermally-sensitive polymer. For example, Fedoruk et al. used Au NPs to aid the polymerization reaction and thermal curing of PDMS at the nanoscale (Fedoruk et al., 2013). Martínez et al. used Au nanostars (NSs) as effective photo-thermal elements to induce the heating of an under-layer thermoplastic polymer (polylactic acid, PLA) above its glass transition temperature. A maskless lithography method was implemented to transfer the desired patterns (Martínez et al., 2019). Another example is the work by Chen et al. in which gold nanorods (Au NRs) were added to a liquid crystalline elastomer matrix. The NFs were functionalized with thiols (mercaptopropionic acid) after synthesis to allow miscibility in the matrix up to $3 \mathrm{wt} \%$. 3D microstructures were then fabricated using two photon lithography (TPL). The photothermal effect on AuNRs under NIR excitation was used to trigger the nematic-to-isotropic transition resulting in a rapid reversible shape change with an maximum elongation of $20 \%$ (Chen et al., 2019).

One of the goals of NCPRs as structural materials for sensors and devices is the microfabrication of electrodes and electrical contacts in a one-step procedure. With this in mind, NFs with intrinsic electrical conductivity are added in the formulation of conductive NCPRs. Conductivity in NCPRs is the result of the formation of a percolating network of NFs occurring for filling fractions $(\phi)$ higher than a critical value called the percolation threshold (Rahaman et al., 2017). Percolation does not imply the NFs to be in physical contact but at a gap distance small enough that charge transport between conducting particles may occur through quantum tunneling and hopping of electrons through the isolating matrix. The resistance at the gap junction is several orders of magnitude smaller than that of the bare polymer. The resistivity of the composite material is highly sensitive to $\phi$ when this value is near the percolation threshold (Foulger, 1999). This imposes major drawbacks: firstly, reproducibility of the electrical performance of the NCPRs relies on a high degree of control over NF concentration; secondly, locality issues arise when microstructuring the NCPRs to produce micron-sized electrodes because the concentration of NFs in that specific location may randomly depart from the average value.

Electrical percolation can be obtained with spherical or elongated NFs. Fillers with high aspect ratio show superior performance due to their ability to form networks with fewer contacting points. As a result, percolation threshold values obtainable for metallic NWs or CNTs are around $15 \mathrm{wt} \%$, much lower than those required for metallic powders (typically above $25 \mathrm{wt} \%$ ). Conductive NCMs and NCPRs with spherical metallic powders require $\phi$ as high as $60 \mathrm{wt} \%$, negatively affecting their processability (White et al., 2010). Thus, highaspect-ratio particles are usually preferred (De et al., 2009; White et al., 2010; Martínez et al., 2016). Low percolation thresholds allow the development of transparent and flexible electrodes (Cho et al., 2017; Kim et al., 2017). In addition, conductive networks based on metallic NWs may function as heating elements, dissipating heat via Joule effect (Huang et al., 2015; Martínez et al., 2018a; Martínez et al., 2018b). Also, the high sensitivity of the resistivity to the percolation status of the NCPRs provides interesting possibilities in the development of strain gauge sensors (Lee et al., 2012; Kim et al., 2015; Martinez et al., 2015) and pressure sensors (Cho et al., 2017; Dan et al., 2019). Upon mechanical deformation, the structure of the percolating network is disrupted and a change in the electrical resistance is easily detected. Obtaining electrical percolation is not restricted to metals; CNTs (to be described further below) can do the job as well.

The incorporation of metallic NPs in PRs dates back to the first works by Jiguet et al., who included commercial Ag colloids in SU-8 (Jiguet et al., 2004; Jiguet et al., 2005). In these works, no surface modification of the Ag NPs was performed. Consequently, poor compatibility with the PR together with a large PSD resulted in an inhomogeneous filling of the cured polymer and in the formation of large NP agglomerates. Also, the high UV absorption of Ag NPs produced undesired masking effects. A back-illumination mode (UV exposing through the quartz substrate) was employed. Interestingly, the percolation threshold was determined to be $\sim 6 \mathrm{vol} \%$, much lower than the usual values required for percolation. In 2008, Chiamori et al. studied the ex-situ strategy for incorporating up to $14 \mathrm{vol} \%$ of $\sim 5 \mathrm{~nm} \mathrm{Au} \mathrm{NPs} \mathrm{(among} \mathrm{other} \mathrm{NPs)} \mathrm{to} \mathrm{SU-8} \mathrm{(Chiamori} \mathrm{et} \mathrm{al.,}$ 2008). They analyzed the miscibility between SU-8 and different solvents, and tested the mechanical and electrical properties of the resulting NCPRs. More recently, Gerardo et al. revisited NCPRs based in Ag NPs in SU-8 (Gerardo et al., 2017). They added $80 \mathrm{~nm}$ Ag NPs to SU-8 at $25 \mathrm{wt} \%$, achieving conductive patterns on rigid and flexible substrates (see Figures 4A,B). A sheet resistance $\left(R_{s}\right)$ of $11.17 \Omega \cdot s q^{-1}$ was obtained. Notice that units of $R_{s}$ are given in Ohms/square, usually expressed as with a square symbol or as $\mathrm{Ohm} / \mathrm{sq}$. Sheet resistance relates with the resistivity $\rho$ as $\rho=R_{s} \cdot t$, where $t$ is the film thickness.

The use of conductive NCPRs represents also a key advantage for EBL and other lithographic methods based on charged particles that require conductive substrates. Conductive NCPRs can be directly applied on insulators like glass and polymers to avoid charge accumulation during EBL. Results 


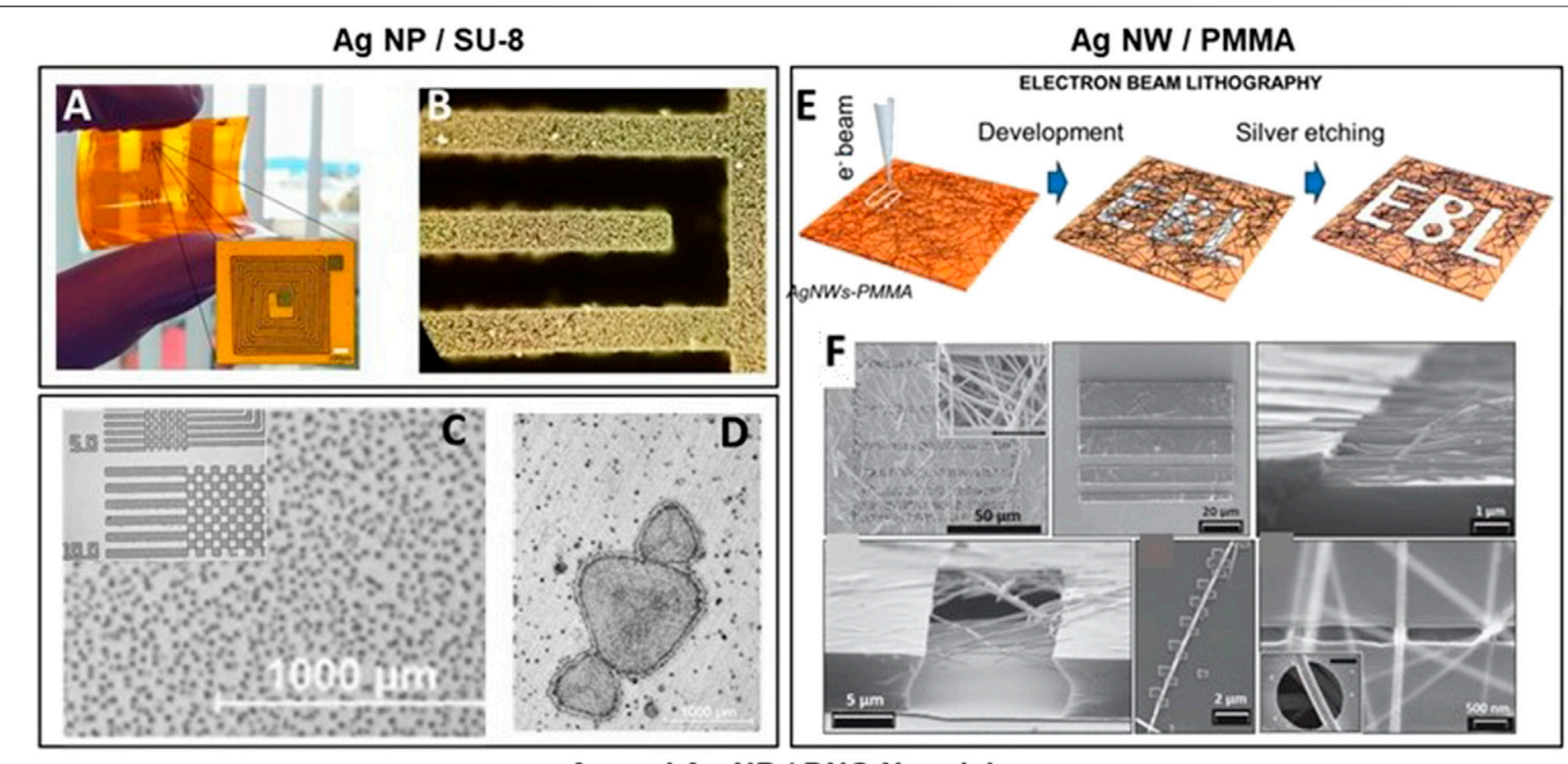

Ag and Au NP / DNQ Novolak

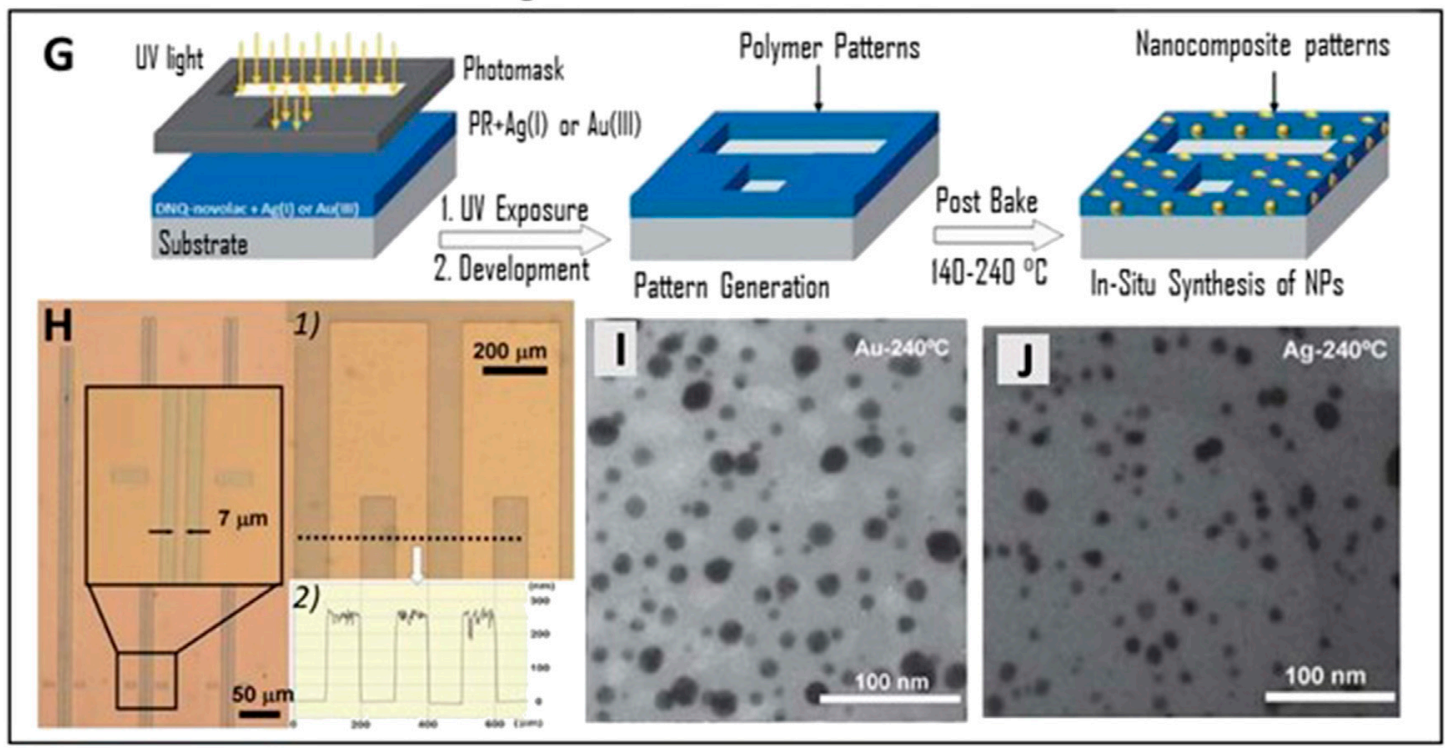

FIGURE 4 | Selected examples of NCPRs containing metallic NFs. (A,B) Flexible conductive circuits using SU-8 loaded with Ag NPs. Adapted from Gerardo et al. (2017) (CC BY license, MDPI). (C,D) In-situ formation of Ag NPs in SU-8 (Fischer et al., 2015) (CC BY license, Beilstein J. Nanotechnol.). (E) Scheme of the EBL process and (F) examples of nanostructuring using Ag NWs in PMMA. Adapted with permission from Martínez et al. (2016) Copyright ${ }^{\odot}$ (2016), Elsevier. (G) Scheme of the photoinduced synthesis and patterning of Ag and Au NPs in DNQ-Novolak NCPRs, (H) metallic tracks of Au formed in-situ. TEM images of (I) Au and (J) Ag NPs formed in-situ and baked at $240^{\circ} \mathrm{C}$. Adapted with permission from Abargues et al. (2010) Copyright ${ }^{\odot}$ (2010) The Royal Society of Chemistry.

from our group (see Figures 4E,F) show the possibilities for nano- and microfabrication of electrodes by EBL and other lithographic techniques (Martínez et al., 2016). Here, extracted Ag NWs synthesized by the polyol route (Jiu et al., 2014) were added to a commercial PMMA resist in chlorobenzene and mixed by vortex agitation. We managed to perform direct writing through EBL on a PMMA-Ag NWs NCM spin-coated on silicon, glass and polyimide. Suspended percolating networks of $\mathrm{Ag}$ NWs were produced using multilayer deposits and EBL on the regions of interest. Alternative patterning methods were reported for Ag NW networks. Ko et al. developed highly conductive Ag NW-based micropatterns using poly(ethylene glycol) (PEG) photo-lithography (Ko et al., 2017). The photosensitive PEG was deposited over the layer of Ag NWs, therefore, this system is not strictly a NCPR. Shin et al. presented a novel NCPR containing Ag NWs, polyvinyl alcohol (PVA) and several additives that allowed direct UV patterning of a deposited film (Shin et al., 2017). The unexposed region presented a sheet 
resistance of $50 \Omega s q^{-1}$, while the exposed regions were nonconductive, with a sheet resistance over $20 \mathrm{M} \Omega s q^{-1}$. The obtained optical transmittance was above $85 \%$.

In-situ methods for producing metal-polymer patterns have also been reported. Abargues presented the formation of $\mathrm{Ag}$ and $\mathrm{Au}$ NPs in DNQ-Novolak PRs (ma-P 1205) (Abargues et al., 2010; Abargues et al., 2013). Here, Ag(I) and Au(III) salts were dissolved in PGMEA and added as precursors to the PR. The formation of Ag and $\mathrm{Au}$ NPs, with broad PSDs between 10 and $20 \mathrm{~nm}$, was achieved by a post bake treatment $\left(100-240^{\circ} \mathrm{C}\right)$ following UV lithography (Figures 4G-J). A similar but ex-situ approach was studied a few years later by Pudlauskaite et al., who mixed pre-sinthesized Ag NPs in DNQ-Novolak PRs and tested the surface roughness on the composite patterns (Pudlauskaite et al., 2013). Fischer and coworkers studied the in-situ formation of Ag NPs from the reduction of $\mathrm{AgNO}_{3}$ dissolved in acetonitrile and added to SU-8 (Fischer et al., 2015). The nucleation of Ag NPs occurred during the pre- and post-bake thermal treatments at $95^{\circ} \mathrm{C}$. Further nucleation of NPs could be induced at higher temperatures. If the concentration of the precursor was kept below $250 \mathrm{~g} \cdot \mathrm{L}^{-1}$, homogeneously distributed Ag NPs $(d \sim 25 \mathrm{~nm})$ were formed within the SU-8 matrix, as shown in Figure 4C. Higher concentrations resulted in agglomeration of Ag NPs (Figure 4D). The post-infiltration strategy was employed by Meyerbröker and co-workers who studied the modification of the swelling and wettability properties of nanometer-thin PEG films under electron irradiation. Irradiated areas become hydrophobic and lose their swelling capabilities. Through EBL, the authors produced patterns in which the irradiated regions showed an enhanced affinity for the adsorption of proteins while the infiltration of Au NPs from aqueous colloids was significantly reduced (Meyerbröker and Zharnikov, 2013). More recently, Tan and co-workers developed a post infiltration procedure to produce SU-8 patterns loaded with Au NPs (Tan et al., 2019). SU-8 was modified by the addition of the diamine curing agent Jeffamine D230. This additive reacts with the epoxide groups of SU-8 forming an expanded polymer structure which promotes the infiltration of the gold precursor solution $\left(\mathrm{HAuCl}_{4}\right)$ after lithography. Furthermore, the infiltration can be spatially controlled by using PDMS stamps with microfluidic channels to produce patterns-within-patterns. By tuning the parameters of the infiltration (concentration of gold precursor, reaction time and temperature) the morphology of the nanoparticle network formed within SU-8 can be controlled along with the resulting physical properties, such as the electrical conductivity and the optical density. The authors successfully applied this method to fabricate microelectrodes and diffraction gratings. Other research groups have developed PDMS-based NCMs including Au NPs (SadAbadi et al., 2013; Romanenko et al., 2020) and conductive fillers (Cong and Pan, 2009; Ozhikandathil et al., 2015) to provide the desired functionality.

A summary of selected works employing metallic NFs in NCPRs is presented in Table 1.

\subsection{Magnetic Nanofillers}

Inorganic NPs with either ferromagnetic or superparamagnetic properties have been successfully employed for the formulation of magnetic NCMs and NCPRs. In their macroscopic form, bulk ferromagnetic materials display spontaneous magnetization at temperatures below the Curie temperature $\left(T_{C}\right)$ with a characteristic remanent magnetization and hysteresis curve related to the formation of a multi-domain structure. For particles below a critical size (about tens of nanometers), the formation of domain walls becomes energetically costly and single domain particles are formed with a permanent magnetization. At zero external magnetic field the orientation of this magnetization is determined by shape, anisotropy and NPNP interactions. At temperatures above the blocking temperature, $T_{B}$, thermal fluctuations can overcome these energies and the NP behaves as a superparamagnetic system. The exact value of $T_{B}$ depends mainly on particle size. When the particle size is small enough (typically below $20 \mathrm{~nm}$ ) ferrous oxides display superparamagnetism at room temperature ( $\mathrm{Lu}$ et al., 2007). In the superparamagnetic state, the single-domain NPs can be forced to align with an external magnetic field showing high magnetization values without hysteresis (like the analogous paramagnet).

Typical magnetic NFs are composed of $\mathrm{Fe}, \mathrm{Co}, \mathrm{Ni}, \mathrm{Mn}$, in pure or alloy forms, or by superparamagnetic iron oxide nanoparticles (SPIONs) like magnetite $\left(\mathrm{Fe}_{3} \mathrm{O}_{4}\right)$ or its oxidized form maghemite $\left(\gamma-\mathrm{Fe}_{2} \mathrm{O}_{3}\right)$ (Mahmoudi et al., 2011). Using superparamagnetic NFs has the major advantage that the absence of a permanent magnetization avoids aggregation. Magnetic moments in NFs align with external magnetic fields while attraction forces are produced under field gradients. Also, alternating magnetic fields can induce heat dissipation through different mechanisms. The possibility of remote magnetic control finds applications in many technologically sound ideas such as magnetic separation or manipulation of particles, drug delivery, shape-memory and magnetic actuators, among others (Song et al., 2015).

Many examples exist in the literature of NCPRs formulated using magnetic NFs. One of the first was presented by Dutoit et al., who incorporated $\mathrm{Sm}_{2} \mathrm{Co}_{17}$ powders into SU-8 to obtain a ferromagnetic NCPR for the production of micromachined magnets (Dutoit et al., 1999). Technically, this work did not employ NFs, since particle size was $\sim 10 \mu \mathrm{m}$; however, it showed the possibilities and difficulties in preparing stable colloids in a polymeric solution. Some years later Damean et al. introduced ferromagnetic nickel NPs $(d \sim 100 \mathrm{~nm})$ into SU-8 (Damean et al., 2005). Mixing was performed by hand without any chemical functionalization of the NFs, resulting in a shelf life of about $36 \mathrm{~h}$. This NCPR was used to microfabricate ferromagnetic cantilevers. In 2009, Wang et al. developed nanocomposite microsprings produced by TPL using a NCPR containing oleic-acid-modified $\mathrm{Fe}_{3} \mathrm{O}_{4}$ NFs $(d \sim 10 \mathrm{~nm})$ at $\phi=2.4 \mathrm{wt} \%$ (Wang et al., 2009). The microsprings could be remotely controlled with a ferromagnet, as shown in Figure 5A. Ingrosso et al. (Ingrosso et al., 2009) presynthesized colloidal oleic acid-capped superparamagnetic $\mathrm{Fe}_{2} \mathrm{O}_{3}$ NPs $(d \sim 11 \mathrm{~nm})$ that were incorporated into an anisole based negative tone epoxy PR. Toluene was used as co-solvent. Using conventional UV mask lithography under $365 \mathrm{~nm}$ light, the NCPR was patterned with an exposure dose of $108 \mathrm{~mJ} \mathrm{~cm}^{-2}$, while the pure $P R$ required $72 \mathrm{~mJ} \mathrm{~cm}^{-2}$. The authors fabricated AFM magnetic probes with a tip apex radius below $30 \mathrm{~nm}$ (see 
TABLE 1 | Examples of NCPRs using metallic NFs.

\begin{tabular}{|c|c|c|c|c|c|c|}
\hline Nanofillers & Polymer matrix & $\begin{array}{l}\text { Interface } \\
\text { chemistry }\end{array}$ & $\begin{array}{l}\text { Formulation (additives, } \\
\text { treatment, etc.) }\end{array}$ & $\begin{array}{l}\text { Lithographic } \\
\text { method }\end{array}$ & $\begin{array}{l}\text { Applications/Main } \\
\text { results }\end{array}$ & References \\
\hline $\begin{array}{l}\text { AgNPs } \phi \text { up to } \\
40 \text { wt } \% . \text { Very } \\
\text { broad PSD }\end{array}$ & SU-8 & $\begin{array}{l}\text { No information } \\
\text { provided }\end{array}$ & $\begin{array}{l}\text { Electric percolation } \\
\text { at } \phi>6 w t \% \text {. }\end{array}$ & $\begin{array}{l}\text { UV-LIGA back } \\
\text { exposure mode }\end{array}$ & $\begin{array}{l}\text { Electrically conductive PR, } \\
\text { microelectrodes }\end{array}$ & $\begin{array}{l}\text { Jiguet et al. (2004); } \\
\text { Jiguet et al. (2005) }\end{array}$ \\
\hline $\begin{array}{l}\mathrm{Au}(d \sim 8 \mathrm{~nm}), \mathrm{Pt} \\
(d \sim 6 \mathrm{~nm}) \mathrm{NPs}\end{array}$ & $\begin{array}{l}\text { Photo cross- } \\
\text { linkable PS }\end{array}$ & $\begin{array}{l}\text { PS- } \mathrm{N}_{3}-\mathrm{SH} \text { for photo- } \\
\text { polimerization with } \\
\text { PS matrix }\end{array}$ & $\begin{array}{l}\text { UV-sensitive azide groups. } \\
\text { Layer-by-layer deposition by } \\
\text { spin-coating }\end{array}$ & Deep UV lithog. & $\begin{array}{l}\text { Free standing organic-metal } \\
\text { multilayers }\end{array}$ & Lee et al. (2009) \\
\hline $\begin{array}{l}\text { Ag NPs/Au NPs } \\
\text { (in-situ) }\end{array}$ & PVA & $\begin{array}{l}\text { Solution of } \\
\text { precursors in water: } \\
\text { ethanol, no additives }\end{array}$ & $\begin{array}{l}\text { Ag NPs }[(\sim 8.5 \mathrm{~nm})] \text { formed } \\
\text { in-situ from } \mathrm{AgNO}_{3} \text { in } \\
\text { exposed regions. PVP cross- } \\
\text { linking on exposure or heat }\end{array}$ & EBL & $\begin{array}{l}\text { Plasmonic negative tone PR } \\
\text { for EBL/One-step 3D-Lithog. }\end{array}$ & $\begin{array}{l}\text { Abargues et al. } \\
\text { (2008)/ } \\
\text { Marqués-Hueso et al. } \\
(2010)\end{array}$ \\
\hline $\begin{array}{l}\text { Ag NPs-Au } \\
\text { NPs (in-situ) }\end{array}$ & $\begin{array}{l}\text { DNQ- } \\
\text { Novolak PR }\end{array}$ & No functionalization & $\begin{array}{l}\text { NPs formed in-situ from } \mathrm{Ag}(\mathrm{l}) \\
\text { and } \mathrm{Au}(\mathrm{III}) \text { precursor salts. } \\
\text { NPs nucleate and grow } \\
\text { during PEB at } 160-240^{\circ} \mathrm{C}\end{array}$ & UV lithog. & Plasmon-based biosensors & Abargues et al. (2010) \\
\hline $\begin{array}{l}\text { Ag NPs } \\
(d \sim 40-80 \mathrm{~nm})\end{array}$ & DNQ-novolac & No functionalization & $\begin{array}{l}\text { Ag/DNQ-novolac films prep. } \\
\text { by spin coating w/10-40 wt } \\
\% \text { AgNPs }\end{array}$ & UV lithog. & $\begin{array}{l}\text { Controlled surf. morphology } \\
\text { of gratings by addition of } \\
\text { varying wt } \% \text { Ag NPs }\end{array}$ & $\begin{array}{l}\text { Pudlauskaite et al. } \\
\text { (2013) }\end{array}$ \\
\hline $\begin{array}{l}\text { Au NPs } \\
(d \sim 20 \mathrm{~nm})\end{array}$ & $\begin{array}{l}\text { Poly(ethylene } \\
\text { glycol) (PBG) }\end{array}$ & $\begin{array}{l}\text { Au NPs citrate- } \\
\text { stabilize }\end{array}$ & $\begin{array}{l}\text { Pure PBs films deposited and } \\
\text { patterned by EBL. NPs } \\
\text { prepared by immersion of } \\
\text { patterned films in Au NP } \\
\text { solution. Protein repelling } \\
\text { properties studied. }\end{array}$ & $\mathrm{EBL}$ & $\begin{array}{l}\text { Patterns w/controlled Au NP/ } \\
\text { protein adhesion areas }\end{array}$ & $\begin{array}{l}\text { Meyerbröker and } \\
\text { Zharnikov (2013) }\end{array}$ \\
\hline $\begin{array}{l}\text { Ag NPs }(d \sim \\
25 \mathrm{~nm})(\text { in-situ) }\end{array}$ & SU-8 & No functionalization & $\begin{array}{l}\text { Ag NPs formed during SB } \\
\text { and PEB. Acetonitrile added } \\
\text { as solvent. Post-bake at } \\
300^{\circ} \mathrm{C} \text { prevented } \\
\text { agglomeration of Ag NPs }\end{array}$ & UV lithog. & $\begin{array}{l}\text { NCMs exhibit high plasmonic } \\
\text { responses. }\end{array}$ & Fischer et al. (2015) \\
\hline $\begin{array}{l}\text { Ag NWs } \\
(d \sim \\
150-250 \mathrm{~nm})\end{array}$ & PMMA & PVP & $\begin{array}{l}\text { Elec. percolation at } 2 \text { wt } \% \text { Ag } \\
\text { NWs, lowest resistance for } \phi \\
\text { Ag NWs > } 4 \text { wt } \% \text {. }\end{array}$ & EBL/Soft lithog. & $\begin{array}{l}\text { Fabrication of flexible } \\
\text { conduct. patterns and } \\
\text { structures w/low Ag content. } \\
\text { NCPR suitable as a } \\
\text { conductive ink }\end{array}$ & Martínez et al. (2016) \\
\hline $\begin{array}{l}\text { Au NPs } \\
(d \sim 20 \mathrm{~nm}) \\
\text { (in-situ) }\end{array}$ & $\begin{array}{l}\text { TMPTA/PETA } \\
\text { (best results w/ } \\
\text { PETA) }\end{array}$ & $\begin{array}{l}\text { No information } \\
\text { provided }\end{array}$ & $\begin{array}{l}\text { Samples w/varying } \\
\text { concentration of monomer } \\
\text { and } \mathrm{Au} \text {. Two photon sensitive } \\
\text { dye (Ru(II) complex) added to } \\
\text { enhanced the geometrical } \\
\text { uniformity and integrity of } \\
\text { patterns }\end{array}$ & EBL & $\begin{array}{l}\text { Production of 3D Au-polymer } \\
\text { structures }\end{array}$ & Liu et al. (2016) \\
\hline $\begin{array}{l}\text { Au NSs } \\
(d \sim 50 \mathrm{~nm})\end{array}$ & PLA & $\begin{array}{l}\text { Au NSs } \\
\text { functionalized } \\
\text { W/MSA }\end{array}$ & $\begin{array}{l}\text { Au NSs deposited on top of a } \\
\text { PLA film w/UCNPs }\end{array}$ & $\begin{array}{l}\text { DLW using a NIR } \\
(980 \mathrm{~nm}) \text { laser }\end{array}$ & $\begin{array}{l}\text { Production of Au- } \\
\text { luminescent patterns for } \\
\text { SERS active substrates }\end{array}$ & Martínez et al. (2019) \\
\hline $\begin{array}{l}\text { Au NRs } \\
(d \sim 10 \mathrm{~nm} \\
L \sim 46 \mathrm{~nm})\end{array}$ & $\begin{array}{l}\text { Liquid crystal } \\
\text { elastomer }\end{array}$ & $\begin{array}{l}\text { Au NRs } \\
\text { functionalized } \\
\text { W/MPA }\end{array}$ & $\begin{array}{l}\text { Au NRs added (1-3 wt\%) to } \\
\text { the solution of monomers in } \\
\text { acetone containing C6BP, } \\
\text { RM257, and } 2 \text { mol\% of } \\
\text { irgacure } 369\end{array}$ & TPL & $\begin{array}{l}\text { 3D microstructures with light } \\
\text { responsive mechanical } \\
\text { deformation }\end{array}$ & Chen et al. (2019) \\
\hline $\begin{array}{l}\text { Au NPs (post- } \\
\text { infiltration) }\end{array}$ & SU-8 & No functionalization & $\begin{array}{l}\text { Diamine curing agent } \\
\text { jeffamine D230 added for } \\
\text { polymer expansion. Au NPs } \\
\text { formed by thermal treatment } \\
\text { after infiltration of patterns } \\
\text { with } \mathrm{HAuCl}_{4} \text { solutions }\end{array}$ & UV lithog. & $\begin{array}{l}\text { Microelectrodes and } \\
\text { diffraction gratings }\end{array}$ & Tan et al. (2019) \\
\hline
\end{tabular}

In table, PS, polystyrene; PEB, post exposure bake; SB, soft bake; TMPTA, trimethylopropane triacrylate; PETA, pentaerythritol triacrylate; MSA, mercapto succinic acid; MPA, mercapto propionic acid; Au NSs, Au NPs star-shaped; Au NRs, Au NPs rod-shaped. The green leaf indicates applications in biosciences.

Figure 5B). Mobile parts like membranes or cantilevers, which can be remotely controlled or used as sensors, have been widely studied in the past. Since the resonance frequency of cantilevers can be altered by changes in surface stress or mass, i.e., by the adhesion of molecules, they may be used as molecular sensors (Boisen et al., 2011). To this end, Suter et al. incorporated superparamagnetic $\mathrm{Fe}_{3} \mathrm{O}_{4}$ NPs into SU-8 (Suter et al., 2011a; Suter et al., 2011b). The NFs were first dispersed in GBL (the 


\section{$\mathrm{Fe}_{3} \mathrm{O}_{4} \mathrm{NP} /$ oleic acid}

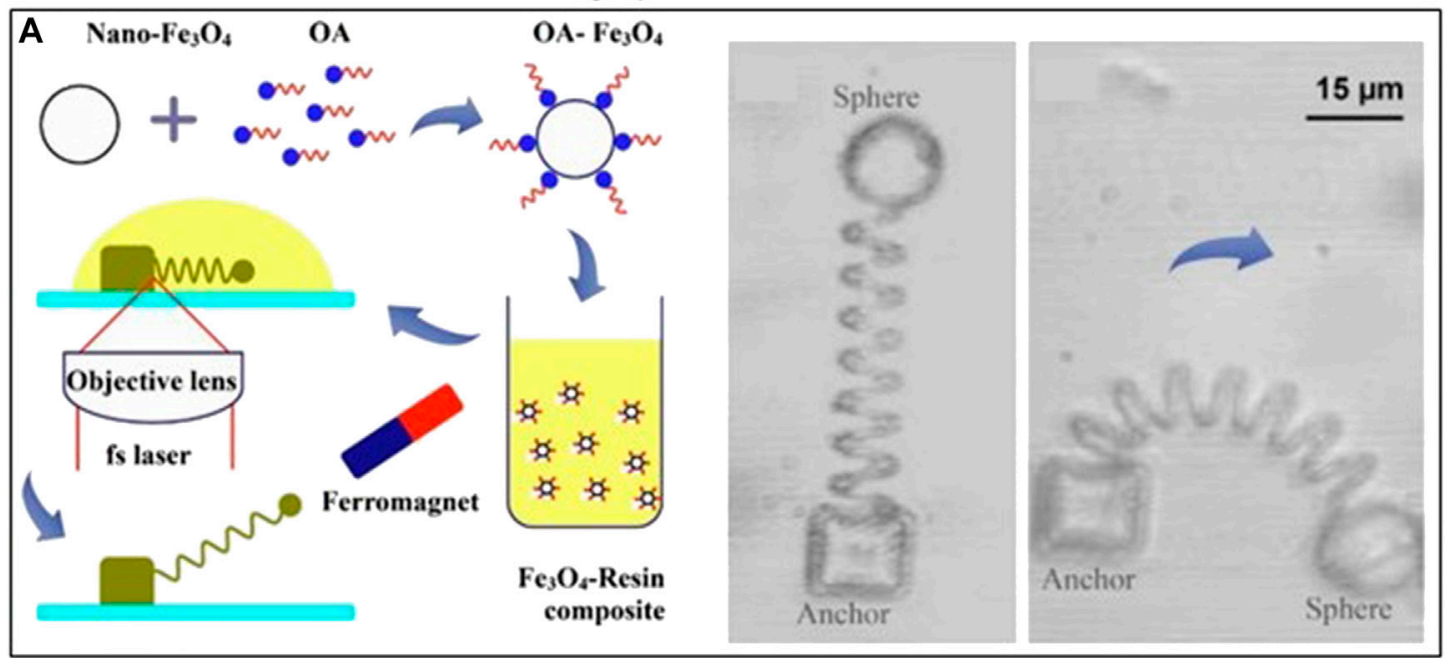

$\mathrm{Fe}_{2} \mathrm{O}_{3} /$ negative tone epoxy

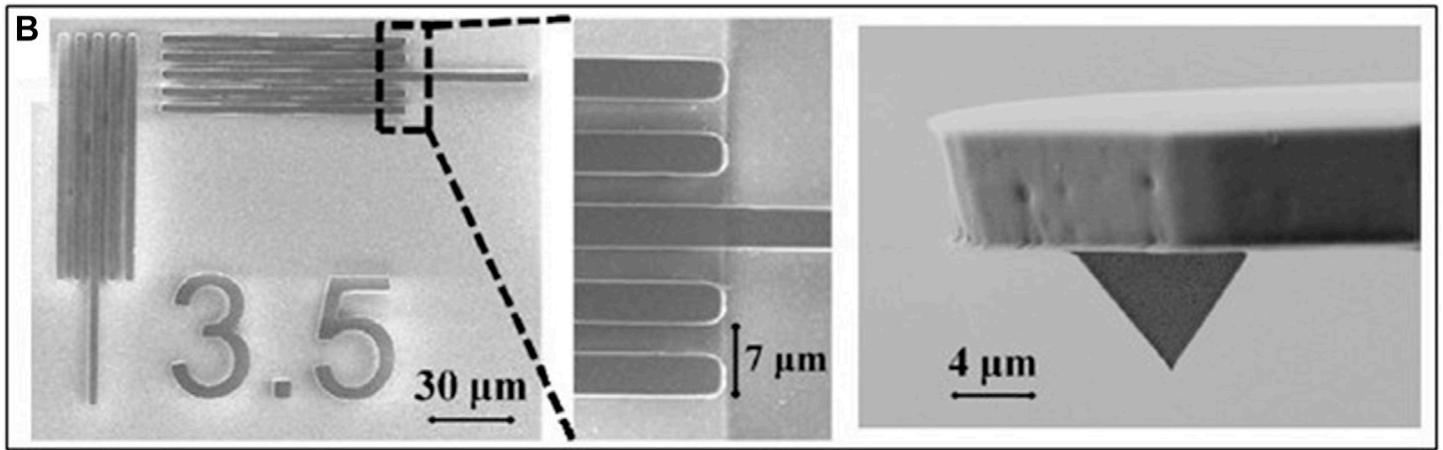

FIGURE 5 | (A) Experimental scheme for the preparation of magnetic NCPR and example of a magnetically remote-driven microspring, adapted from Wang et al. (2009), Copyright $^{\odot}$ (2009) Optical Society of America. (B) SEM images of patterned structures and $\mathrm{AFM}$ probe produced using Fe $\mathrm{O}_{3} \mathrm{NCPR}$ adapted with permission from Ingrosso et al. (2009) Copyright ${ }^{\odot}$ (2009) Elsevier B.V.

solvent of the SU-8 formulation used) and capped with phosphate-based molecules. Linear copolymers with phosphate groups resulted in a more homogeneous dispersion. The fabricated superparamagnetic composite cantilevers could be successfully actuated at their resonance frequencies by an external magnetic field. Kuo et al. prepared magnetic NPpolymer nanocomposite cantilevers and probed their natural resonance frequency under external magnetic excitation (Kuo et al., 2013). For a magnetically actuated cantilever with $5 \mathrm{wt} \% \mathrm{NF}$ loading and dimensions of $1.8 \mu \mathrm{m} \times 15 \mu \mathrm{m} \times 200 \mu \mathrm{m}$, the resonance frequency was $7 \mathrm{kHz}$, with a Q-factor in air of $\sim 7$. More recently, Huong $\mathrm{Au}$ et al. continued with this approach using NCPRs containing SPIONs in SU-8 for free floating magnetic microstructures (Huong $\mathrm{Au}$ et al., 2018). Blends of commercially available carbon coated cobalt NPs of $d \sim 50 \mathrm{~nm}$ and SU-8 resists were used by Kandpal et al. The NFs were first dispersed in CPN, the solvent of the used SU-8 formulation. Interestingly, the use of ultrasound for improving the dispersion of NFs resulted in excess heat generation requiring an ice bath. Regular procedures for spin-coating and UV lithography were applied to construct freely suspended micro magnetic membranes with a resonance frequency of $29 \mathrm{kHz}$ (Kandpal et al., 2015). The combination of SPIONs and SU-8 has also been explored by Nguyen et al., who developed a direct laser writing (DLW) method based on ultra-low one-photon absorption (LOPA), as opposed to the more conventional TPL, for the construction of 3D magnetically actuated structures (Nguyen et al., 2018). More recently, Nakahara et al. exploited a photo-sensible magnetic composite resist to fabricate a membrane for a micro-pump (Nakahara et al., 2020). The composite was developed from a mixture of SU-8 and magnetic particles. The composite made of $50 \mathrm{wt} \% \mathrm{Fe}$ particles of $d \sim 35 \mu \mathrm{m}$ presented the maximum values for magnetization and attractive force. Although the particles used were too large to be considered NFs, and therefore this is not strictly a NCPRs, the studied approach worth mentioning. The micropump was fabricated using a simple process which included the manufacture of both an active membrane and a hollow structure in a one-step self-aligned photo-lithography using the UV-transmission of the NCM. The flow rate of the 
micropump was evaluated by particle tracking method showing a good performance. For a recent review covering several strategies regarding responsive membranes, the reader is referred to the work by Tian et al. (Tian et al., 2020).

\subsection{Magnetic Actuators and Surfaces}

The tendency of magnetic moments to minimize their energy by aligning with an applied field was implemented elegantly by Xia et al. in a microelectro-mechanical system (MEMS) application. A magnetic NCPR was obtained by functionalizing the surface of $\mathrm{Fe}_{3} \mathrm{O}_{4}$ NPs $(d \sim 10 \mathrm{~nm})$ with MPS, making them both dispersable and photopolymerizable. Subsequently, the MPS- $\mathrm{Fe}_{3} \mathrm{O}_{4} \mathrm{NPs}$ were added to a photoresist composed of methyl-acrylate, PETA, a photoinitiator and BAMPB, a photosensitizer. 3D microturbines were fabricated through TPL and the remote rotation of the turbine, controlled by an external field, was demonstrated (Xia et al., 2010). By performing the lithography under an applied magnetic field it was possible to fix the position and orientation of the magnetic moments providing a "programmed anisotropy". After UV-induced polymerization and the removal of the external magnetic field these chain nanostructures persisted, providing the cured polymer structures with a programmed magnetic easy axis. Magnetically operated micro-actuators capable of multi-directional movement can be fabricated this way (Kim et al., 2011). By freely programming the rotational axis of each component, the authors demonstrated pre-designed, complex two- and three-dimensional motion of the magnetic actuators. Programmed magnetic anisotropy is widely used to prepare devices which require rotational motion or controlled orientation (Tierno, 2014; Erb et al., 2016; Teo et al., 2016). Kuo et al. for example, fabricated a magnetic hydrogel-based microgripper that could be wirelessly manipulated using magnetic fields (Kuo et al., 2014). They showed that the device could move freely in liquids when driven by static magnetic fields, and perform a gripping motion by using alternating magnetic fields. By dispersing carbon nanotubes into the material, the overall response time of the gripping motion decreased 2 -fold. $\mathrm{Li}$ et al. fabricated polymer magnets using SU-8 with micron-size $\mathrm{NdFeB}$ ferromagnetic particles (not strictly a NCPRs) (Li et al., 2013). The controlled movement of lithographically determined "pac-man" shaped magnetic actuators was demonstrated. A recent review on the applications of magnetic assemblies, with an overview of NCPRs, was presented by $\mathrm{Li}$ and collaborators ( $\mathrm{Li}$ et al., 2020).

In addition to membranes and cantilevers, a full surface can be covered with a magnetic structure to respond "smartely" to certain stimuli. Wang et al. developed large arrays of hybrid magnetic micropillars using a UV-curable poly(urethane acrylate) (PUA) based NCPR containing $\mathrm{Fe}_{3} \mathrm{O}_{4} @ \mathrm{SiO}_{2} \mathrm{NFs}(d \sim 30 \mathrm{~nm})$. This approach is based on the manipulation of the spatial distribution of magnetic NFs within individual elastomer micropillars under a magnetic field gradient as shown in Figure 6A. Micropillars with different degrees of bending deformation can be configured in any spatial pattern using a photomask-assisted template-casting technique (Wang et al., 2020) (see Figures 6B,C). Jiang et al. developed a "smart" surface for microfluidic applications. They propose a $3 \mathrm{D}$ droplet/multi-droplet transport strategy based on magnetically-responsive microplates array actuated by spatially varying and periodic magnetic field. The modified superhydrophobic surface can transport droplets rapidly both in horizontal and vertical directions, and even realize against-gravity up-slope propulsion (Jiang et al., 2020).

Superparamagnetic NPs have also been added to microstrucured surfaces for applications in bioscience. Paun et al. used $5 \mathrm{~nm}$ maghemite $\left(\gamma-\mathrm{Fe}_{2} \mathrm{O}_{3}\right)$ NPs as NFs added to the commercial photo-polymer Ormocore (Paun et al., 2019; Paun et al., 2020). Films of the NCPR were submitted to DLW through TPL to pattern $3 \mathrm{D}$ scaffolds or surfaces where cell cultures were grown. The authors studied the morphology and attachment of different cell types under an external magnetic field, finding significant differences ascribed to the effect of local magnetic field gradients produced by the magnetic NFs (see Figure 7A).

\subsection{Magnetic Microswimmers and Microcarriers}

An interesting field of application for NCPRs lay in the microfabrication of magnetically controlled free-mobile objects, also called microswimmers. For example, Sakar et al. incorporated commercial $d \sim 50 \mathrm{~nm} \mathrm{Fe}_{3} \mathrm{O}_{4}$ NPs into SU-8 (Sakar et al., 2010). The two components were mixed without the addition of surfactants or functionalization of the NFs. The NCPR was deposited on a glass substrate containing a sacrificial layer of dextran. By conventional UV mask lithography, they produced magnetic U-shaped actuators that were released by dissolving the dextran film. The microstructures were used as magnetically controlled transporters for the direct manipulation of T. pyriformis cells. A different strategy was followed by Suter et al. who used TPL to develop controllable swimming microrobots from a NCPR consisting of magnetite NPs in SU-8 (Suter et al., 2013). Structures with $\phi$ up to $10 \mathrm{vol} \%$ had negligible cytotoxicity after $24 \mathrm{~h}$ incubation, enabling their use in a biological medium. The helical microdevices were capable of performing corkscrew motion in water under weak uniform rotating magnetic fields. Magnetic manipulation of cells is a popular topic. Kim et al. fabricated 3D hydrogel cell microcarriers with their optofluidic maskless lithography system (Kim et al., 2011). They cured poly(ethylene glycol) diacrylate (PEGDA) containing iron oxide NFs to prepare microparticles with a microwell structure, and loaded them with HeLa and T24 cells. They demonstrated the possibility of magnetic separation of cell-loaded particles and solution exchange. Using a magnetic NCPR and TPL, Peters et al. presented helical micro-actuators with programmed magnetic anisotropy. These were able to swim with improved ability in aqueous environment. The surface of the swimmers was functionalized with a protein which confirmed their potential for biomedical delivery applications (Peters et al., 2014; Peters et al., 2016). More recently, Ceylan et al. reported a hydrogelbased, magnetically powered and controlled, enzymatically degradable microswimmer, responsive to pathological markers in its micro-environment and able to perform cargo delivery and theranostic tasks. This double-helical 3D microswimmer was 


\section{$\mathrm{Fe}_{3} \mathrm{O}_{4} @ \mathrm{SiO}_{2} \mathrm{NF} / \mathrm{PUA}$}

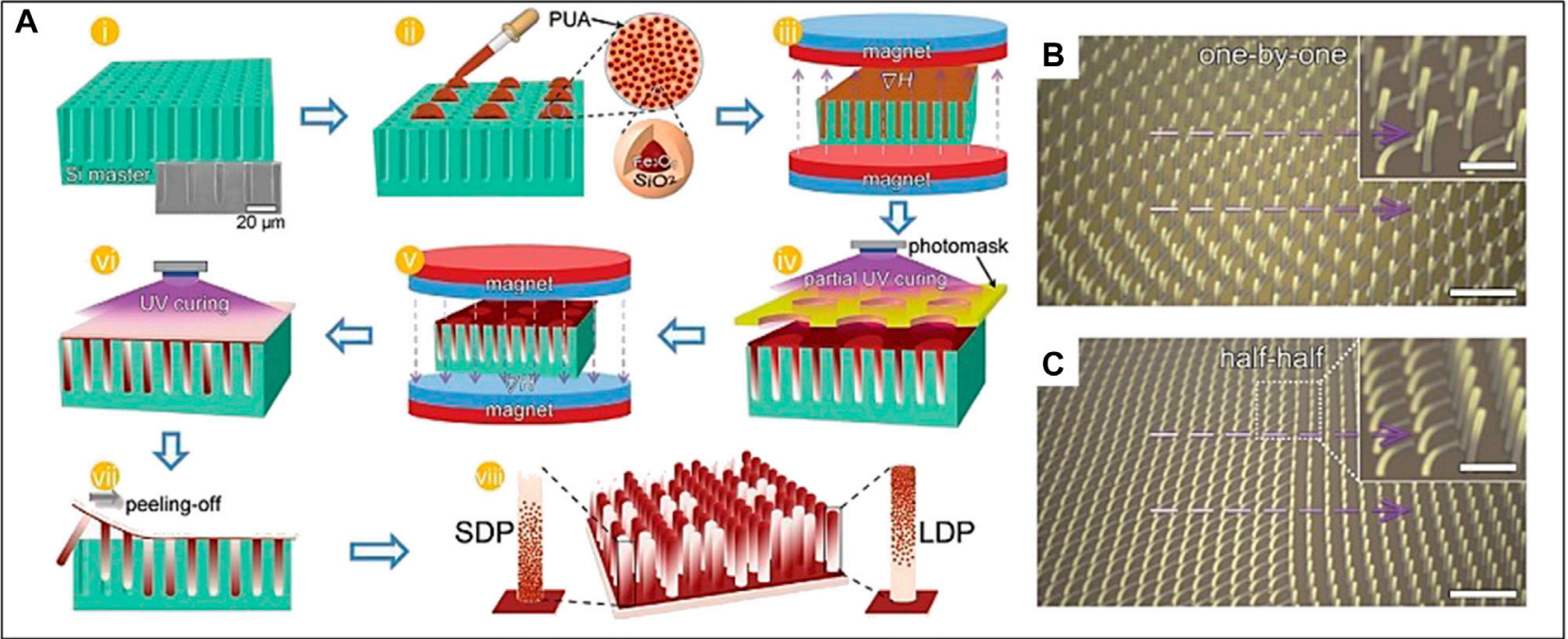

FIGURE 6 | (A) Fabrication scheme of nanocomposite micropillars structures with different magnetic responsivities using a PUA/Fe $\mathrm{O}_{4} @ \mathrm{SiO}_{2} \mathrm{NCPRs}_{\text {. Three types }}$ of pillars are produced: uniform pillars (UP), small deformation pillars (SDPs) and large deformation pillars (LDPs) depending on the distribution of the magnetic NFs. (B,C) Optical images of the micropillars response to an applied horizontal magnetic field (B) one-SDP-by-one-LDP hybrid and (C) half surface with SDPs and half surface with LDPs. Adapted with permission from Wang et al. (2020) Copyright ${ }^{\odot}$ (2020), Wiley.

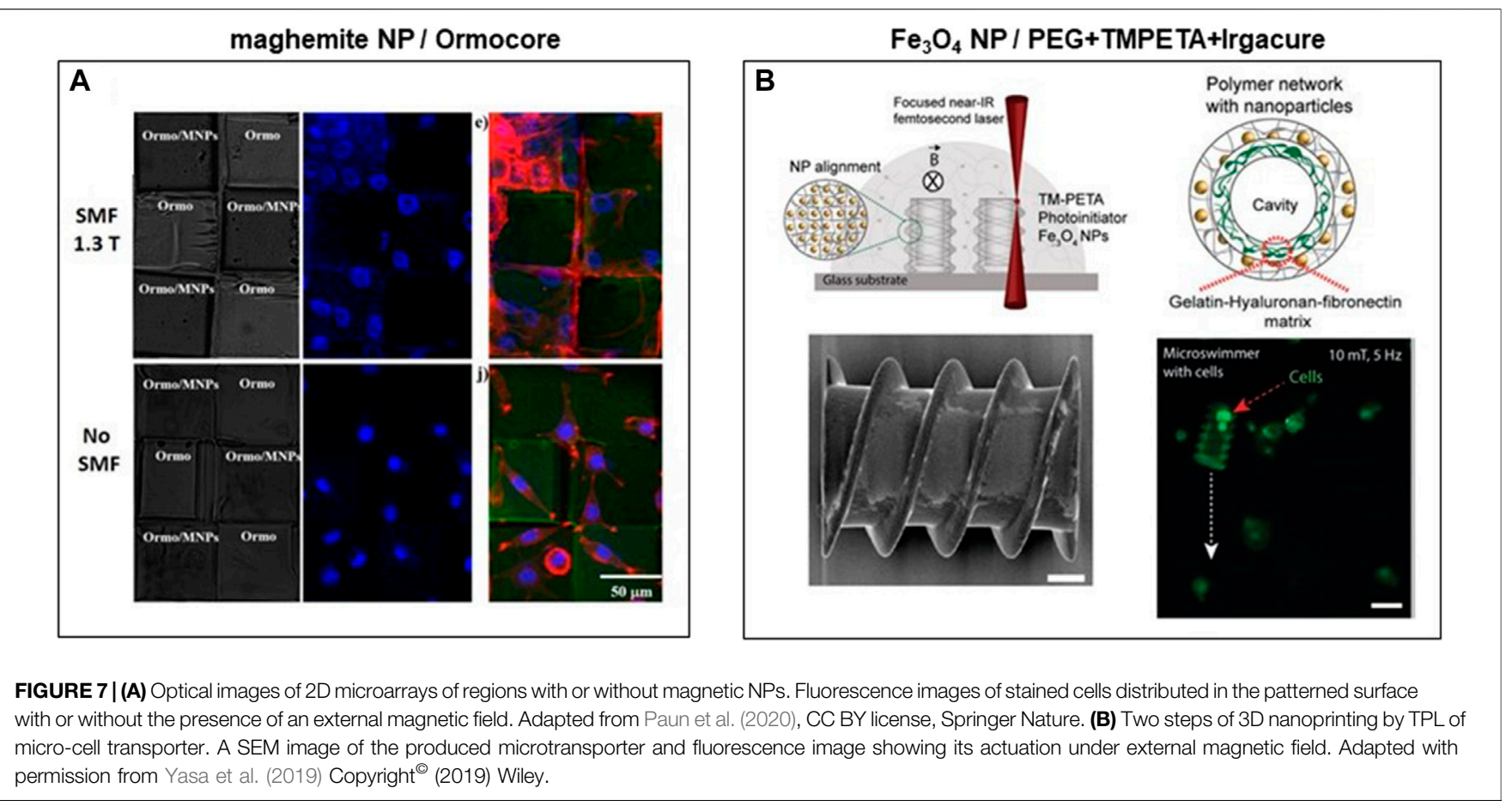

controlled by a rotational magnetic field and printed using TPL from a magnetic precursor suspension composed of gelatin methacryloyl and biofunctionalized superparamagnetic iron oxide NPs (Ceylan et al., 2019). The direct manipulation of cells using magnetic microactuators was reported by Yasa and collaborators (Yasa et al., 2019) following previous works on the subject (Sakar et al., 2010; Tottori et al., 2012). The authors developed a NCPR for micro-stereolithography based on $50 \mathrm{~nm}$ $\mathrm{Fe}_{3} \mathrm{O}_{4} \mathrm{NPs}$ added to a mixture composed of a PEG-derivative and a trimethylolpropane ethoxylate triacrylate (TMPETA) precursor solution containing 3\% (wt/vol) Irgacure 369 photo-initiator. The NFs were previously functionalized with alkyl-phosphonate to 
improve their dispersion in the polymer solution. The concentration of the NFs was controlled down to $20 \mathrm{mg} \mathrm{L}^{-1}$. Hollow double helical microswimmers were fabricated with the NCPR by a commercial 3D nanoprinting system using TPL as shown in Figure 7B. A uniform magnetic field was applied during TPL to define an axis of magnetization perpendicular to the helical axis. Afterward, the inner surfaces were modified by a femtosecond laser to generate a local cross-linking of the unreacted acrylate groups with a pre-polymer solution containing collagen I-derivative, gelatin methacryloyl and hyaluronan-acrylate. This provides a fine-tuned biochemical environment for cell affinity inside the cavity. These transporters act as stem cells delivery systems designed to be magnetically steerable, forcing stem cells to remain trapped (and alive) in its interior until the target location was reached and then releasing the cells into the body. The authors were able to control the microswimmer rotational propulsion movement. Inducing a $10 \mathrm{~Hz}$ rotation, bare $76 \mu \mathrm{m}$ transporters without cells displayed swimming at $10 \mathrm{mT}$ with an average swimming speed of $(11.14 \pm 0.46) \mu \mathrm{m} \mathrm{s}^{-1}$. Entrapment and release of cells were also demonstrated (Yasa et al., 2019). Advances in magnetically driven micro- and nanorobots have been reviewed by Chen et al. (Chen et al., 2017). Among the cited works, the alternative presented by Huang and co-workers is worth mentioning. Here, lithographic patterning of hydrogel sheets for creating compound micromachines from biocompatible materials was proposed (Huang et al., 2016). Hydrogels can form complex 3D structures through stressinduced bending. The authors combined multilayered patterning and local reinforcement to precisely and independently control the folding behavior for each component. The ability of self-motion was induced through the addition of magnetic NPs in the hydrogel layers and tailored by magnetically aligning the particles during polymerization. Magnetic NPs are also utilized as reinforcing components, and the folding axis can be programmed through their selective alignment. Consequently, self-folding transforms a 2D hydrogel microstructure into a $3 \mathrm{D}$ biomimetic microswimmer with tailored shape and magnetic anisotropy.

Magnetic components embedded into microfluidic systems have recently gained considerable attention. Following this idea, Nakahara et al. fabricated a magnetically controlled valve in a microfluidic channel using a composite resist prepared with micron-size magnetic particles of pure iron (Nakahara et al., 2018). The microvalve elements were fabricated by one-step photo-lithography. They demonstrated magnetic driving of an array of microvalves. Flow rate was decreased by $50 \%$ compared to devices without the valves, indicating usefulness for micro total analysis system ( $\mu$ TAS) applications. This idea was implemented in a different manner by Chung et al. who used optofluidic maskless lithography to cure a NCPR containing iron oxide NFs embedded in PDMS channels (Chung et al., 2011). Yu et al. used a multichannel microfluidic reactor and the photocuring of two NCPRs to prepare Janus particles with magnetic NPs on one face and a self-assembled colloidal photonic crystal (PC) on the other. When assembled on a surface, the exposed side, and therefore the optical features, could be controlled by an external magnetic field operating as a simple display (Yu et al., 2012). The combination of optics and microfluidics has been highlighted in a recent review by Lee et al. (Lee et al., 2020).

\subsection{Magnetic Structural Coloration}

Magnetic control of the optical properties also lies within the scope of NCPRs. In 2009, researchers from Kwon's group presented a NCPR termed "M-ink" whose optical properties could be magnetically tuned and lithographically fixated (Kim et al., 2009). The NCPR contained silica-capped superparamagnetic magnetite NPs as NFs in a photo-curable resin consisting of PEGDA and the photo-initiator 2,2dimethoxy-2-phenylacetophenone. After deposition on a PEG coated glass substrate the NCPR was exposed to an external magnetic field which resulted in ordering of the magnetic NFs in chain-like structures along the field lines. The interparticle distance determines the reflectivity spectrum, providing a structural coloration that can be tuned by changing the intensity of the magnetic field. Once the desired color was obtained, the NCPR was photo-cured (acting as a negative tone resist) by UV light, fixing the distribution of NFs and, thus, retaining the structural color (see Figure 8). A mask was used to restrict the coloration to a specific region. The authors used a digital micromirror device (DMD) as an efficient and versatile maskless lithography system. Following works of the same group showed the capabilities of such a NCPR in creating optical encoding particles and free-floating particles with multi-axis rotational magnetic control (Lee et al., 2010) and multiple magnetic microstructured actuators (Chung et al., 2011; Kim et al., 2011; Kim et al., 2013; Kim et al., 2020). Ge et al. implemented structural coloring by coating the surface of superparamagnetic magnetite colloidal nanocrystal clusters with PLA or silica shells functionalized with alkoxysilanes for the further formation of reverse micelles. The interparticle distances were determined by the balance between magnetic attraction and electrostatic repulsion. Thus, the wavelength of reflected color could be tuned by external magnetic fields (Ge et al., 2010). Li et al. used a NCPR with $\mathrm{Fe}_{3} \mathrm{O}_{4}$ nanocubes to achieve structural color through the controlled formation of chains of edge-by-edge connected NCMs (Li et al., 2019d). These 1D PCs presented bright colors in broad viewing angles and patterns observable only with light incident at a particular angle, interesting as anticounterfeit measures.

Selected works employing magnetic NFs are presented in Table 2.

\subsection{Luminescent Nanofillers}

Inorganic nanomaterials displaying Stokes or anti-Stokes photoluminescence have been extensively used as NFs to produce luminescent micropatterns. Typical NPs with Stokes luminescence are QDs, which are semiconductor NPs. For characteristic dimensions smaller than $\sim 10 \mathrm{~nm}$, quantum confinement leads to the formation of discrete energy levels. A progressive widening of the effective band-gap occurs as the size of the crystal is reduced (Reimann and Manninen, 2002), 


\section{$\mathrm{Fe}_{3} \mathrm{O}_{4} @$ silica NP/ PEGDA+photo-init}

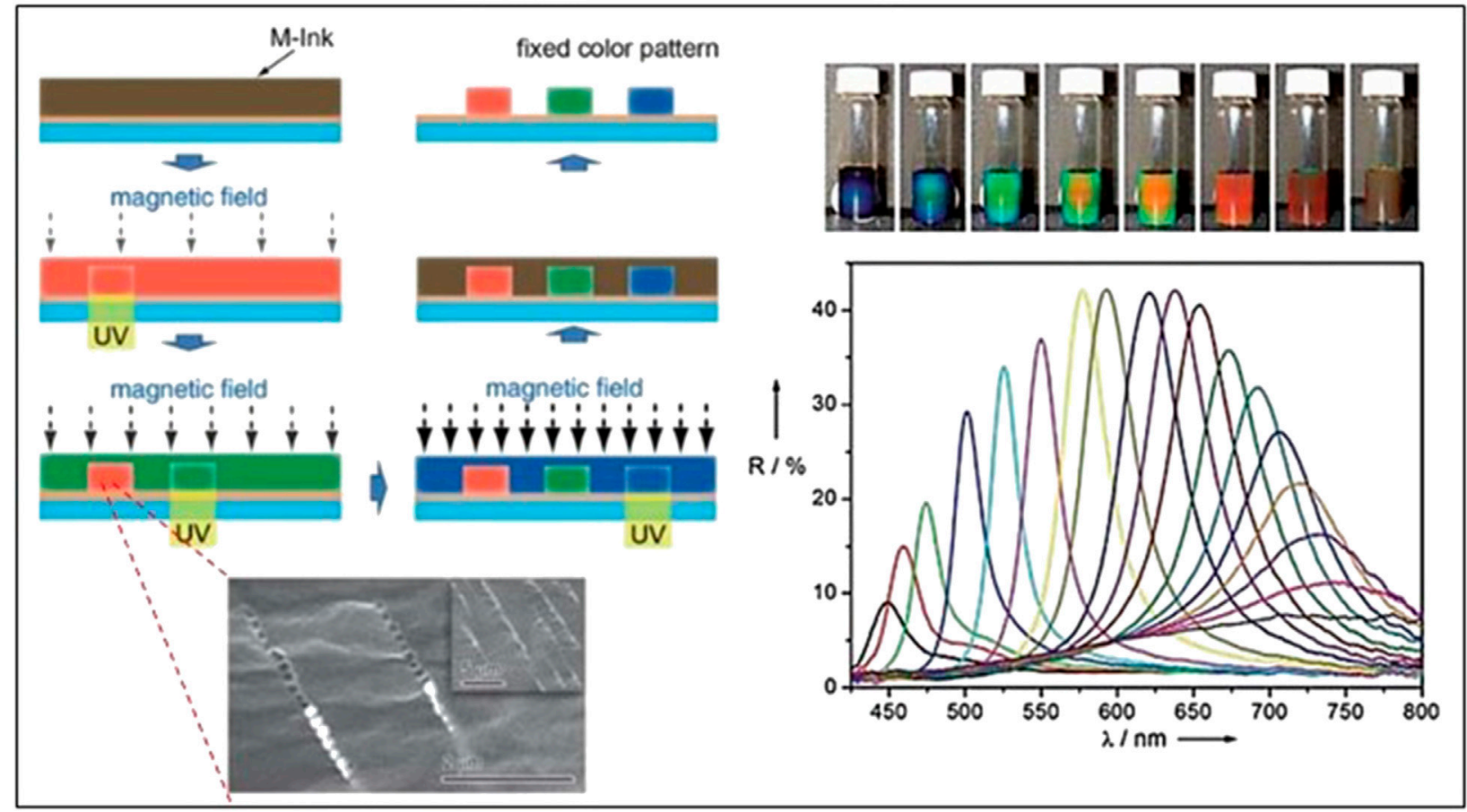

FIGURE 8 | Scheme of the structural color formation through photolithography under applied magnetic field using a magnetic NCPR. SEM image shows the alignment of magnetic NPs (scale bar length is $2 \mu \mathrm{m}$ and $5 \mu \mathrm{m}$ for inset). Photographs and reflection spectra of the NCPR under an external field with increasing strength from right to left. Adapted with permission from Ge et al. (2010) Copyright ${ }^{\odot}$ (2010) Royal Society of Chemistry.

inducing a blue shift of the emission. QDs are typically made up of II-VI (CdS, PbSe, $\mathrm{ZnO}$, etc.) and III-V (InP, InGaP, etc.) semiconductors (Reiss et al., 2009; Jain et al., 2020). Their emission band is narrow and can be fine-tuned during synthesis from near-infrared (NIR) to UV. Other important photo-luminescent nanomaterials are metal clusters (Huang et al., 2018; Yang et al., 2020b), carbon QDs (CDs) (Lim et al., 2015) and nanodiamonds (Vaijayanthimala and Chang, 2009). Regarding anti-Stokes photo-luminescence, lanthanide trivalent ions $\left(\mathrm{Ln}^{3+}\right)$ are essential sources for upconversion (Nadort et al., 2016) when added as dopants in glasses, bulk crystals, or NPs. In upconverting materials, excitation with NIR light results in the emission of visible photons. In particular, UCNPs based on the energy transfer mechanism between sensitized and activator dopants have been extensively developed in recent years due to the capabilities of the chemical synthesis, their chemical endurance, low toxicity and excellent optical stability (Wang et al., 2010; Chen et al., 2014). Luminescent NCPRs have many applications: photo-curing of PRs with embedded QDs has been studied for on-chip detection of heavy metal ions (Xu et al., 2013), bar-coding particles (Zhao et al., 2011), development of high quality displays (Li et al., 2019c) and deterministic integration of quantum emitters into waveguides (Lio et al., 2019; Xu et al., 2020b), nanoantennas (Broussier et al., 2019) and remotely controllable magnetic structures (Au et al., 2020). A recent review by Smith et al. contains a section on lithographically pattered QD NCPRs (Smith et al., 2019).

A first example of the integration of luminescent NPs in commercial PRs was presented by Ingrosso et al. (Ingrosso et al., 2007). They incorporated trioctyl phosphine oxide/ trioctylphosphine (TOPO/TOP)-capped CdSe@ZnS NPs into negative-tone epoxy PRs. To form a homogeneous and stable colloid the authors searched for a common solvent, compatible with the host PR. Anisole, a low-polarity solvent, was selected to match the apolar nature of the capping molecules. The modified epoxy resist was successfully patterned by UV lithography obtaining high-aspect-ratio 3D structures with micrometer resolution and high-intensity luminescence as shown in Figures 9A,B. Photo-sensitive nanocomposite multilayers were developed by Lee et al. by employing photo-cross-linkable polystyrene with UV-sensitive azide groups (PS- $\mathrm{N}_{3}$ ) and thiolterminated random copolymers, denoted PS- $\mathrm{N}_{3}-\mathrm{SH}$ (Lee et al., 2009). Oleic acid-stabilized CdSe@ZnS with different sizes, emitting in the red, green or blue parts of the spectrum, were synthesized and submitted to ligand exchange reaction in the presence of $2 \mathrm{wt} \%$ PS- $\mathrm{N}_{3}-\mathrm{SH}$ and then added to the PS- $\mathrm{N}_{3}$ polymer solution. Multilayer structures were prepared by repetitive steps of spin-coating and UV curing as shown in Figures 9C,D. The cross-linking reaction by UV-triggered photo-dissociation of azide groups was confirmed by FTIR. Using a shadow mask, the authors prepared free-standing multilayers with patterned structures containing features sizes 
TABLE 2 | Examples of NCPR using Magnetic NFs.

\begin{tabular}{|c|c|c|c|c|c|c|}
\hline Nanofillers & $\begin{array}{l}\text { Polymer } \\
\text { matrix }\end{array}$ & Interface chemistry & $\begin{array}{l}\text { Formulation (additives, } \\
\text { treatment, etc.) }\end{array}$ & $\begin{array}{l}\text { Lithographic } \\
\text { method }\end{array}$ & $\begin{array}{l}\text { Applications/Main } \\
\text { results }\end{array}$ & References \\
\hline $\begin{array}{l}\text { Nickel NPs } \\
d \sim 80-150 \mathrm{~nm} \\
\phi=1.3-13.3 \mathrm{wt} \% \\
\text { (commercial) }\end{array}$ & SU-8 & No information provided & $\begin{array}{l}\text { Mixed by hand, resting } \\
\text { time: } 12 \mathrm{~h} \text {, endurance } \\
\text { time: } 36 \mathrm{~h}\end{array}$ & $\begin{array}{l}\text { UV lithog. HB } \\
\text { treatment }\end{array}$ & $\begin{array}{l}\text { Ferromagnetic NCPR. } \\
\text { Magnetically actuated } \\
\text { micromirrors. Magnetic } \\
\text { cantilevers }\end{array}$ & $\begin{array}{l}\text { Damean et al. } \\
\text { (2005) }\end{array}$ \\
\hline $\begin{array}{l}\mathrm{Fe}_{3} \mathrm{O}_{4} \mathrm{NPs} \\
d \sim 10 \mathrm{~nm} \\
\phi=2.4 \mathrm{wt} \%\end{array}$ & $\begin{array}{l}\text { Acrylate based } \\
\text { photo-polymer } \\
\text { formulated } \\
\text { ad-hoc }\end{array}$ & Oleic acid capped NFs & NFs added to the NCPR & TPL & $\begin{array}{l}\text { Remotely-driven magnetic } \\
\text { microsprings }\end{array}$ & $\begin{array}{l}\text { Wang et al. } \\
(2009)\end{array}$ \\
\hline $\begin{array}{l}\mathrm{Fe}_{2} \mathrm{O}_{3} \mathrm{NPS} \\
d \sim 11 \mathrm{~nm}, \\
C_{N P}=2 \times 10^{-3} \mathrm{M}\end{array}$ & $\begin{array}{l}\text { Negative tone } \\
\text { epoxy- } \\
\text { based PR }\end{array}$ & Oleic acid capped NFs & $\begin{array}{l}\text { NFs in toluene added to the } \\
\text { formulated PR }\end{array}$ & UV lithog. & AFM probes & $\begin{array}{l}\text { Ingrosso et al. } \\
\text { (2009) }\end{array}$ \\
\hline $\begin{array}{l}\mathrm{Fe}_{3} \mathrm{O}_{4} \mathrm{NPS} \\
d \sim 50 \mathrm{~nm} \\
\phi=1-10 \mathrm{wt} \%\end{array}$ & SU-8 & $\begin{array}{l}\text { Commercial NFs used w/o } \\
\text { modification }\end{array}$ & No additives declared & UV lithog. & $\begin{array}{l}\text { Ferromagnetic } \\
\text { microtransporters }\end{array}$ & $\begin{array}{l}\text { Sakar et al. } \\
(2010)\end{array}$ \\
\hline $\begin{array}{l}\mathrm{Fe}_{3} \mathrm{O}_{4} \\
\mathrm{NPs} d \sim 170 \mathrm{~nm}\end{array}$ & PEGDA & $\begin{array}{l}\text { NPs capped with silica } \\
\text { shells }\end{array}$ & $\begin{array}{l}\text { NPs dispersed in } \\
\text { photocurable resin with } \\
\text { ethanol used as solvation } \\
\text { liquid. }\end{array}$ & $\begin{array}{l}\text { NCPR cured with } \\
\text { spatially } \\
\text { controlled UV } \\
\text { lithog. }\end{array}$ & $\begin{array}{l}\text { Generation of multicoloured } \\
\text { patters by repetitive tuning } \\
\text { and fixing of the structural } \\
\text { color }\end{array}$ & $\begin{array}{l}\text { Kim et al. } \\
\text { (2009); Kim } \\
\text { et al. (2011) }\end{array}$ \\
\hline $\begin{array}{l}\mathrm{Fe}_{3} \mathrm{O}_{4} \mathrm{NPs} \\
d \sim 12 \mathrm{~nm} \\
\phi=4-32 \mathrm{wt} \%\end{array}$ & SU-8 & $\begin{array}{l}\text { Two different phosphate- } \\
\text { containing dispersing } \\
\text { agents were used. Linear } \\
\text { copolymers with phosphate } \\
\text { groups gives better results }\end{array}$ & $\begin{array}{l}\text { NFs in GBL, sonication for } \\
10 \text { min }\end{array}$ & UV lithog. & Magnetic cantilevers & $\begin{array}{l}\text { Suter et al. } \\
\text { (2011a); Suter } \\
\text { et al. (2011b) }\end{array}$ \\
\hline $\begin{array}{l}\text { Carbon coated } \\
\text { cobalt NPs } \\
d \sim 20-80 \mathrm{~nm}\end{array}$ & SU-8 & Carbon capped NPs & $\begin{array}{l}\text { Co NPs dissolved in } \\
\text { cyclopentonone and } \\
\text { added to SU-8-2002. } \\
\text { Some agglomeration was } \\
\text { observed }\end{array}$ & UV lithog. & $\begin{array}{l}\text { Multiple potential } \\
\text { applications for MEMs } \\
\text { sensors. Fabrication and } \\
\text { actuation of a micro } \\
\text { membrane demonstrated }\end{array}$ & $\begin{array}{l}\text { Kandpal et al. } \\
\text { (2015) }\end{array}$ \\
\hline $\begin{array}{l}\mathrm{Fe}_{3} \mathrm{O}_{4} \mathrm{NPs} d \sim \\
11 \mathrm{~nm} \phi \text { up to } \\
10 \text { wt\% }\end{array}$ & SU-8 & $\begin{array}{l}\text { No functionalization or } \\
\text { surfactants were used }\end{array}$ & $\begin{array}{l}\text { Ultrasonic mixing for } \\
30 \mathrm{~min}\end{array}$ & UV lithog. & $\begin{array}{l}\text { Free-floating } \\
\text { microstructures }\end{array}$ & $\begin{array}{l}\text { Huong Au et al. } \\
\text { (2018) }\end{array}$ \\
\hline $\begin{array}{l}\mathrm{Fe}_{3} \mathrm{O}_{4} \\
\mathrm{NPs} \phi=2 \mathrm{wt} \%\end{array}$ & SU-8 & No functionalization. & $\begin{array}{l}\text { Magnetic NPs directly } \\
\text { mixed with SU-8 }\end{array}$ & LOPA & $\begin{array}{l}\text { Fabrication and actuation of } \\
\text { micro-swimmers, fans, } \\
\text { springs and magneto- } \\
\text { photonic crystals } \\
\text { demonstrated. }\end{array}$ & $\begin{array}{l}\text { Nguyen et al. } \\
(2018)\end{array}$ \\
\hline $\begin{array}{l}\mathrm{Fe}_{3} \mathrm{O}_{4} \text { nano-cubes. } \\
I \sim 344 \mathrm{~nm}\left(\mathrm{w} / \mathrm{SiO}_{2}\right. \\
\text { shell })\end{array}$ & $\begin{array}{l}\text { Acrylamide } \\
\text { monomer }\end{array}$ & $\begin{array}{l}\text { Nano-cubes coated with a } \\
\text { layer of } \mathrm{SiO}_{2}\end{array}$ & $\begin{array}{l}\text { Thickness } 25 \mathrm{~nm} \\
\text { Nanocubes dispersed in } \\
\text { hydrogel precursor } \\
\text { containing acrylamide } \\
\text { monomer, photoinitiator } \\
\text { and BIS in ethanol }\end{array}$ & UV lithog. & $\begin{array}{l}\text { Patterns with bright } \\
\text { structural colors at broad } \\
\text { viewing angles, } \\
\text { advantageous for anti- } \\
\text { counterfeiting features in } \\
\text { thin objects. }\end{array}$ & Li et al. (2019d) \\
\hline $\begin{array}{l}\mathrm{Fe}_{3} \mathrm{O}_{4} \mathrm{NPs} \\
d \sim 10 \mathrm{~nm} \\
(\phi=1 \text { wt } \%) \text { and } \\
\mathrm{CdSe} / \mathrm{CdS} \text { QDs }\end{array}$ & SU-8 & $\begin{array}{l}\text { No functionalization. Core- } \\
\text { shell QDs dissolved in } \\
\text { hexane/octane solution. }\end{array}$ & $\begin{array}{l}\mathrm{SU}-8 \text { mixed } w / \mathrm{Fe}_{3} \mathrm{O}_{4} \mathrm{NPs} \\
\text { and spin-coated on PMMA } \\
\text { substrate. QD solution } \\
\text { spin-coated on top. }\end{array}$ & UV lithog./LOPA & $\begin{array}{l}\text { Magnetic luminescent } \\
\text { structures fabricated. } \\
\text { Structures released and } \\
\text { manipulated by magnetic } \\
\text { fields. Several potential } \\
\text { applications in medicine/ } \\
\text { Controlled movement of } \\
\text { SPS in 3D space }\end{array}$ & $\begin{array}{l}\text { Perry et al. } \\
(2019) / A u \text { et al. } \\
(2020)\end{array}$ \\
\hline $\begin{array}{l}\mathrm{Fe}_{3} \mathrm{O}_{4} \mathrm{NPS} \\
d \sim 50 \mathrm{~nm} \\
\phi=20 \mathrm{~g} \mathrm{~L}^{-1}\end{array}$ & TMPETA & $\begin{array}{l}\text { SPIONs functionalized with } \\
\text { alkyl-phosphonate to } \\
\text { prevent agglomeration }\end{array}$ & 3 wt\% photoinitiator & TPL & $\begin{array}{l}\text { Fabrication of a steerable } \\
\text { micro cell transporter } \\
\text { demonstrated. }\end{array}$ & $\begin{array}{l}\text { Yasa et al. } \\
(2019)\end{array}$ \\
\hline $\begin{array}{l}\mathrm{Fe}_{3} \mathrm{O}_{4} \mathrm{NPs} \text { with } \mathrm{SiO}_{2} \\
\text { shells } \\
d \sim 30 \mathrm{~nm}, \\
\phi=29.5 \text { wt } \%\end{array}$ & PUA & $\begin{array}{l}\mathrm{Fe}_{3} \mathrm{O}_{4} @ \mathrm{SiO}_{2} \mathrm{NPs} \text { were } \\
\text { silanized with } \gamma \text {-MPS }\end{array}$ & $\begin{array}{l}\mathrm{PUA} / \mathrm{Fe}_{3} \mathrm{O}_{4} @ \mathrm{SiO}_{2} \mathrm{NCPR} \\
\text { prepared by mechanical } \\
\text { mixing overnight and } \\
\text { subsequent blending in a } \\
\text { centrifugal mixer. }\end{array}$ & UV lithog. & $\begin{array}{l}\text { Micro-pillars with different } \\
\text { degrees of bending } \\
\text { obtained through several } \\
\text { steps of manipulation of NP } \\
\text { location in the pillars and UV } \\
\text { curing }\end{array}$ & $\begin{array}{l}\text { Wang et al. } \\
(2020)\end{array}$ \\
\hline
\end{tabular}


TABLE 2 | (Continued) Examples of NCPR using Magnetic NFs.

\begin{tabular}{|c|c|c|c|c|c|c|}
\hline Nanofillers & $\begin{array}{l}\text { Polymer } \\
\text { matrix }\end{array}$ & Interface chemistry & $\begin{array}{l}\text { Formulation (additives, } \\
\text { treatment, etc.) }\end{array}$ & $\begin{array}{l}\text { Lithographic } \\
\text { method }\end{array}$ & $\begin{array}{l}\text { Applications/Main } \\
\text { results }\end{array}$ & References \\
\hline $\begin{array}{l}\gamma-\mathrm{Fe}_{2} \mathrm{O}_{3} \\
\mathrm{NPs} d \sim 4.9 \mathrm{~nm}\end{array}$ & Ormocore & No information provided & $\begin{array}{l}\text { NCPR prepared by } \\
\text { ultrasonication. }\end{array}$ & TPL & $\begin{array}{l}\text { Fabrication of scaffolds for } \\
\text { promotion of the } \\
\text { mineralization of osteoblast } \\
\text { cells. }\end{array}$ & $\begin{array}{l}\text { Paun et al. } \\
\text { (2019); Paun } \\
\text { et al. (2020) }\end{array}$ \\
\hline
\end{tabular}

In Table, HB, hard bake; BIS, N,N'- methylenebisacrylamide; PUA, poly(urethane acrylate). The green leaf indicates applications in biosciences.

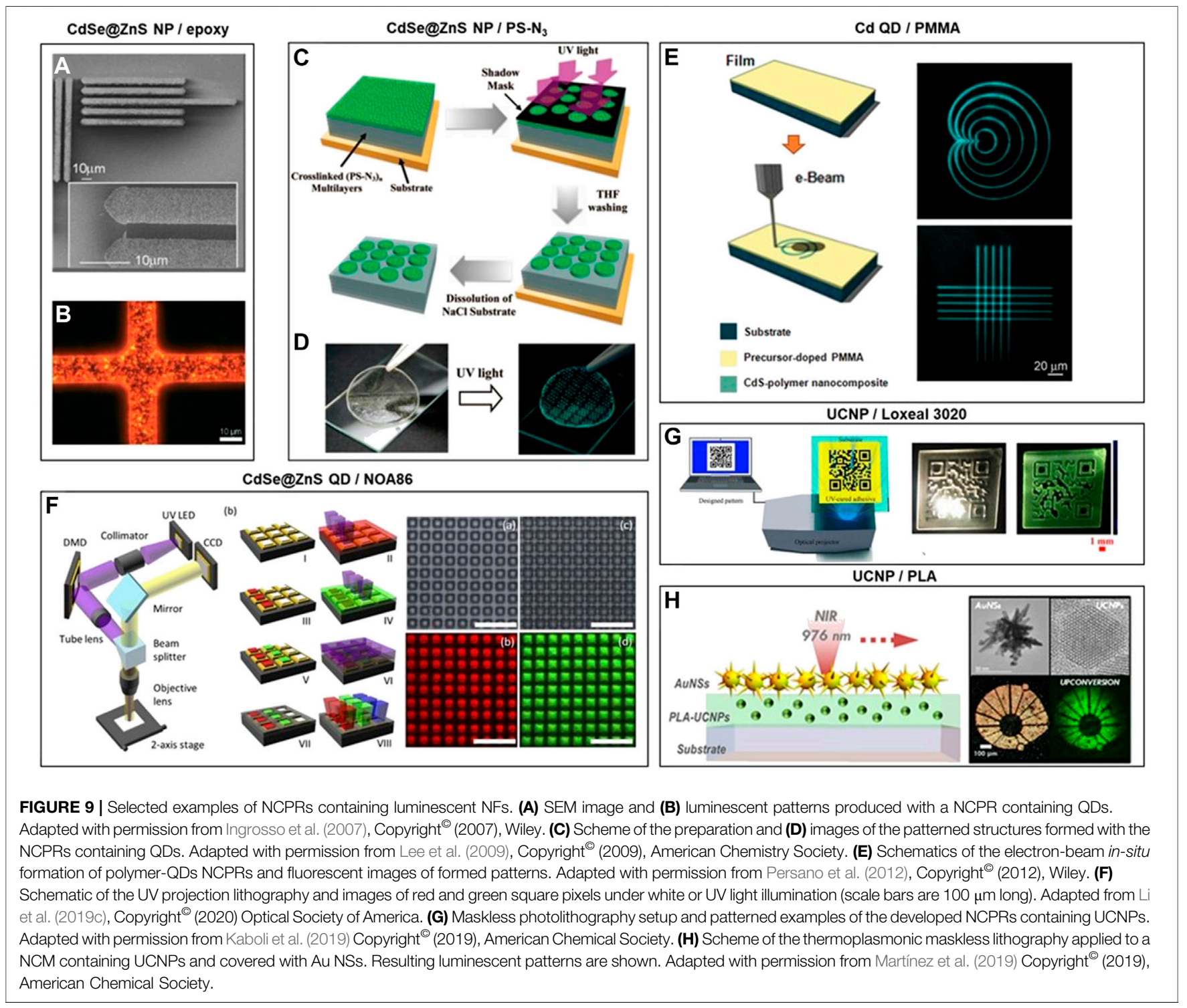

of $500 \mu \mathrm{m}$. The versatility of these multilayer structures showed great promise for the fabrication of color-tunable and flexible emitting patterns for integration in optical devices such as display panels. Park et al. used luminescent NCPRs based on CdSe@ZnS QDs to construct high-resolution 2D and 3D photonic structures using TPL (Park et al., 2010). Through EBL, Persano et al. induced the in-situ synthesis of $\sim 3 \mathrm{~nm}$ CdS QDs in a modified
PMMA PR containing Cd-complexes formed by cadmiumbis(benzylthiol) and 1-methylimidazole in chloroform (Persano et al., 2012). The designed patterns appear bright with a homogeneous distribution of CdS nanocrystals, as presented in Figure 9E. Another interesting example was reported by Li et al. who used QDs embedded into a commercial thiol-ene based photo-polymer (NOA86, Norland Optics) for direct patterning 
using projection lithography (Li et al., 2019c). CdSe@Zns coreshell QDs capped with octadecylamine and emitting in the red or green part of the spectrum were dispersed in chloroform $\left(5 \mathrm{gL}^{-1}\right)$ and then NOA86 was added while mixing to different final concentrations. The NCPR was drop-casted onto the substrate and chloroform was evaporated. The samples were patterned using a maskless projection lithography printing system containing a high-resolution DMD. The thiol-ene reaction was triggered by $405 \mathrm{~nm}$ UV light projection. Upon exposure, thiyl radicals are formed that rapidly react with -ene functional groups, producing the cross-linking of the polymer matrix. Because the QDs were capped with amine surface groups, they were not involved in the thiol-ene polymerization, preventing phase separation or QD aggregation. Using this NCPR, the authors performed the patterning of red or green labeled NCPRs directly on the pixels of a $0.5 \mathrm{~mm}$ square blue LED micro-array. In this way, they obtained a full RGB device, as shown in Figure 9F.

In 2019, two different groups developed maskless photolithographic techniques to transfer photo-luminescent patterns based on UCNPs. Kaboli et al. presented a NCPR based on a commercial acrylate-based UV-curable resist (Loxeal 3020) to which the authors added an hexane-based colloid of UCNPs (Kaboli et al., 2019). Hexane was removed through evaporation by keeping the NCPR in a desiccator for $24 \mathrm{~h}$ prior to use. Films deposited on glass substrates were submitted to maskless lithography. The transfer of the designed pattern was performed with an optical projector by exposing the nanocomposite films for $20 \mathrm{~s}$ and then developing the samples with acetone. The luminescent patterns were visible under $980 \mathrm{~nm}$ laser illumination (see Figure 9G). Emission color could be tuned by changing the pump power, temperature and excitation frequency. Single and double color patterns were developed to be used as QR security features, readable using only a smartphone. Using a different approach, Martínez et al. deposited thermoplastic PLA films loaded with UCNPs on rigid and flexible substrates and then covered them with a thin layer of densely assembled AuNSs. Luminescent patterns were successfully transferred through DLW (see Figure 9H). The thermoplasmonic effect on AuNSs under a focused laser beam at $976 \mathrm{~nm}$ assisted in the local heating at the spot region. As the temperature surpasses the glass transition temperature, the AuNSs got attached to the PLA. The unexposed regions were readily dissolved in acetone, while the exposed parts remained, implying a possible cross-linking of the PLA layer (Martínez et al., 2019).

Laser applications are also possible, as shown by Smirnova et al. The authors encapsulated CdSe@ZnS nanocrystals and $\mathrm{ZrO}_{2} \mathrm{NPs}$ and prepared distributed feedback (DFB) structures by holographic lithography (Smirnova et al., 2009b). They achieved amplified spontaneous emission and proved that a DFB structure composed of QDs confined in a polymer matrix displayed enhanced light emission intensity and a narrower peak width. These properties of DFB structures have been widely used in following works (Sakhno et al., 2009; Sakhno et al., 2011; Smirnova et al., 2011).

Mayer and collaborators fabricated 3D optical security features from different numbers of pentaerythritol triacrylate (PETA) and core@shell QD NCPRs (Mayer et al., 2017). In a first step, a non-fluorescent 3D grid-like structure was fabricated from a PETA based PR. Next, fluorescent markers were added to this grid by multi-photon lithography (MPL) with one or several NCPRs (this determined the number of colors on the final product) consisting of PETA and $0.01 \mathrm{wt} \%$ alkyl functionalized CdSe-based QDs with different emission colors. Through multiple MPL steps, differently colored NCPR are polymerized in the desired positions in the grid. To study the robustness of the fabricated structures against bleaching, a region was continuously excited and intensity curves were recorded. Encapsulated samples showed little degradation even after six months of exposure to environmental conditions. More recently, the same group extended this approach by combining a 3D DLW system with a microfluidic chamber, leading to a doubling of the number of fluorescent colors (blue and green with CdSSe-based (oleic acid) functionalized core-shell QD doped PETA NCPR, red and orange with alkyne functionalized organic Atto dye doped PETA NCPR) in the structure and a four-fold increase in marker density (Mayer et al., 2019).

Luminescent NCPRs based on bio-friendly hydrogels have been widely used for detection of specific biomolecules. Bioassays in microfluidic environments have received attention due to fast reaction times, cost effectiveness, and low sample volume requirements (Dittrich and Manz, 2006). Photo-curable polymers have been employed in the detection of proteins (Appleyard et al., 2011a; Appleyard et al., 2011b; Srinivas et al., 2011) and nucleic acids (Pregibon and Doyle, 2009), including miRNA (Bong et al., 2010; Chapin and Doyle, 2011; Suh et al., 2012; Lee et al., 2014) and mRNA (Choi et al., 2012). In most of the above works, microparticles are endowed with a graphical enconding region consisting of a hydrogel NCPR with a flourecent NF which is typically pattered with holes of varying dimensions. A magnetic region is sometimes included for particle orientation and control (Bong et al., 2010). The use of lanthanidedoped NFs for color-codes and multiplexing has several advantages. In particular NIR light excited upconversion and downshifting nanomaterials have narrow excitation and emission wavelengths and tunable emission lifetime and intensity (Xu et al., 2020a). Gerver et al. synthesized hydrophilic PEG-acrylate polymer beads encoded with lanthanide nanophosphors using a microfluidic device. The codes differed by less than $3 \%$ from their target values and could be distinguished from each other with an error rate smaller than $0.1 \%$ (Gerver et al., 2012). Recently, Zeng et al. implemented a multiplexed detection system based on lithography-made upconversion barcodes for bioassay detection modules (see Figure 10) (Zeng et al., 2020). They demonstrated the use of upconversion barcodes in a DNA hybridization test with high target specificity, low detection limit, enabling potential development of biomarkers for many applications. Yang et al. implemented a microfluidic based fabrication for a barlike code using core@shell microparticles (Yang et al., 2020a). The encoded particles were of small and uniform size. The core droplets were filled with different QDs and dyes, and the outer oil phase droplets of TMPETA were solidified into the shell of the encoded particles and supplied the surface for capturing targets. Compared with conventional encoding methods, this 
D

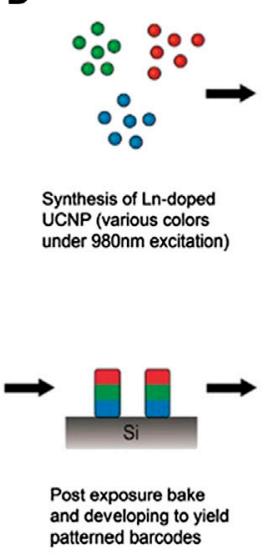

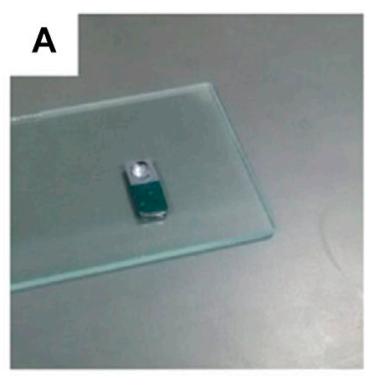
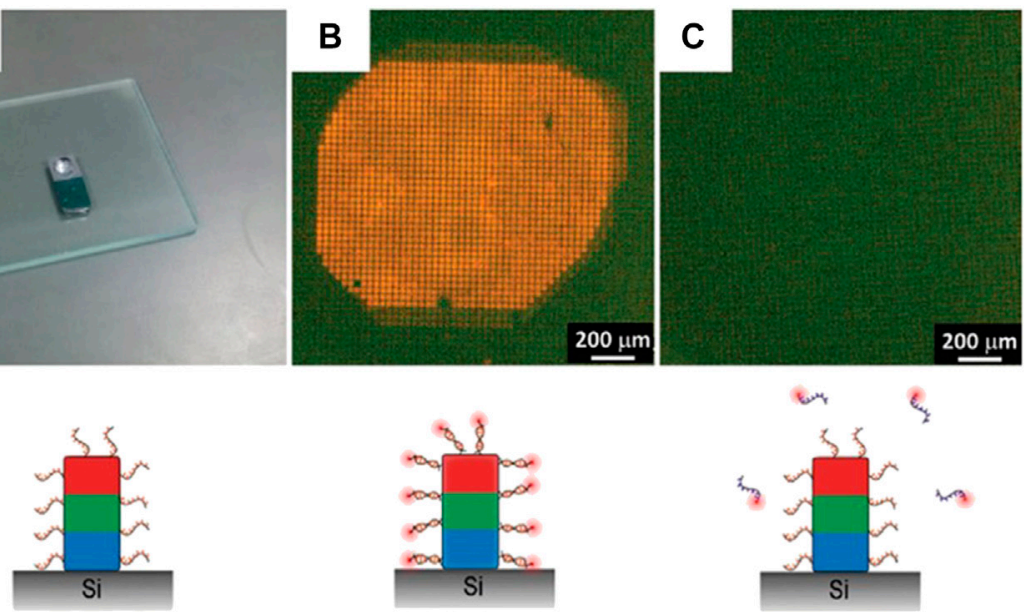

FIGURE 10 | D-Schematic illustration of the fabrication process of microbarcodes with immobilized DNA molecules. UCNPS with their characteristic emission colors are mixed with SU-8 and spin-coated repeatedly onto Si substrate to form multilayer thin films. The film subsequently undergoes UV exposure. The exposed regions is cross-linked and remain unwashed during the developing stage. Biomolecules, including DNA and proteins can be covalently conjugated to the microbarcode surface thereafter and a brief sonication lifts all the molecule-tagged barcodes for further detection experiments. (A) Photograph showing the reaction process of conjugating probe DNA strands onto the SU-8 surface. (B) Hybridization trial on barcode array. After immobilizing the probe DNA strands onto SU-8, complementary DNA strands (Cy3 labeled) are transferred onto the SU-8 substrate. Hybridization takes place, as evidenced by the luminescence mark left on the SU-8 after stringent wash. In regions outside the luminescence circle where capture DNA strands do not exist, the weak fluorescence signal is detected, indicating that negligible nonspecific absorption occurs on SU-8 surfaces. (C) When non-complementary DNA (Cy3 labeled) is applied to the substrate, fluorescence is not detected, hence hybridization is not achieved (Zeng et al., 2020).

approach increases the encoding number by a hundred times, and has great potential for high-throughput multiplexed analysis.

The combination of magnetic and luminescent NFs has been studied in several interesting works. In 2019, Perry et al. reported the fabrication of free-floating magnetic and luminescent polymer-based micro-sized structures through mask lithography by adding $\mathrm{Fe}_{3} \mathrm{O}_{4}$ NPs into SU-8 and depositing QDs on top (Perry et al., 2019). The resulting microstructures could be externally manipulated due to the magnetic properties of the $\mathrm{Fe}_{3} \mathrm{O}_{4}$ NFs while the QDs (CdSe@ $\mathrm{CdS}$ ) provided luminescent properties. The $\mathrm{Fe}_{3} \mathrm{O}_{4}$ NFs were mixed with the SU-8 without functionalization. After coating a PMMA-covered substrate with the NCPRs, an hexane/ octane colloid of the QDs was spin-coated on top. Standard UV mask lithography protocols followed and the PMMA sacrificial layer was dissolved in acetone releasing the magnetic nanocomposite microstructures. The authors demonstrated the external control of the structures in three dimensions using magnetic fields. The same group extended their efforts in a following work showing the capabilities of SU-8 based NCPRs for the fabrication of 2D and 3D magneto-photonic devices through LOPA DLW (Au et al., 2020). Lastly, Augurio et al. proposed a multifunctional nanocomposite hydrogel which could be used for tracking (optical) and manipulation (magnetic) (Augurio et al., 2020). The authors incorporated core-shell $\mathrm{SrF}_{2}$ UCNPs, doped with $\mathrm{Yb}^{3+}, \mathrm{Tm}^{3+}$ and $\mathrm{Nd}^{3+}$ into a gelatin methacryloyl matrix. Upon excitation with $800 \mathrm{~nm}$ wavelength, the emission of the NPs allowed for deep monitoring of 3D-printed structures.
Self-assembled iron oxide NPs were added to the hydrogel. These provided magnetic anisotropy and, therefore, magnetic responsiveness and the possibility of remote manipulation.

Table 3 summarizes selected examples of NCPRs containing luminescent NFs.

\subsection{Carbon-Based Nanofillers}

Carbon-based materials have fascinating physical properties that have been a subject of interest in composite materials science for a long time. In recent decades, the emergence of purely carbonbased macromolecular nanostructures, including fullerene, graphene, single- (SWCNTs) or multi-wall carbon nanotubes (MWCNTs) and diamondoids has become a major topic of research (Patel et al., 2019). The inclusion of this type of NFs in polymeric matrices seeks to improve one (or several) of the following three physical properties: thermal conductivity, electrical conductivity and mechanical strength (Potts et al., 2011).

One of the first works on novel NCPRs containing carbon nanomaterials was presented in the late 90 by Ishii et al. (Ishii et al., 1997). The authors modified commercial PRs for EBL (PMMA, ZEP520 and SAL601) by adding C60 fullerene. C60 powder was first dispersed in o-dichlorobenzene, and then mixed with each resist solution. The best results were obtained for $\phi=5 \mathrm{wt} \%$. The C60 NFs acted as a strong dissolution inhibitor during development and a highly resistant agent during substrate dry etching. These properties allow the formation of films of less than $50 \mathrm{~nm}$, which improves both the contrast and resolution of EBL. Ten years later, Vaudreuil et al. produced NCMs formed by MWCNTs in PMMA 
TABLE 3 | Examples of NCPR using Photonic NFs.

\begin{tabular}{|c|c|c|c|c|c|c|}
\hline Nanofillers & $\begin{array}{l}\text { Polymer } \\
\text { matrix }\end{array}$ & Interface chemistry & $\begin{array}{l}\text { Formulation (additives, } \\
\text { treatment, etc.) }\end{array}$ & Lithographic method & $\begin{array}{l}\text { Applications/Main } \\
\text { results }\end{array}$ & References \\
\hline CdSe@ZnS QDs & $\begin{array}{l}\text { mr-L6005xP } \\
\text { (neg. } \\
\text { epoxy PR) }\end{array}$ & $\begin{array}{l}\text { TOP/TOPO as } \\
\text { synthesized }\end{array}$ & $\begin{array}{l}\text { Diff. solvents explored. } \\
\text { Best results with anisole. }\end{array}$ & UV lithog. & $\begin{array}{l}\text { Luminescent PR and } \\
\text { microstructures }\end{array}$ & $\begin{array}{l}\text { Ingrosso et al. } \\
(2007)\end{array}$ \\
\hline CdSe@ZnS QDs & $\begin{array}{l}\text { Photo cross- } \\
\text { linkable PS }\end{array}$ & $\begin{array}{l}\text { Functionalized with PS- } \\
\mathrm{N}_{3}-\mathrm{SH} \text { for photo- } \\
\text { polimerization with PS } \\
\text { matrix }\end{array}$ & $\begin{array}{l}\text { UV-sensitive azide groups. } \\
\text { Layer-by-layer deposited } \\
\text { by spin-coating }\end{array}$ & Deep UV lithog. & $\begin{array}{l}\text { Luminescent coatings in } \\
\text { multi-layered structures }\end{array}$ & $\begin{array}{l}\text { Lee et al. } \\
\text { (2009) }\end{array}$ \\
\hline $\begin{array}{l}\text { CdSe@ZnS } \\
\text { nanocrystal QDs and } \\
\mathrm{ZrO}_{2} \mathrm{NPs} d \sim 6-8 \mathrm{~nm}\end{array}$ & $\begin{array}{l}\text { Acrylate-based } \\
\text { polymer }\end{array}$ & $\begin{array}{l}\text { QDs covered with } \\
\text { TOPO } \mathrm{ZrO}_{2} \text { stabilized } \\
\text { achieved using DBSA }\end{array}$ & $\begin{array}{l}\text { Photoinitiator irgacure } \\
1,700 \text { used. NPs and QDs } \\
\text { dispersed in chloroform } \\
\text { and added to the monomer } \\
+ \text { photoinitiator mixture }\end{array}$ & Holographic recording & $\begin{array}{l}\text { Fabrication of volume } \\
\text { DFB structures. Amplified } \\
\text { spontaneous emission } \\
\text { obtained. }\end{array}$ & $\begin{array}{l}\text { Smirnova et al. } \\
\text { (2009b) }\end{array}$ \\
\hline $\begin{array}{l}\mathrm{HfO}_{2} \mathrm{NPs} d \sim \\
1-4 \mathrm{~nm} \phi=7.6 \mathrm{wt} \%\end{array}$ & $\begin{array}{l}\text { PMAdMA-co- } \\
\text { GBLMA }^{(c)}\end{array}$ & $\begin{array}{l}\text { Acetate capping } \\
\text { exchanged for TDHT }\end{array}$ & $\begin{array}{l}\text { NPs w/TDHT capping } \\
\text { dispersed in PGMEA as } \\
\text { co-solvent }\end{array}$ & $\begin{array}{l}\text { Deep UV lithog. } \\
\text { and EBL }\end{array}$ & $\begin{array}{l}\mathrm{PR} \text { w/high refractive index } \\
\text { and low scattering }\end{array}$ & $\begin{array}{l}\text { Bae et al. } \\
(2010)\end{array}$ \\
\hline CdS QDs $d \sim 4 \mathrm{~nm}$ & PMMA & No functionalization & $\begin{array}{l}\text { One-step synthesis After } \\
\text { patterning in-situ synthesis } \\
\text { of CdS QDs was carried } \\
\text { out using EBL }\end{array}$ & $\begin{array}{l}\text { Patterning of films using } \\
\text { RT-NIL. EBL for 2D } \\
\text { luminescent patters. }\end{array}$ & $\begin{array}{l}\text { Fab. of light-emitting } \\
\text { patterns with sub- } \\
\text { micrometer resolution }\end{array}$ & $\begin{array}{l}\text { Persano et al. } \\
\text { (2012) }\end{array}$ \\
\hline $\begin{array}{l}\text { CdSe-based core@ } \\
\text { shell QDs w/different } \\
\text { emission } \\
\text { colors } \phi=0.01 \text { wt\% }\end{array}$ & $\begin{array}{l}\text { PETA (50 wt } \\
\%), \text { TDDDA } \\
\text { (50wt\%) }\end{array}$ & Alkyl functionalized QDs & $\begin{array}{l}\text { Nonfluorescent 3D cross- } \\
\text { grid first printed using } \\
\text { PETA + } 1 \text { wt } \% \text { irgacure } \\
819 . \text { Fluorescent markers } \\
\text { added in multiple steps } \\
\text { of MPL }\end{array}$ & MPL & $\begin{array}{l}\text { Fabrication of 3D } \\
\text { deterministic security } \\
\text { features }\end{array}$ & $\begin{array}{l}\text { Mayer et al. } \\
\text { (2017)/Mayer } \\
\text { et al. (2019) }\end{array}$ \\
\hline $\begin{array}{l}\mathrm{NaYF}_{4}: \mathrm{Yb}^{3+}: \mathrm{Tm}^{3+} \\
\mathrm{Er}^{3+} \\
\text { UCNPs } d \sim 15 \mathrm{~nm}\end{array}$ & Loxeal 3020 (-) & $\begin{array}{l}\text { Oleic acid capped } \\
\text { UCNPs }\end{array}$ & $\begin{array}{l}\text { UCNPs in hexane mixed } \\
\text { with PR }\end{array}$ & $\begin{array}{l}\text { Maskless lithog. (UV } \\
\text { projector) }\end{array}$ & $\begin{array}{l}\text { Anticounterfeiting } \\
\text { printings }\end{array}$ & $\begin{array}{l}\text { Kaboli et al. } \\
\text { (2019) }\end{array}$ \\
\hline $\begin{array}{l}\mathrm{NaGdF}_{4}: \mathrm{Yb}^{3+}: \mathrm{Er}^{3+} \\
\text { UCNPS } d \sim 10 \mathrm{~nm}\end{array}$ & $\begin{array}{l}\text { PLA } 2 \text { wt\% } \\
\text { PLA in } \\
\text { chloroform }\end{array}$ & $\begin{array}{l}\text { Oleic acid capped } \\
\text { UCNPs }\end{array}$ & $\begin{array}{l}\text { Chloroform used as co- } \\
\text { solvent }\end{array}$ & $\begin{array}{l}\text { Thermoplasmonic } \\
\text { lithog. }(976 \mathrm{~nm})\end{array}$ & $\begin{array}{l}\text { Luminescent patterns on } \\
\text { rigid and flexible } \\
\text { substrates. SERS active } \\
\text { nano-/micro-structures }\end{array}$ & $\begin{array}{l}\text { Martínez et al. } \\
\text { (2019) }\end{array}$ \\
\hline $\begin{array}{l}\text { CdSe@ZnS } \\
\text { QDs } \phi=5 \mathrm{gL}^{-1}\end{array}$ & $\begin{array}{l}\text { NOA86 thiol- } \\
\text { ene photo- } \\
\text { polymer }\end{array}$ & $\begin{array}{l}\text { QDs capped with } \\
\text { octadecylamine }\end{array}$ & $\begin{array}{l}\text { Chloroform used as co- } \\
\text { solvent }\end{array}$ & Projection lithog. & $\begin{array}{l}\text { Pixel-by-pixel patterning } \\
\text { of a blue LED micro-array }\end{array}$ & Li et al. (2019c) \\
\hline $\begin{array}{l}\text { UCNPs emitting in } \\
\text { red }\left(\mathrm{NaYF}_{4}: \mathrm{Mn} / \mathrm{Yb} /\right. \\
\text { Er), blue }\left(\mathrm{NaYF}_{4}: \mathrm{Yb} /\right. \\
\mathrm{Tm}) \text { and green } \\
\left(\mathrm{NaYF}_{4}: \mathrm{Yb} / \mathrm{Er}\right)\end{array}$ & SU-8 & $\begin{array}{l}\text { Oleate surface ligands } \\
\text { on UCNPs exchanged } \\
\text { for benzoate ions for } \\
\text { stable dispersion in SU8 }\end{array}$ & $\begin{array}{l}\text { UCNPs mixed w/SU-8 } \\
\text { using sonication. NCPRs } \\
\text { with different UCNPs spin } \\
\text { coated LBL to form } \\
\text { multilayer films } \\
\text { subsequently patterned } \\
\text { into multicolor bars }\end{array}$ & UV lithog. & $\begin{array}{l}\text { Bioassay detection } \\
\text { modules }\end{array}$ & $\begin{array}{l}\text { Zeng et al. } \\
(2020)\end{array}$ \\
\hline
\end{tabular}

In Table, RT, room temperature; PS, polystyrene; DBSA, para-dodecylbenzenesulfonic acid; PMAdMA-co-GBLMA, poly(methyladamantane methacrylate-co-a-methacryloxy-gbutyrolactone); TDHT, (S)-(+)-Tetrahydrofurfuryl-O-O'-diacetyl-(2R,3R)-hydro-gentartrate; PETA, pentaerythritol triacrylate; TDDDA, tricyclodecaned-imethanol diacrylate. The green leaf indicates applications in biosciences.

(Vaudreuil et al., 2007). They compared the use of MWCNTs with and without functionalization by acid or base oxidation. Interestingly, no significant difference was observed in terms of dispersion in the PMMA matrix; however, the electrical conductivity was augmented up to three orders of magnitude for $2 \mathrm{wt} \%$ unmodified MWCNTs; an enhancement superior than that for modified MWCNTs. Although the lithographic capabilities were not studied, the sensitivity of PMMA to deep-UV and electron beams make it possible to extrapolate the results for the formulation of a NCPR. Using the in-situ approach, Min and collaborators developed a NCPR to act as a photo-patternable catalyst for the in-situ formation of CNTs during a post-burning procedure (Min et al., 2006). The NCPR consisted in the addition of ferrocene to a novolak-type commercial PR (AZ5214E). After UV photolithography, and before the growth of CNTs, all organic substances were removed by baking the samples at $550^{\circ} \mathrm{C}$ under an oxygen flux. Catalytic particles were formed on the defined region. CNT growth was carried out using acetylene gas as carbon precursor in a CVD reactor at $900^{\circ} \mathrm{C}$. Hydrogen and nitrogen gas were flowed during growth. Dawan et al. presented a modified NCPR based on carbon-black NFs with mean size of $42 \mathrm{~nm}$ in Epon SU-8-5 and SU-8-50 (Dawan et al., 2008). These SU-8 formulations contain GBL as a solvent. $\phi$ was varied between 0.2 and $20 \mathrm{wt} \%$. For values above $10 \mathrm{wt} \%$ cracking was observed after the soft-baking stage. The electrical conductivity was largely augmented even at $2 \mathrm{wt} \%$, showing a sheet resistance of $\sim 19 \mathrm{k} \Omega s q^{-1}$. Thick films were submitted to XRL and were 


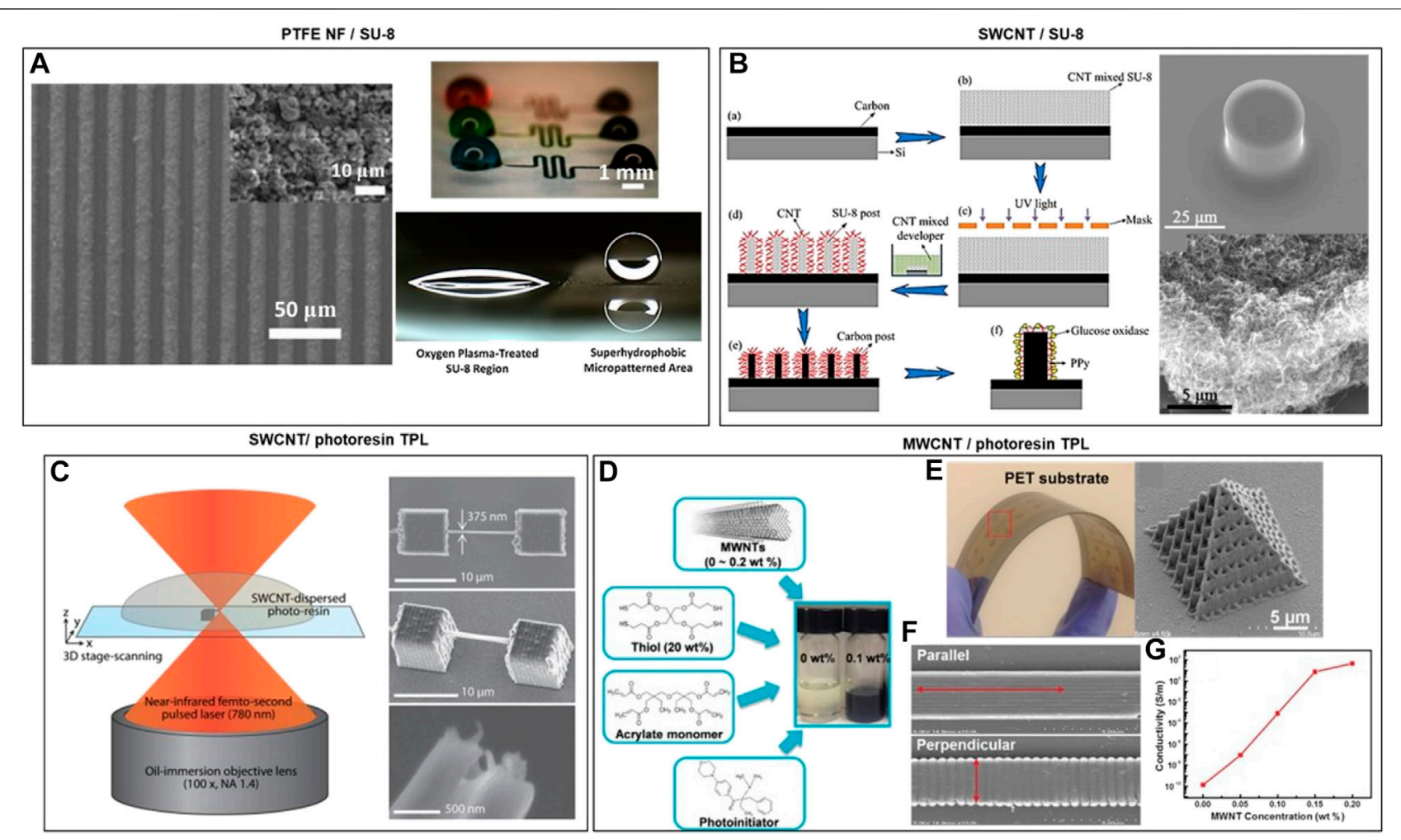

FIGURE 11 | (A) SEM and optical images of a superhydrophobic features constructed using a NCPRs containing polytetrafluoroethylene (PTFE) NPs adapted from Hong and Pan (2011) CS License (2011). (B) Fabrication scheme of CNT/C-MEMS bio-electrodes and SEM images of micropillars formed using a NCPRs containing SWCNTs. Adapted with permission from Xi et al. (2013) Copyright $^{\odot}$ (2013), Elsevier. (C) 3D fabrication by TPL using SWCNT-NCPRs of suspended CNTs bridges. Adapted with permission from Ushiba et al. (2014) Copyright ${ }^{\odot}$ (2014), Wiley. (D-G) MWCNTs-NCPRs used for TPL. (D) Experimental formulation of NCPRs containing MWCNTs. (E) A PET substrate used for patterning and a SEM image of a 3D micropyramid produced by TPL are shown. (F) SEM images of structures fabricated using scanning of the laser in the directions indicated by red arrows. (G) Electrical conductivity of nanocomposite films as a function of the MWNT concentration in the NCPR. Adapted with permission from Xiong et al. (2016) Copyright ${ }^{\oplus}$ (2016), Wiley.

successfully used for the microfabrication of micro-resistive heaters and micro-heat sink arrays. However, conventional UV lithography could not be employed due to a significant change in the optical properties of the NCPRs, resulting in a decreased penetration depth (Dawan et al., 2008). Indeed, UV photo-polymerization may be inhibited when dealing with carbon NCPRs because of an increased absorption and scattering of UV light. In a recent work, Wang et al. developed efficient, three-component photoinitiating systems for polymerization with visible light (Wang et al., 2019). In particular, a photoinitiaing system based on 1,5-DAAQ/ iodonium salt/4-N,N-trimethylaniline was tested on a PEGDA/ MWCNT NCPRs with up to $10 \mathrm{wt} \%$ filling fraction. No reduction in polymerization efficiency was measured for $\phi \leq 10 \mathrm{wt} \%$. SWCNTs and diamondoids (diamantanes $\mathrm{C}_{14} \mathrm{H}_{20}$ ) were used as fillers in SU-8 by Chiamori and co-workers (Chiamori et al., 2008). Diamantanes or SWCNTs were first dispersed in chloroform and then mixed with SU-8 at varying $\phi$. In the case of SWCNTs, sonication for extended periods of time (1.5 days) was required. Diamantane-SU-8 NCPRs presented reduced residual stress and increased elastic modulus. NCPRs with $0.25 \mathrm{wt} \%$ SWCNTs-SU-8 were non-conductive. However, the change in resistance $(\Delta R / R)$ vs. strain show linear trends for 1 and $5 \mathrm{wt} \%$ SWCNTs-SU-8 NCPRs, with gauge factors of approximately 2 to 4 , similar to conventional metallic strain gauges.

Following a different approach, Cong et al. developed electrically conductive and optically transparent micropatterns on flexible substrates by combining SU-8 lithography and spray coating of SWCNTs (Cong et al., 2010). A thick film of SU-8 2050 was first spin-coated and patterned through UV mask lithography. Before development, a NCPR formed by adding SWCNTs to SU-8 2000.5 was spray-coated onto the exposed SU8 surface and submitted to a $100^{\circ} \mathrm{C}$ baking. The percolating network of SWCNTs provides electrical conductivity to the patterned structures while the high transparency of SU-8, in conjunction with the low $\phi$, resulted in high optical transmission (up to $90 \%$ ). Both properties depend on the concentration of SWCNTs. An interesting phenomenon was observed when testing the minimal resolution of the lithography: a bridge containing SWCNTs was formed between two adjacent micropillars with $6 \mu \mathrm{m}$ separation. The capabilities of the proposed composite lithography was demonstrated by fabricating a capacitive pressure sensor on PDMS shaped as a contact-lens flexible device. Thus, the authors demonstrated the possible biosensing applications of this novel NCM. 
The inclusion of polymeric NPs as NFs should also be considered as a case of carbon-based NCM. One of the reasons to include polymer NFs is to modify the wetting properties of the composite. Hong and Pan (2011) developed a NCPR based on PTFE NPs (200-300 nm in diameter) into SU-8 (2000.5) at a weight ratio of 1:15. Ultrasound was used to obtain a uniform dispersion. The high hydrophobicity of PTFE NFs remarkably increases the wetting angle of the surfaces of films made with this NCPRs. Photolithography was employed to establish non-wettable micropatterns on a desired substrate as shown in Figure 11A. In this work, a pre-deposited film of SU-8 was covered with the NCPRs. After conventional UV lithography, the patterned structures were submitted to an oxygen plasma treatment to render the sidewalls of the bottom SU- 8 hydrophilic, while the top NCPRs remained superhydrphobic. This way, the wettability contrast was harvested to construct microfluidic channels and surface tension-driven micropumps.

An extensive series of studies on CNTs-SU-8 NCPRs were conducted by Mionic et al. First, the functionalization of MWCNTs with - $\mathrm{COOH}$ groups was demonstrated to favor the homogeneous dispersion of NFs in SU-8 using different cosolvents Mionic et al. (2009). The mechanical properties were studied by nano-indentation to show an increase in the elastic modulus up to $104 \%$ (Mionić et al., 2010). NCPRs were later studied for applications as conductive inks for inkjet printing on flexible substrates (Mionić et al., 2012). Later on, the same group studied the electrical percolation, showing that it can be fine tuned by adjusting the volume fraction of MWCNTs or the processing conditions of the composites. Tunneling and percolating conduction regimes were identified (Grimaldi et al., 2013). A similar work was performed on NCPRs formed by reduced graphene oxide flakes and SU-8, where high conductivity was interpreted as being dominated by tunneling processes (Majidian et al., 2014). An interesting approach was reported by $\mathrm{Xi}$ and co-workers who utilized SWCNTs/SU-8 mixtures as NCPRs to fabricate microelectrodes for glucose sensing as shown in Figure 11B. The NCPR was deposited over a carbon film produced by pyrolysis and then patterned using conventional UV lithography. Development was done using the regular developer containing dispersed CNTs. A second step of pyrolysis followed and the obtained nanostructure were finally covered electrochemically by polymerized polypyrrole and glucose oxidase. Amperometric measurements of this integrated electrode for glucose detection demonstrated a linear response from 5 to $80 \mathrm{mM}$ (Xi et al., 2013).

In 2014, Ushiba et al. presented a TPL DLW method for the microfabricaton of $3 \mathrm{D}$ nanostructures containing aligned SWCNTs (Figure 11C) (Ushiba et al., 2014). A $0.01 \mathrm{wt} \%$ solution of SWCNTs was loaded into an acrylate monomer and dispersed by sonication for $1 \mathrm{~h}$. A photo-initiator and a photo-sensitizer were added to the formulation of the NCPR. The SWCNT-NCPR was casted on a glass substrate and lithographed. Using polarized Raman spectroscopy, the SWCNTs were shown to be aligned in the writing direction. The alignment mechanism was discussed by the authors, who identified three relevant factors: the spatial confinement when patterning small features like NWs, the volume shrinkage occurring during rinse and drying stages, and acting optical gradient forces from the laser beam. 3D structures as well as suspended NWs were fabricated by this method. In a following work, the same group developed a method to incorporate a large-amount of well-aligned MWCNTs into an acrylate-based resist for TPL (Figures 11D-G) (Xiong et al., 2016). The quality of the dispersion of the MWCNTs was claimed to be favored by grafting thiol groups onto individual MWCNTs. NCPRs for TPL containing up to $0.2 \mathrm{wt} \%$ of MWCNTs were used to manufacture electrical components and 3D microstructures with significantly enhanced electrical conductivity and mechanical strength. The MWCNTs were oriented along the laser writing direction, providing highly anisotropic electrical properties. A conductivity up to 1,000 times higher was observed when the MWCNTs were aligned parallel to the current flow as opposed to a perpendicular alignment. More recently, Chavez et al. studied the effect of applying an electric field during 3D printing of a MWCNT-polymer NCPR. Application of an AC electric field resulted in a better dispersion of the MWCNTs and, thus, in enhanced mechanical properties of the final piece. Pieces printed under an electric field presented both higher elongation at break and tensile strength. Furthermore, conductivity of the samples was also influenced by the applied field, being six times higher in samples prepared with an applied field parallel to measurement direction (Chavez et al., 2019).

Selected works on carbon-based NCPRs are described in Table 4.

\subsection{Ceramic Nanofillers}

Several classes of ceramic NPs and NWs have been used as fillers in NCMs, mostly based on transition metal oxides such as $\mathrm{TiO}_{2}$ (An et al., 2012; Burunkova et al., 2013), $\mathrm{ZrO}_{2}, \mathrm{HfO}_{2}$ (Bae et al., 2010), ZnO (Kandpal et al., 2012), silica (Hu et al., 2001; Jiguet et al., 2006b; Cho et al., 2006; Singh et al., 2011), $\mathrm{BaTiO}_{3}$ (Xu and Wong, 2007; Kim et al., 2014; Marino et al., 2015b) and naturally occurring clays (Paul and Robeson, 2008). A common goal behind the addition of ceramic NFs is to reinforce mechanical properties of a PR (Tjong, 2006). However, the incorporation of ceramic NFs may also lead to an augmentation of the refractive index of polymer matrices (Bremer et al., 2009; Bae et al., 2010) or to enhanced the resistance of NCPRs to chemical or plasma etching (Hu et al., 2001; Merhari et al., 2002; Ali et al., 2003).

Incorporation of silica NFs into electron sensitive NCPRs may reduce scattering during $\mathrm{EBL}$ due to their high atomic number compared to organic polymers. In $\mathrm{Hu}$ et al. (2001), chemically modified $d \sim 12 \mathrm{~nm}$ silica NPs were mixed with ZEP520. With $4 \mathrm{wt}$ $\%$ silica NPs the PR exhibited similar contrast and sensitivity to pure ZEP520 but much higher resolution and resistance to $\mathrm{O}_{2}$ plasma etching. In a later work by the same authors (Merhari et al., 2002) this approach was applied to a chemically amplified resist, KRS-XE. In 2001, a brief review on hybrid organic-inorganic NCPRs was published by the same authors (Gonsalves et al., 2001). Shrinking and cracking of PRs are also problems that may be avoided by the addition of silica NFs. In Jiguet et al. (2006a) surface-functionalized $d \sim 12 \mathrm{~nm}$ silica NPs were mixed with SU-8 at varying $\phi$ (up to $\sim 15 \mathrm{wt} \%$ ), obtaining a negative PR for UV lithography. The addition of NPs resulted in a PR with higher sensitivity, better adhesion and 
TABLE 4 | Examples of NCPR using Carbon-based NFs.

\begin{tabular}{|c|c|c|c|c|c|c|}
\hline Nanofillers & Polymer matrix & Interface chemistry & $\begin{array}{l}\text { Formulation (additives, } \\
\text { treatment, etc.) }\end{array}$ & $\begin{array}{l}\text { Lithographic } \\
\text { method }\end{array}$ & $\begin{array}{l}\text { Applications/Main } \\
\text { results }\end{array}$ & References \\
\hline $\begin{array}{l}\text { C60 } \\
\phi=5-30 w t \%\end{array}$ & $\begin{array}{l}\text { PMMA, ZEP520, } \\
\text { SAL601 }\end{array}$ & Not functionalized & Solvent: o-DCB, 30 wt\% & EBL & $\begin{array}{l}\text { Dry etching improved } \\
\text { resistance. Pattern contrast } \\
\text { in thin film ( } 50 \mathrm{~nm})\end{array}$ & Ishii et al. (1997) \\
\hline $\begin{array}{l}\text { Ferrocene as } \\
\text { catalyst for } \\
\text { CNTs }\end{array}$ & $\begin{array}{l}\text { Novolak PR } \\
\text { AZ5214E }\end{array}$ & $\begin{array}{l}\text { Cyclopentadienyl } \\
\text { gropus in ferrocene } \\
\text { allows dissolution in PR } \\
\text { solvent }\end{array}$ & $\begin{array}{l}\text { Pyrolysis of NCPRs and CVD } \\
\text { growth of SWCNTs on formed } \\
\text { catalyst NPS }\end{array}$ & UV lithog. & $\begin{array}{l}\text { Suspended CNTs } \\
\text { microstructures }\end{array}$ & Min et al. (2006) \\
\hline $\begin{array}{l}\text { Carbon black } \\
\phi= \\
0.2-20 \text { wt } \%\end{array}$ & SU-8 & No functionaliz & Moderate stirring. & X-ray lithog. & $\begin{array}{l}\text { Improved thermal } \\
\text { conductivity for } \phi>4 \text { wt } \% \\
\text { Micro-heat sink arrays. } \\
\text { Micro-resistive heaters. }\end{array}$ & $\begin{array}{l}\text { Dawan et al. } \\
(2008)\end{array}$ \\
\hline $\begin{array}{l}\text { Diamantanes } \\
\phi=1-7 \text { wt } \% \\
\text { SWCNTs } \\
\phi=1-5 \text { wt } \%\end{array}$ & SU-8 & $\begin{array}{l}\text { NFs used as received. } \\
\text { No functionaliz. }\end{array}$ & $\begin{array}{l}\text { Physical stirring of NFs in pure SU- } \\
8 \text { or dispersed in chloroform. } \\
\text { CNTs sonicated for } 1.5 \mathrm{~d}\end{array}$ & UV lithog. & $\begin{array}{l}\text { Tensile strength assays/ } \\
\text { Piezoresistive tests }\end{array}$ & $\begin{array}{l}\text { Chiamori et al. } \\
\text { (2008) }\end{array}$ \\
\hline $\begin{array}{l}\text { PTFE NPs } \\
d \sim \\
200-300 \mathrm{~nm}\end{array}$ & SU-8 & Not functionalized & $\begin{array}{l}\text { Ultrasonication (40 W, } 20 \text { min) } \\
\text { applied for uniform dispersion of } \\
\text { NFs in SU-8 } 2000.5\end{array}$ & UV lithog. & $\begin{array}{l}\text { Superhydrophobic } \\
\text { patterns. Surface } \\
\text { microfluidic systems }\end{array}$ & $\begin{array}{l}\text { Hong and Pan } \\
\text { (2011) }\end{array}$ \\
\hline $\begin{array}{l}\text { MWCNTs } \\
\phi=5 \text { wt } \%\end{array}$ & SU-8 & $\begin{array}{l}\text { CNTs functionalized } \\
\text { with - } \mathrm{COOH} \text { groups } \\
\text { for improved interface } \\
\text { with the PR }\end{array}$ & $\begin{array}{l}\text { PGMEA and GBL probed as } \\
\text { suitable co-solvents. Additional } \\
\text { photoinitiator included in } \\
\text { formulation }\end{array}$ & UV lithog. & $\begin{array}{l}\text { NCPR with percolating } \\
\text { network of homogeneously } \\
\text { dispersed CNTs. Elastic } \\
\text { modulus increased by up to } \\
\text { 104\%. Conductive inkjet } \\
\text { printable NCPRs }\end{array}$ & $\begin{array}{l}\text { Mionic et al. } \\
\text { (2009); Mionić } \\
\text { et al. (2010); } \\
\text { Mionić et al. } \\
\text { (2012); Grimaldi } \\
\text { et al. (2013) }\end{array}$ \\
\hline $\begin{array}{l}\text { SWCNTs or Au } \\
\text { NPs } d \sim 22 \mathrm{~nm}\end{array}$ & Chitosan & $\begin{array}{l}\text { Sodium dodecyl sulfate } \\
\text { (SDS)-coated SWNTs/ } \\
\text { Sodium citrate- } \\
\text { stabilized Au AuNPs }\end{array}$ & $\begin{array}{l}\mathrm{CH} / \mathrm{SWNT} \text { and } \mathrm{CH} / \text { AuNPs } \\
\text { nanocomposites prepared using } \\
\text { LBL assembly. }\end{array}$ & $\begin{array}{l}\text { Direct write } \\
\text { maskless UV } \\
\text { lithog. }\end{array}$ & $\begin{array}{l}\text { Highly conductive } \\
\text { nanocomposite. Patterning } \\
\text { into BLASP patterns } \\
\text { demonstrated. }\end{array}$ & Bai et al. (2012) \\
\hline SWCNTS & SU-8 & Not functionalized & $\begin{array}{l}\text { Direct mixing of CNTs and PR. } \\
\text { Pyrolysis of the NCPRs after } \\
\text { lithog. CNTs added to the } \\
\text { developer }\end{array}$ & UV lithog. & $\begin{array}{l}\text { Electrode arrays for glucose } \\
\text { sensors }\end{array}$ & Xi et al. (2013) \\
\hline $\begin{array}{l}\text { Reduced } \\
\text { graphene oxide } \\
\text { flakes } \\
\phi= \\
0.04-3 \text { wt } \%\end{array}$ & SU-8 & $\begin{array}{l}\text { RGO flakes where } \\
\text { dispersed in GBL as } \\
\text { co-solvent. }\end{array}$ & $\begin{array}{l}\text { Vigorous stirring for } 24 \mathrm{~h} \text { and } \\
\text { sonication. Surfactant Disperbyk- } \\
145 \text { was added in certain } \\
\text { formulations }\end{array}$ & UV lithog. & $\begin{array}{l}\text { Patterning of sub-10 } \mu \mathrm{m} \\
\text { patterns with high electrical } \\
\text { conductivity. Potential } \\
\text { applications in MEMs. }\end{array}$ & $\begin{array}{l}\text { Majidian et al. } \\
(2014)\end{array}$ \\
\hline $\begin{array}{l}\text { SWCNTS } \\
\phi=0.01 \text { wt } \%\end{array}$ & $\begin{array}{l}\text { Acrylate } \\
\text { monomer R712 }\end{array}$ & Not functionalized & $\begin{array}{l}\text { Photo-initiator (benzil) and photo- } \\
\text { sensitizer (2-benzyl-2- } \\
\text { (dimethylamino)- } 4^{\prime}- \\
\text { morpholinobutyrophenon were } \\
\text { addedd at ratios of } 1.67 \text { wt } \% \text { and } \\
1.6-7 \text { wt } \% \text {, respectively. }\end{array}$ & TPL & $\begin{array}{l}\text { 3D microstructures with } \\
\text { aligned CNTs in desired } \\
\text { directions. }\end{array}$ & $\begin{array}{l}\text { Ushiba et al. } \\
(2014)\end{array}$ \\
\hline $\begin{array}{l}\text { MWCNTs } \\
\phi=0-0.2 \text { wt } \%\end{array}$ & $\begin{array}{l}\text { Acrylate } \\
\text { photopolymer }\end{array}$ & $\begin{array}{l}\text { Thiol molecules are } \\
\text { believed to be grafted } \\
\text { to the MWCNTs }\end{array}$ & $\begin{array}{l}\text { MWCNTs added to a homemade } \\
\text { TPL-compatible thiol-acrylate } \\
\text { resin }\end{array}$ & TPL & $\begin{array}{l}\text { Microfabrication of } \\
\text { microelectronic } \\
\text { components with } \\
\text { anisotropic electrical } \\
\text { properties due to alignment } \\
\text { of MCNTs }\end{array}$ & Xiong et al. (2016) \\
\hline SWCNTS & PVA & $\begin{array}{l}\text { SWCNTs dispersed in } \\
\text { PSS } 1 \text { wt\% using } \\
\text { ultrasonic agitation }\end{array}$ & $\begin{array}{l}\text { NCM fabricated by LBL } \\
\text { deposition. }\end{array}$ & $\begin{array}{l}\text { Optical } \\
\text { photolitography }\end{array}$ & $\begin{array}{l}\text { Strain sensing grid } \\
\text { fabricated on flexible } \\
\text { substrate. Application as a } \\
\text { sensing skin for structure } \\
\text { monitoring. }\end{array}$ & Sun et al. (2018) \\
\hline $\begin{array}{l}\text { MWCNTs } \\
\phi=0-10 \text { wt } \%\end{array}$ & PEGDA & $\begin{array}{l}\text { Not functionalized } \\
\text { MWCNTs dispersed in } \\
\text { PEGDA }\end{array}$ & $\begin{array}{l}\text { 1,5-diaminoanthraquinone/ } \\
\text { iodonium salt/4-N,N- } \\
\text { trimethylaniline }\end{array}$ & $\begin{array}{l}\text { Photocuring with } \\
518 \mathrm{~nm} \text { LED light }\end{array}$ & $\begin{array}{l}3 \mathrm{D} \text { printing of photocurable } \\
\text { resin }\end{array}$ & Wang et al. (2019) \\
\hline MWCNTS & $\begin{array}{l}\text { Genesis } \\
\text { photopolymer } \\
\text { resin (Tethon3D) }\end{array}$ & $\begin{array}{l}\text { MWCNTs were treated } \\
\text { in a nitric acid solution }\end{array}$ & $\begin{array}{l}\text { MWCNTs:Polymer mixed in a 1: } \\
99 \text { weight ratio. Electrical } \\
\text { alignment of MWCNTs }\end{array}$ & SLA & $\begin{array}{l}\text { Reinforced } \\
\text { nanocomposites }\end{array}$ & $\begin{array}{l}\text { Chavez et al. } \\
(2019)\end{array}$ \\
\hline
\end{tabular}

In Table, o-DCB: ortho-dichlorobenzene, BLASP, bus-line-and- stimulation-pads; PSS, poly(styrenesulfonate); SLA, stereolithography. The green leaf indicates applications in biosciences. 
less cracking. The NCPRs had higher sensitivity (higher etch depth for equal dose) as compared to pure SU-8. The resolution of the patterned structures was maintained for up to $\sim 2.5 \mathrm{wt} \%$ of $\mathrm{NFs}$; however, for higher $\phi$, it decreased due to scattering by the silica NPs. These NCPRs, however, had lower Young's modulus (700-750 MPa) compared to pure SU-8 with the same thermal treatment $(900 \mathrm{MPa})$ and thermal expansion coefficients $(33 \mathrm{ppm} /$ ${ }^{\circ} \mathrm{C}$ vs. $54 \mathrm{ppm} /{ }^{\circ} \mathrm{C}$ for pure $\left.\mathrm{SU}-8\right)$.

In Tiwale et al. (2019) a positive organic-inorganic hybrid resist for EBL was formulated by incorporating $\mathrm{AlO}_{x}$ into PMMA, resulting in a PR with tunable sensitivity, contrast and plasma etch resistance. The fabrication procedure is an example of post-infiltration. A Si substrate was spin-coated with a PMMA film, loaded into an ALD chamber and subjected to repeated cycles of introduction of the $\mathrm{Al}$ precursor TMA into the chamber, followed by chamber purging, introduction of an oxidizing agent $\left(\mathrm{H}_{2} \mathrm{O}\right)$ and another purging step. The number of cycles determined the final concentration of $\mathrm{AlO}_{x}$ in the PMMA matrix and, consequently, the properties of the NCPR. The oxidizing precursor was pulsed multiple times during its half cycle to promote a more homogeneous and higher amount of infiltration. An Al-rich layer, whose width depends on the number of infiltration cycles, formed on the surface of the infiltrated PR, resulting in a highly increased contrast. An example of patterning of $\mathrm{Si}$ was carried out using such a hybrid PR (with four infiltration cycles), demonstrating an extremely high etching selectivity ( 71.2). Even higher selectivity $(>300)$ was estimated for a PR with eight infiltration cycles. The hybrid PR presented an increased required exposure dose value $\left(\sim 2,000 \mu \mathrm{C} \mathrm{cm}^{-2}\right)$ which, however, remains lower than that for hydrogen silsesquioxane (HSQ) hybrid PRs $\left(\sim 5,000 \mu \mathrm{C} \mathrm{cm}^{-2}\right)$. As another example, in Dusoe et al. (2017) $\mathrm{AlO}_{x}$ was infiltrated into SU-8 columns patterned through EBL. After definition of the columns an ALD system was used to expose the structures to TMA and water for different numbers of cycles. The resulting structures had extremely large elastic energy storage capability, product of the simultaneously high yield strength $(\sim 500 \mathrm{MPa})$ with and low Young's modulus ( $7 \mathrm{GPa})$.

Certain ceramic NFs may endow a NCM with piezoelectricity. Several components of the human body (bone, neurons, cartilage, muscle, etc.) behave as piezoelectric materials (Kapat et al., 2020), making NCMs with this property interesting for biological applications, such as stimulation of bones and neurons, targeted drug delivery and tissue regeneration (Tandon et al., 2018; Kapat et al., 2020). In particular, NPs composed of barium titanate $\left(\mathrm{BaTiO}_{3}\right)$, a ferroelectric material with high piezoelectric constant (Acosta et al., 2017), may be combined with a photo-curable polymer for this purpose. The group of Marino demonstrated several possible bio-applications of $\mathrm{BaTiO}_{3}$ NPs (Marino et al., 2015a; Marino et al., 2015b; Marino et al., 2018; Marino et al., 2019), of which Marino et al. (2015b) constitutes one of the few examples of a piezoelectric NCPR. In this work Ormocomp, a bio- compatible, commercially-available PR, was mixed with $\mathrm{BaTiO}_{3} \mathrm{NPs}$ at $\sim 10 \mathrm{wt} \%$ by sonication. The obtained NCPR was shown to be patternable using slice-by-slice TPL, and had a much higher piezoelectric coefficient $\left(d_{33}=0.57 \mathrm{pm} \mathrm{V}^{-1}\right)$ than plain Ormocomp $\left(0.07 \mathrm{pm} \mathrm{V}^{-1}\right)$. An interesting application of piezoelectric NCMs is the fabrication of scaffolds, i.e., 3D structures for enhancement of cell adhesion and growth. In Marino et al. (2015b) piezoelectric 3D structures shaped like bone trabeculae ("Osteo prints") were printed using TPL. Experiments with human osteoblastlike SaOS-2 cells were performed to see if the combination of topographic and piezoelectric stimulation favored osteogenesis. SaOS-2 cells were cultivated on scaffolds with and without barium titanate nanoparticles (BTNPs) and ultrasound stimulation, safe for the human body. After appropriate seeding time, osteogenesis was induced. Results showed an enhanced osteogenic differentiation of SaOS-2 cells in samples with BNTPs doping and ultrasound stimulation. This was attributed to an interplay of topological (i.e., extra roughness due to presence of BTNPs) and piezoelectric phenomena (Marino et al., 2015b). Scaffolds have also been fabricated through TPL of superparamagnetic NCPRs (Paun et al., 2019; Paun et al., 2020). Several works in this direction do not employ NCPRs but are nevertheless interesting (Klein et al., 2011; Rasoulianboroujeni et al., 2019; Yu et al., 2019a; Yang et al., 2020c).

More recently, Zhang and co-workers obtained structured films with very high piezoelectric sensitivity by combining PEGDA with very low amounts $(\sim 0.2 \mathrm{wt} \%)$ of boron nitride nanotubes (BNNTs) (Zhang et al., 2020). Projection stereolithography was used to structure the NCPR (Figure 12A). As shown in Figures 12B,C the fabricated piezoelectric films could be used as conformal sensors for spatial pressure distribution on uneven surfaces such as robotic hands. Samples were fabricated with pristine BNNTs and with 3-(trimethoxysilyl)propyl methacrylate (TMSPM) functionalized BNNTs. The latter were shown to produce a far more stable resin with well dispersed BNNTs. Piezoelectric testing was performed on flat films obtained from the NCPRs. Results showed that films made from functionalized BNNTs which had undergone a poling process (a previous alignment of the electric dipoles with a strong applied field) showed higher voltage output in response to mechanical stimuli. Interestingly, the authors compared the performance of $\sim 0.2 \mathrm{wt} \%$ and $\sim 10 \mathrm{wt} \%$ BNNT NCPRs and found nearly identical piezoelectric performance. Furthermore, piezoelectric tests were performed on patterned films with different motives. A response $\sim 10$ times higher than that of the flat film was measured for an optimized pattern design. Compared to other works with various NFs, the piezoelectric response obtained in this work is very high for extremely low $\phi$, see Figure 12E. Using an array of 14 independent sensors placed onto the phalanges of a robotic hand the authors showed that different positions and actions could be mapped into specific strain induced voltages.

Some polymers may be intrinsically piezoelectric, as in the case of poly(vinylidene fluoride) (PVDF). PVDF is a polymorphic 


\section{BNNTs / PEGDA}

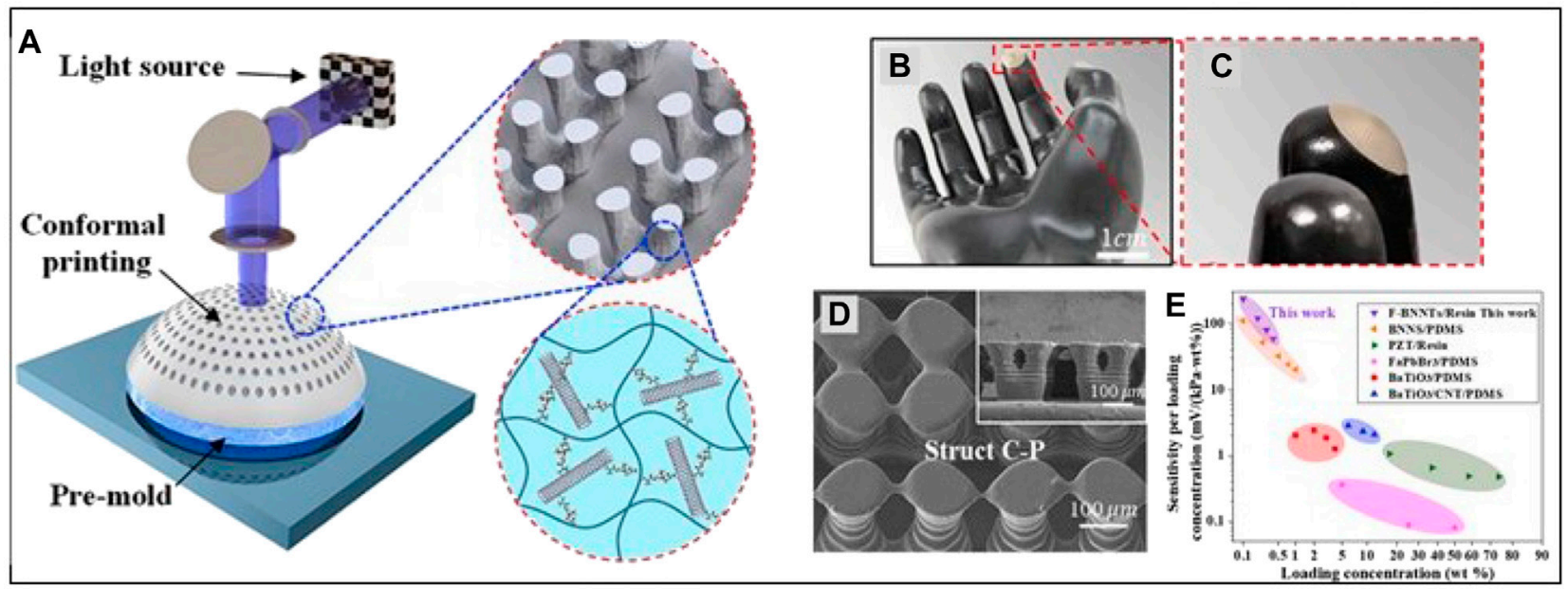

\section{ZnO NW/ phtotoresin TPL}

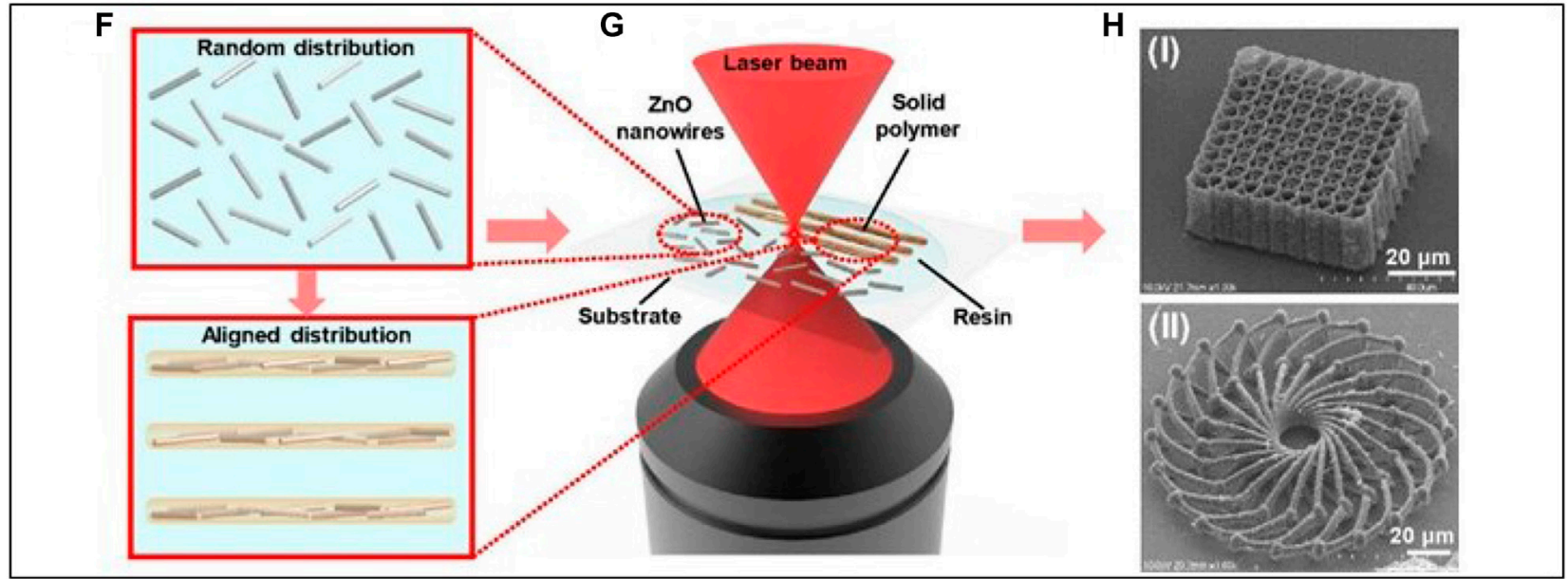

FIGURE 12 | (A-E) Selected figures from Zhang et al. (2020) (A) Diagram of the micro-3D printing system used. A projection stereolitography set-up, consisting of a projection system, resin bath, sample stage and three axes is used to print the NCPRs into the rows of columns shown in the top close up. A spherical mold is used to achieve a concave surface. Bottom close up shows a sketch of the NCPR composition, that is, TMSPM functionalized BNNTs and monomer chains. (B) Photographs of the printed device on the fingerprint of a rubber hand model. A close up is shown in (C). (D) SEM image of one of the many structures printed with the piezoelectric NCPR. This particular style showed the greatest output voltage for a given mechanical stimulation. (E) Comparison of relative sensitivity of different inorganic piezoelectric filler-polymer NCPRs. Clearly in this work (purple triangles) the authors achieve high piezoelectric response for very low $\phi$. Adapted with permission from Zhang et al. (2020), Copyright ${ }^{\odot}$ (2020) Elsevier. (F-H) Selected figures from Long et al. (2020). (F,G) Scheme of the fabrication process and structure of the samples. In (F) ZnO NWs go from being randomly distributed in the NCPR to being aligned in the direction of laser writing. (G) Schematic of TPL fabrication of structures from ZnO NW acrylate NCPR. (H) Examples of 3D fabricated structures. Reprinted with permission from Long et al. (2020), Copyright ${ }^{\odot}$ (2020) American Chemical Society.

polymer, and has excellent piezoelectric properties in its $\beta$ phase. In An et al. (2011) PVDF was mixed with $d \sim 21 \mathrm{~nm} \mathrm{TiO}_{2} \mathrm{NPs}_{\text {at }}$ $5 \mathrm{wt} \%$, using acetone and DMF as solvents. After evaporation at $100^{\circ} \mathrm{C}$, films with $\mathrm{TiO}_{2}$ NPs were shown to crystallize predominately in the $\beta$ phase. In (An et al., 2012) patterning of the same NCPR with UV lithography was demonstrated. As mentioned above, we have found few other examples in the literature of ceramic piezoelectric NCPRs suitable for photolithography (Xu and Wong, 2007; Kim et al., 2014). Structuring of $\mathrm{BaTiO}_{3}$ NCMs has also been accomplished using other methods (Palevicius et al., 2013; Kim et al., 2019). Lastly, we mention the recent work of Long et al. (2020), in which the fabrication of high resolution $(\sim 300 \mathrm{~nm})$ arbitrarily shaped $3 \mathrm{D}$ and $2 \mathrm{D}$ structures with aligned $\mathrm{ZnO}$ NWs through TPL was demonstrated. In summary, $\mathrm{ZnO}$ NWs $(d \sim 50 \mathrm{~nm}, l \sim 300 \mathrm{~nm})$ were functionalized with 3 (trimethoxysilyl) propyl methacrylate and mixed with an acrylate resin, a mixture of $1 \mathrm{wt} \%$ photo-initiator 2Benzyl-2-(dimethylamino)- $\quad 4^{\prime}$-morpholinobutyrophenone (BDMP) and $99 \mathrm{wt} \%$ of the acrylate monomer ditrimethylolpropane tetraacrylate (di-TMPTTA). The resulting PR was patterned using TPL, which resulted in an alignment of the $\mathrm{ZnO} \mathrm{NWs}$ in the direction of laser writing, see Figures 12F-H. The authors studied the alignment under different conditions, varying the $\phi$ of $\mathrm{ZnO} \mathrm{NWs}$, laser intensity, scan speed and hatch distance. Optimal results were obtained for a 
TABLE 5 | Examples of NCPRs using Ceramic NFs.

\begin{tabular}{|c|c|c|c|c|c|c|}
\hline Nanofillers & $\begin{array}{l}\text { Polymer } \\
\text { matrix }\end{array}$ & Interface chemistry & $\begin{array}{l}\text { Formulation (additives, } \\
\text { treatment, etc.) }\end{array}$ & $\begin{array}{l}\text { Lithographic } \\
\text { method }\end{array}$ & $\begin{array}{l}\text { Applications/Main } \\
\text { results }\end{array}$ & References \\
\hline $\begin{array}{l}\text { Silica NPs } \\
d \sim \\
1-2 \mathrm{~nm} \\
\phi=4 \mathrm{wt} \%\end{array}$ & $\begin{array}{l}\text { ZEP520, } \\
\text { KRS-XE }\end{array}$ & $\begin{array}{l}\text { Hydrophobic alkyl-alkenyl } \\
\text { capping }\end{array}$ & Sonication for $12 \mathrm{~h}$ & $\begin{array}{l}\text { EBL/lon projection } \\
\text { lithog. }\end{array}$ & $\begin{array}{l}\text { High res. PR. Line res. } \\
\text { improved from } 130-46 \mathrm{~nm} \text {. } \\
\text { Improved resistance to } \\
\text { plasma etching } \mathrm{w} / \mathrm{O}_{2} . \mathrm{PR} \\
\text { for ion projection lithog. }\end{array}$ & $\begin{array}{l}\text { Hu et al. (2001); } \\
\text { Merhari et al. } \\
\text { (2002) }\end{array}$ \\
\hline $\begin{array}{l}\text { Silica NPs } \\
\begin{array}{l}d \sim 12 \mathrm{~nm} \\
\phi=2.5-5 \text { wt } \%\end{array}\end{array}$ & SU-8 & No information provided & $\begin{array}{l}\text { Methyl ethyl ketone used as co- } \\
\text { solvent }\end{array}$ & $\begin{array}{l}\text { UV-LIGA, Back } \\
\text { mode illumination }\end{array}$ & $\begin{array}{l}\text { Lower coef. of thermal } \\
\text { expansion. Reduced } \\
\text { residual stress }\end{array}$ & $\begin{array}{l}\text { Jiguet et al. } \\
\text { (2006a) }\end{array}$ \\
\hline $\begin{array}{l}\mathrm{TiO}_{2} \mathrm{NPs} \\
d \sim 20 \mathrm{~nm} \\
\phi=5 \mathrm{wt} \%\end{array}$ & PDVF & No information provided & $\begin{array}{l}\mathrm{TiO}_{2} \text { NPs mixed with PVDF } \\
\text { powder. Acetone and DMF used } \\
\text { as solvents. Thin films ( } 20 \mu \mathrm{m}) \\
\text { prepared by spin coating. }\end{array}$ & UV lithog. & $\begin{array}{l}\text { Potential application in the } \\
\text { large scale fabrication of } \\
\text { actuators and sensors. }\end{array}$ & An et al. (2012) \\
\hline $\begin{array}{l}\text { ZnO NPs } \\
d \leq 100 \mathrm{~nm} \\
\text { varying } \phi\end{array}$ & SU-8 & No surface functionalization & $\begin{array}{l}\text { ZnO NPs dispersed into } \\
\text { cycolpentanone and sonicated } \\
\text { before being mixed with SU8 }\end{array}$ & UV lithog & Fabrication of MEMS & $\begin{array}{l}\text { Kandpal et al. } \\
\text { (2012) }\end{array}$ \\
\hline $\begin{array}{l}\mathrm{BaTiO}_{3} \mathrm{NPs} \\
d \sim 479 \mathrm{~nm} \\
\phi=10 \mathrm{wt} \%\end{array}$ & Ormocomp & No surface functionalization. & $\begin{array}{l}\text { Ormocomp and BNNTs mixed } \\
\text { directly }\end{array}$ & $\mathrm{TPL}$ & $\begin{array}{l}\text { Fabrication of 3D } \\
\text { pizoelectric structures. } \\
\text { Osteo-Prints patterned by } \\
\text { TPL for biological testing on } \\
\text { human osteoblast-like } \\
\text { SaOS-2 cells. }\end{array}$ & $\begin{array}{l}\text { Marino et al. } \\
(2015 b)\end{array}$ \\
\hline $\mathrm{AlO}_{x}(e x-s i t u)$ & $\begin{array}{l}\text { PMMA } \\
\text { SU-8 }\end{array}$ & $\begin{array}{l}\mathrm{Al}^{3+} \text { precursor attached to } \\
\text { carbonyl groups and } \\
\text { oxidized to } \mathrm{AlOH} \text {. } \mathrm{AlO}_{x} \text { grow } \\
\text { on top of } \mathrm{AlOH} / \mathrm{ALD} \text { applied } \\
\text { after patterning of } \\
\text { micropillars }\end{array}$ & $\begin{array}{l}\text { Infiltration degree controlled } \\
\text { through cycle repetition of ALD } \\
\text { process }\end{array}$ & EBL/UV lithog. & $\begin{array}{l}\text { Improved sensitivity, } \\
\text { contrast and ressistance to } \\
\text { plasma etching/Improved } \\
\text { mechanical properties. } \\
\text { Elastic energy storage } \\
\text { micropillars }\end{array}$ & $\begin{array}{l}\text { Tiwale et al. } \\
\text { (2019)/Dusoe } \\
\text { et al. (2017) }\end{array}$ \\
\hline $\begin{array}{l}\text { ZnO NWs } \\
d \sim 50 \mathrm{~nm} \\
l \sim 300 \mathrm{~nm} \\
\phi=4 \mathrm{wt} \%\end{array}$ & $\begin{array}{l}\text { Acrylate } \\
\text { resin }\end{array}$ & $\begin{array}{l}\text { NWs functionalized with 3- } \\
\text { (trimethoxysilyl) propyl } \\
\text { methacrylate }\end{array}$ & $\begin{array}{l}\text { NWs aligned along the laser } \\
\text { scanning pathway }\end{array}$ & $\mathrm{TPL}$ & $\begin{array}{l}\text { Fabrication of arbitrary 3D } \\
\text { structures with high } \\
\text { resolution and orientation } \\
\text { control. Polarization- } \\
\text { resolved UV photodetector } \\
\text { fabricated }\end{array}$ & $\begin{array}{l}\text { Long et al. } \\
(2020)\end{array}$ \\
\hline $\begin{array}{l}\text { Boron nitride } \\
\text { nanotubes } \\
\phi=0.2 \text { wt } \%\end{array}$ & PEGDA & $\begin{array}{l}\text { Samples fabricated with } \\
\text { pristine and TMSPM } \\
\text { functionalized BNNTs }\end{array}$ & $\begin{array}{l}\text { N-Dimethylacetamide solvent } \\
\text { used }\end{array}$ & $\begin{array}{l}\text { Projection } \\
\text { stereolithography }\end{array}$ & $\begin{array}{l}\text { Fabrication of conformal } \\
\text { tactile sensor array to } \\
\text { enable haptic sensing of } \\
\text { robotic hand and detect } \\
\text { spatial distribution of force } \\
\text { on uneven surfaces. }\end{array}$ & $\begin{array}{l}\text { Zhang et al. } \\
\text { (2020) }\end{array}$ \\
\hline
\end{tabular}

In Table, PEGDA, poly(ethylene glycol) diacrylate; TMSPM, 3-trimethoxysilylpropyl methacrylate. The green leaf indicates applications in biosciences.

laser power of $10 \mathrm{~mW}$, scanning speed of $50 \mu \mathrm{m} \mathrm{s}^{-1}$ and hatch distance of $400 \mathrm{~nm}$. The authors proposed a mechanism for ZnO NW alignment through DLW and showed that the effect of the optical gradient force was much smaller than that of the shear and stress forces and spatial confinement effects. Fabrication of a polarization based photo-detector was also demonstrated. Ceramic-based NCPRs are summarized in Table 5 .

\subsection{Hybrid \\ Photo-Sensitive-Nanocomposites for In-Situ Formation of Nanofillers}

In the previous sections, NFs were added to the PRs, the main challenge being the avoidance of aggregation and the adequate chemical interaction with the host polymer. In this sense, the lithographic capabilities are determined by the PR and the NFs play a relatively passive role. An advanced approach is focused in the development of new photo-sensitive polymers in which the NFs, or their chemical precursors, play an active role in the photo-chemical properties of the composite. Efforts are made in the organic chemistry engineering of the monomers to favor or enhance the interaction with the NFs. Substantial work has been done by Saifullah and co-workers in the formulation of radiation sensitive resists (Saifullah, 2009) for the direct patterning of metal oxides including $\mathrm{ZnO}$ (Saifullah et al., 2005), $\mathrm{TiO}_{2}$ (Saifullah et al., 2003; Voicu et al., 2007), $\mathrm{Al}_{2} \mathrm{O}_{3}$ (Saifullah et al., 1999), $\mathrm{ZrO}_{2}$ (Subramanian et al., 2004) $\mathrm{HfO}_{2}$ (Saifullah et al., 2010), among others. An interesting example of this approach was reported by Mahapatra and collaborators who demonstrated the in-situ formation of Ag and Au NPs from precursor salts of $\mathrm{Ag}(\mathrm{I})$ and $\mathrm{Au}(\mathrm{III})$ dissolved in a PVA films under exposure to an electron beam (Mahapatra et al., 2007). Following this work, Marqués-Hueso and co-workers used EBL to produce patterns of $\mathrm{Ag}$ and Au NPs from precursor salts in 
water:ethanol solutions of PVA (Abargues et al., 2008; MarquesHueso et al., 2010; Marqués-Hueso et al., 2010). As explained by the authors, the alcohol groups in PVA are able to reduce the metal cations upon exposure to the electron beam. A proton is released in the process, inducing the protonation of PVA and the formation of cationic intermediates that induce the crosslinking of neighboring PVA chains. This results in a lower solubility of the exposed region, giving the composite a resemblance to a negative tone $\mathrm{PR}$. The authors show that additional thermal treatment above $140^{\circ} \mathrm{C}$ can be applied to complete the reduction and cross-linking. In following works, the authors showed that it was possible to construct structures with 3D height-profiles by taking advantage of the progressive cross-linking of the PVA at different levels of the e-beam dose (Marqués-Hueso et al., 2010).

A popular inorganic based negative tone resist for EBL contains HSQ, a Si-caged monomer, in a carrier solvent of methylisobutylketone. The resist is commercialized by Dow Chemical under the brand name XR-1541, and allows patterning with extremely high resolution (Grigorescu and Hagen, 2009). However, this resist has high exposure dose requirements and suffers from problems common to other high resolution PRs: pattern collapse (Tiwale et al., 2019) and the proximity effect (Jiguet et al., 2006a). A recent review with a detailed description of the photo-chemical processes involved in hybrid resist containing organo-metallic precursors was presented by Luo et al. (Luo et al., 2020).

\section{CONCLUSION AND PERSPECTIVES}

We hope the collection of papers discussed in this review has been effective in showing the wide variety of materials and techniques available for microfabrication of nanocomposite structures and the possible applications of NCPRs. We have addressed the modification of commercial PRs by incorporation of customsynthesized or in-situ produced NFs, as well as the formulation of new photosensitive polymers relevant for NCPR applications. In every case, the challenge is to obtain a homogeneous distribution of the NFs and a strong and stable interface with the polymer matrix. A remarkable trend in this multidisciplinary research topic is the combined effort of researchers with vastly different backgrounds and expertise.

Throughout this survey certain preferred directions were noticed: 1) regarding the polymers used as matrices, epoxybased commercial PRs, such as the different SU-8 series, are mostly used. This is likely related to their convenient mechanical properties suitable for structural components. 2) During the preparation of this review we found several interesting works dealing with nanocomposite hydrogels, many with special focus in biomedical applications; composites photoresists containing micron-size particles, and promising NCMs not used for microfabrication. Although these fall outside the scope of this review, specific examples were mentioned in the text, which readers are encouraged to visit. 3) Considering the manufacturing methods, maskless photolithography processes are being increasingly used. Especially DLW processes such as TPL which allow the construction of high-resolution 3D structures. However, it should be noted that the application of DLW methods is restricted to the manufacturing of a small number of units. Thus, these techniques are useful in the development of prototypes and proofs of concept while the extension to large-scale manufacturing is time-consuming and therefore limited. In contrast, many works make use of fast replication soft-lithography and additive manufacturing methods, providing versatile tools for the microstructuring of NCMs. Because no radiation-based lithography was employed, we have not addressed this topic in detail. The interested reader is encouraged to visit the specific articles cited. 4) Regarding NFs, we came across a large amount of work employing magnetic NFs to achieve remote manipulation of devices. This is likely due to the excellent performance of SPIONs, their relative ease of synthesis and the harmless use of weak magnetic fields in biomedical applications. 5) Concerning applications, magnetic actuators such as micro-swimmers and carriers for the precise control and manipulation of biological materials and drug delivery are the subject intense research. Other magnetic components, such as valves for microfluidics and MEMS applications have also been developed. We highlight the structural coloration induced by magnetic fields on nanocomposite structures containing magnetic NFs and the technologies derived from this. 6) Regarding photonic applications, the microfabrication of optical bar-coding particles tagged with biomolecules sensitive to the chemical environment is being intensively studied for sensing.

Based on the content discussed so far, we anticipate that future work in this field will make use of combinations of NFs of different nature and custom-designed polymers to complement top-down and bottom-up strategies. Observing the most recent research in the field of NCPRs, we highlight the uprising and fast development of NCMs for shape memory materials and dynamic morphological microstructures. Developments in soft matter, colloidal chemistry and micromanufacturing technologies will need to be closely monitored as they all converge on the topic discussed here.

\section{AUTHOR CONTRIBUTIONS}

All authors listed have made a substantial, direct, and intellectual contribution to the work and approved it for publication.

\section{FUNDING}

EM acknowledges funding from National Agency for the Promotion of Science and Technology (ANPCyT), Argentina, through grant PICT 2017-0307. EM, LSA and HP acknowledge funding from the same institution through grant PICT Start-Up 2019-00017. AP and MG acknowledge doctoral fellowships from CNEA. 


\section{REFERENCES}

Abargues, R., Marqués-Hueso, J., Canet-Ferrer, J., Pedrueza, E., Valdés, J. L., Jiménez, E., et al. (2008). High-resolution electron-beam patternable nanocomposite containing metal nanoparticles for plasmonics. Nanotechnology 19, 355308. doi:10.1088/0957-4484/19/35/355308

Abargues, R., Mart, J. P., Marqués-Hueso, J., Abargues, R., Valdés, J. L., MartínezPastor, J. P., et al. (2010). Ag and Au/DNQ-novolac nanocomposites patternable by ultraviolet lithography: a fast route to plasmonic sensor microfabrication. J. Mater. Chem. 20, 7436-7443. doi:10.1039/ c0jm01226b

Abargues, R., Martinez-Marco, M. L., Rodriguez-Canto, P. J., Marques-Hueso, J., and Martinez-Pastor, J. P. (2013). "Metal-polymer nanocomposite resist: a step towards in-situ nanopatterns metallization," in Advances in resist materials and processing technology XXX (Bellingham, WA: SPIE), 8682, 86820X. doi:10.1117/12.2011555

Acosta, M., Novak, N., Rojas, V., Patel, S., Vaish, R., Koruza, J., et al. (2017). Batio3based piezoelectrics: fundamentals, current status, and perspectives. Appl. Phys. Rev. 4, 041305. doi:10.1063/1.4990046

Ali, M. A., Gonsalves, K. E., Agrawal, A., Jeyakumar, A., and Henderson, C. L. (2003). A new nanocomposite resist for low and high voltage electron beam lithography. Microelectron. Eng. 70, 19-29. doi:10.1016/S0167-9317(03) 00363-0

An, N., Liu, H., Ding, Y., Lu, B., and Zhang, M. (2012). Fabrication of microstructures on a $\mathrm{PVDF} / \mathrm{TiO}_{2}$ nano-composite film using photocatalytic lithography. Appl. Surf. Sci. 258, 5052-5055. doi:10.1016/j.apsusc.2012. 01.103

An, N., Liu, H., Ding, Y., Zhang, M., and Tang, Y. (2011). Preparation and electroactive properties of a pvdf/nano- $\mathrm{TiO}_{2}$ composite film. Appl. Surf. Sci. 257, 3831-3835. doi:10.1016/j.apsusc.2010.12.076

Appleyard, D. C., Chapin, S. C., and Doyle, P. S. (2011a). Multiplexed protein quantification with barcoded hydrogel microparticles. Anal. Chem. 83, 193-199. doi:10.1021/ac1022343

Appleyard, D. C., Chapin, S. C., Srinivas, R. L., and Doyle, P. S. (2011b). Bar-coded hydrogel microparticles for protein detection: synthesis, assay and scanning. Nat. Protoc. 6, 1761-1774. doi:10.1038/nprot.2011.400

Au, T. H., Perry, A., Audibert, J., Trinh, D. T., Do, D. B., Buil, S., et al. (2020). Controllable movement of single-photon source in multifunctional magnetophotonic structures. Sci. Rep. 10, 1-9. doi:10.1038/s41598-020-61811-8

Augurio, A., Cortelletti, P., Tognato, R., Rios, A., Levato, R., Malda, J., et al. (2020). A multifunctional nanocomposite hydrogel for endoscopic tracking and manipulation. Adv. Intell. Syst. 2, 1900105. doi:10.1002/aisy.201900105

Bae, W. J., Trikeriotis, M., Sha, J., Schwartz, E. L., Rodriguez, R., Zimmerman, P., et al. (2010). High refractive index and high transparency $\mathrm{HfO}_{2}$ nanocomposites for next generation lithography. J. Mater. Chem. 20, 5186-5189. doi:10.1039/c0jm00679c

Baffou, G., Berto, P., Bermúdez Ureña, E., Quidant, R., Monneret, S., Polleux, J., et al. (2013). Photoinduced heating of nanoparticle arrays. ACS Nano 7, 6478-6488. doi:10.1021/nn401924n

Bai, Y., Ho, S., and Kotov, N. A. (2012). Direct-write maskless lithography of LBL nanocomposite films and its prospects for MEMS technologies. Nanoscale 4, 4393-4398. doi:10.1039/c2nr30197k

Bhagat, A. A. S., Jothimuthu, P., and Papautsky, I. (2007). Photodefinable polydimethylsiloxane (PDMS) for rapid lab-on-a-chip prototyping. Lab. Chip 7, 1192-1197. doi:10.1039/b704946c

Boisen, A., Dohn, S., Keller, S. S., Schmid, S., and Tenje, M. (2011). Cantilever-like micromechanical sensors. Rep. Prog. Phys. 74, 036101. doi:10.1088/0034-4885/ $74 / 3 / 036101$

Bong, K. W., Chapin, S. C., and Doyle, P. S. (2010). Magnetic barcoded hydrogel microparticles for multiplexed detection. Langmuir 26, 8008-8014. doi:10. 1021/la904903g

Bremer, L., Tuinier, R., and Jahromi, S. (2009). High refractive index nanocomposite fluids for immersion lithography. Langmuir 25, 2390-2401. doi:10.1021/la8026896

Brighenti, R., Li, Y., and Vernerey, F. J. (2020). Smart polymers for advanced applications: a mechanical perspective review. Front. Mater. 7, 1-18. doi:10. 3389/fmats.2020.00196
Broussier, A., Issa, A., Le Cunff, L. O., Nguyen, T. H., Dinh, X. Q., Blaize, S., et al. (2019). Hybrid plasmonic nanosystem with controlled position of nanoemitters. Appl. Phys. Lett. 114, 163106. doi:10.1063/1.5093360

Brust, M., Walker, M., Bethell, D., Schiffrin, D. J., and Whyman, R. (1994). Synthesis of thiol-derivatised gold nanoparticles in a two-phase Liquid-Liquid system. J. Chem. Soc. Chem. Commun. 24, 801-802. doi:10.1039/C39940000801

Burunkova, J. A., Denisyuk, I. Y., Bulgakova, V., and Kokenyesi, S. (2013). " $\mathrm{TiO}_{2}$ acrylate nanocomposites elaborated by UV-curing with tunable properties," in Solid state phenomena (Switzerland: Trans Tech Publications Ltd.), 200, 173-177. doi:10.4028/www.scientific.net/SSP.200.173

Campo, a. D., and Greiner, C. (2007). SU-8: a photoresist for high-aspect-ratio and 3D submicron lithography. J. Micromech. Microeng. 17, R81-R95. doi:10.1088/ 0960-1317/17/6/R01

Carlotti, M., and Mattoli, V. (2019). Functional materials for two-photon polymerization in microfabrication. Small 15, 1-22. doi:10.1002/smll. 201902687

Caseri, W. (2000). Nanocomposites of polymers and metals or semiconductors: historical background and optical properties. Macromol. Rapid Commun. 21, 705-722. doi:10.1002/1521-3927(20000701)21:11<705::AID-MARC705>3.0. $\mathrm{CO} ; 2-3$

Caseri, W. R. (2006). Nanocomposites of polymers and inorganic particles: preparation, structure and properties. Mater. Sci. Tech. 22, 807-817. doi:10. 1179/174328406X101256

Ceylan, H., Yasa, I. C., Yasa, O., Tabak, A. F., Giltinan, J., and Sitti, M. (2019). 3DPrinted biodegradable microswimmer for theranostic cargo delivery and release. ACS Nano 13, 3353-3362. doi:10.1021/acsnano.8b09233

Chapin, S. C., and Doyle, P. S. (2011). Ultrasensitive multiplexed microrna quantification on encoded gel microparticles using rolling circle amplification. Anal. Chem. 83, 7179-7185. doi:10.1021/ac201618k

Chavez, L. A., Regis, J. E., Delfin, L. C., Garcia Rosales, C. A., Kim, H., Love, N., et al. (2019). Electrical and mechanical tuning of $3 \mathrm{~d}$ printed photopolymer-mwent nanocomposites through in situ dispersion. J. Appl. Polym. Sci. 136, 47600. doi:10.1002/app. 47600

Chen, G., Qiu, H., Prasad, P. N., and Chen, X. (2014). Upconversion nanoparticles: design, nanochemistry, and applications in theranostics. Chem. Rev. 114, 5161-5214. doi:10.1021/cr400425h

Chen, L., Dong, Y., Tang, C. Y., Zhong, L., Law, W. C., Tsui, G. C., et al. (2019). Development of direct-laser-printable light-powered nanocomposites. ACS Appl. Mater. Inter. 11, 19541-19553. doi:10.1021/acsami.9b05871

Chen, X.-Z., Hoop, M., Mushtaq, F., Siringil, E., Hu, C., Nelson, B. J., et al. (2017). Recent developments in magnetically driven micro- and nanorobots. Appl. Mater. Today 9, 37-48. doi:10.1016/j.apmt.2017.04.006

Chiamori, H., Brown, J., Adhiprakasha, E., Hantsoo, E., Straalsund, J., Melosh, N., et al. (2008). Suspension of nanoparticles in SU-8: processing and characterization of nanocomposite polymers. Microelectronics J. 39, 228-236. doi:10.1016/j.mejo.2007.05.012

Cho, J. D., Ju, H. T., Park, Y. S., and Hong, J. W. (2006). Kinetics of cationic photopolymerizations of UV-curable epoxy-based SU8-negative photoresists with and without silica nanoparticles. Macromol. Mater. Eng. 291, 1155-1163. doi:10.1002/mame.200600124

Cho, S., Kang, S., Pandya, A., Shanker, R., Khan, Z., Lee, Y., et al. (2017). Large-area cross-aligned silver nanowire electrodes for flexible, transparent, and forcesensitive mechanochromic touch screens. ACS Nano 11, 4346-4357. doi:10. 1021/acsnano.7b01714

Choi, N. W., Kim, J., Chapin, S. C., Duong, T., Donohue, E., Pandey, P., et al. (2012). Multiplexed detection of mrna using porosity-tuned hydrogel microparticles. Anal. Chem. 84, 9370-9378. doi:10.1021/ac302128u

Chow, W. S., and Mohd Ishak, Z. A. (2020). Smart polymer nanocomposites: a review. Express Polym. Lett. 14, 416-435. doi:10.3144/expresspolymlett.2020.35

Chung, S. E., Kim, J., Choi, S.-E., Kim, L. N., and Kwon, S. (2011). In situ fabrication and actuation of polymer magnetic microstructures. J. Microelectromech. Syst. 20, 785-787. doi:10.1109/JMEMS.2011.2159093

Cong, H., Hong, L., Harake, R. S., and Pan, T. (2010). CNT-based photopatternable nanocomposites with high electrical conductivity and optical transparency. J. Micromech. Microeng. 20, 025002. doi:10.1088/0960$1317 / 20 / 2 / 025002$

Cong, H., and Pan, T. (2009). "Microfabrication of conductive PDMS on flexible substrates for biomedical applications," in 2009 4th IEEE international 
conference on nano/micro engineered and molecular systems, Shenzhen, China, January 5-8, 2009, 731-734. doi:10.1109/NEMS.2009.5068682

Cotton, D. P. J., Popel, A., Graz, I. M., and Lacour, S. P. (2011). Photopatterning the mechanical properties of polydimethylsiloxane films. J. Appl. Phys. 109, 054905. doi:10.1063/1.3552917

Damean, N., Parviz, B. a., Lee, J. N., Odom, T., and Whitesides, G. M. (2005). Composite ferromagnetic photoresist for the fabrication of microelectromechanical systems. J. Micromech. Microeng. 15, 29-34. doi:10. 1088/0960-1317/15/1/005

Dan, L., Shi, S., Chung, H.-J., and Elias, A. (2019). Porous polydimethylsiloxanesilver nanowire devices for wearable pressure sensors. ACS Appl. Nano Mater. 2, 4869-4878. doi:10.1021/acsanm.9b00807

Dawan, F., Jin, Y., Goettert, J., and Ibekwe, S. (2008). High functionality of a polymer nanocomposite material for MEMS applications. Microsyst. Technol. 14, 1451-1459. doi:10.1007/s00542-008-0577-4

De, S., Higgins, T. M., Lyons, P. E., Doherty, E. M., Nirmalraj, P. N., Blau, W. J., et al. (2009). Silver nanowire networks as flexible, transparent, conducting films: extremely high DC to optical conductivity ratios. ACS Nano 3, 1767-1774. doi: $10.1021 / \mathrm{nn} 900348 \mathrm{c}$

Dinh, D.-H., Chien, H.-L., and Lee, Y.-C. (2019). Maskless lithography based on digital micromirror device (DMD) and double sided microlens and spatial filter array. Opt. Laser Tech. 113, 407-415. doi:10.1016/j.optlastec.2019.01.001

Dittrich, P. S., and Manz, A. (2006). Lab-on-a-chip: microfluidics in drug discovery. Nat. Rev. Drug Discov. 5, 210-218. doi:10.1038/nrd1985

Do, M. T., Nguyen, T. T. N., Li, Q., Benisty, H., Ledoux-Rak, I., and Lai, N. D. (2013). Submicrometer 3d structures fabrication enabled by one-photon absorption direct laser writing. Opt. Express 21, 20964. doi:10.1364/oe.21. 020964

Dusoe, K. J., Ye, X., Kisslinger, K., Stein, A., Lee, S.-W., and Nam, C.-Y. (2017). Ultrahigh elastic strain energy storage in metal-oxide-infiltrated patterned hybrid polymer nanocomposites. Nano Lett. 17, 7416-7423. doi:10.1021/acs. nanolett.7b03238

Dutoit, B., Besse, P.-A., Blanchard, H., Guérin, L., and Popovic, R. S. (1999). High performance micromachined $\mathrm{Sm}_{2} \mathrm{Co}_{17}$ polymer bonded magnets. Sensors Actuators A. Phys. 77, 178-182. doi:10.1016/S0924-4247(99)00193-4

El-Atab, N., Mishra, R. B., Al-Modaf, F., Joharji, L., Alsharif, A. A., Alamoudi, H., et al. (2020). Soft actuators for soft robotic applications: a review. Adv. Intell. Syst. 2, 2000128. doi:10.1002/aisy.202000128

Erb, R. M., Martin, J. J., Soheilian, R., Pan, C., and Barber, J. R. (2016). Actuating soft matter with magnetic torque. Adv. Funct. Mater. 26, 3859-3880. doi:10. 1002/adfm.201504699

Fan, M., Andrade, G. F. S., and Brolo, A. G. (2011). A review on the fabrication of substrates for surface enhanced Raman spectroscopy and their applications in analytical chemistry. Anal. Chim. Acta 693, 7-25. doi:10.1016/j.aca.2011. 03.002

Fedoruk, M., Meixner, M., Carretero-Palacios, S., Lohmüller, T., and Feldmann, J. (2013). Nanolithography by plasmonic heating and optical manipulation of gold nanoparticles. ACS Nano 7, 7648-7653. doi:10.1021/nn402124p

Firestone, M. A., Hayden, S. C., and Huber, D. L. (2015). Greater than the sum: synergy and emergent properties in nanoparticle-polymer composites. MRS Bull. 40, 760-767. doi:10.1557/mrs.2015.202

Fischer, S. V., Uthuppu, B., and Jakobsen, M. H. (2015). In situ SU-8 silver nanocomposites. Beilstein J. Nanotechnol. 6, 1661-1665. doi:10.3762/bjnano. 6.168

Foulger, S. H. (1999). Electrical properties of composites in the vicinity of the percolation threshold. J. Appl. Polym. Sci. 72, 1573-1582. doi:10.1002/(SICI) 1097-4628(19990620)72:12<1573::AID-APP10>3.0.CO;2-6

Fourkas, J. T. (2020). "Chapter 1.3-fundamentals of two-photon fabrication," in Three-dimensional microfabrication using two-photon polymerization. 2nd Edn, Editor T. Baldacchini (Norwich, NY: William Andrew Publishing), 57-76. doi:10.1016/B978-0-12-817827-0.00051-5

Fu, S., Sun, Z., Huang, P., Li, Y., and Hu, N. (2019). Some basic aspects of polymer nanocomposites: a critical review. Nano Mater. Sci. 1, 2-30. doi:10.1016/j. nanoms.2019.02.006

Ganesan, R., Lim, S. H., Saifullah, M. S., Hussain, H., Kwok, J. X., Tse, R. L., et al. (2011). Direct nanoimprinting of metal oxides by in situ thermal copolymerization of their methacrylates. J. Mater. Chem. 21, 4484-4492. doi:10.1039/c0jm04105j
Ge, J., Kwon, S., and Yin, Y. (2010). Niche applications of magnetically responsive photonic structures. J. Mater. Chem. 20, 5777-5784. doi:10.1039/c0jm00083c

Gerardo, C. D., Cretu, E., and Rohling, R. (2017). Fabrication of circuits on flexible substrates using conductive SU-8 for sensing applications. Sensors 17, 1420. doi: $10.3390 / \mathrm{s} 17061420$

Gerver, R. E., Gómez-Sjöberg, R., Baxter, B. C., Thorn, K. S., Fordyce, P. M., Diaz-Botia, C. A., et al. (2012). Programmable microfluidic synthesis of spectrally encoded microspheres. Lab. Chip 12, 4716-4723. doi:10.1039/ c2lc40699c

Gonsalves, K. E., Merhari, L., Wu, H., and Hu, Y. (2001). Organic-inorganic nanocomposites: unique resists for nanolithography. Adv. Mater. 13, 703-714. doi:10.1002/1521-4095(200105)13:10<703::aid-adma703>3.0.co;2-a

Grigorescu, A. E., and Hagen, C. W. (2009). ZResists for sub-20-nm electron beam lithography with a focus on HSQ: state of the art. Nanotechnology 20, 292001. doi:10.1088/0957-4484/20/29/292001

Grimaldi, C., Mionic, M., Gaal, R., Forro, L., and Magrez, A. (2013). Electrical conductivity of multi-walled carbon nanotubes-SU8 epoxy composites. Appl. Phys. Lett. 102, 223114. doi:10.1063/1.4809923

Hanemann, T., and Szabó, D. V. (2010). Polymer-nanoparticle composites: from synthesis to modern applications. Materials 3, 3468-3517. doi:10.3390/ ma3063468

Henderson, C. (2012). Photoresists and advanced patterning. Polym. Sci. A Compr. Reference 10 (8), 37-76. doi:10.1016/B978-0-444-53349-4.00201-6

Hines, L., Petersen, K., Lum, G. Z., and Sitti, M. (2017). Soft actuators for smallscale robotics. Adv. Mater. 29, 1603483. doi:10.1002/adma.201603483

Hong, L., and Pan, T. (2011). Surface microfluidics fabricated by photopatternable superhydrophobic nanocomposite. Microfluid Nanofluid 10, 991-997. doi:10. 1007/s10404-010-0728-7

Hu, A., Li, R., Bridges, D., Zhou, W., Bai, S., Ma, D., et al. (2016). Photonic nanomanufacturing of high performance energy devices on flexible substrates. J. Laser Appl. 28, 022602. doi:10.2351/1.4944449

Hu, C., Pané, S., and Nelson, B. J. (2018). Soft micro-and nanorobotics. Annu. Rev. Control Rob. Auton. Syst. 12, 53-75. doi:10.1146/annurev-control060117

Hu, M. Z., and Zhu, T. (2015). Semiconductor nanocrystal quantum dot synthesis approaches towards large-scale industrial production for energy applications. Nanoscale Res. Lett. 10, 1-15. doi:10.1186/s11671-015-1166-y

$\mathrm{Hu}, \mathrm{Y}$., Wu, H., Gonsalves, K., and Merhari, L. (2001). Nanocomposite resists for electron beam nanolithography. Microelectron. Eng. 56, 289-294. doi:10.1016/ S0167-9317(01)00420-8

Huang, H.-W., Sakar, M. S., Petruska, A. J., Pané, S., and Nelson, B. J. (2016). Soft micromachines with programmable motility and morphology. Nat. Commun. 7. doi:10.1038/ncomms 12263

Huang, Q., Shen, W., Fang, X., Chen, G., Guo, J., Xu, W., et al. (2015). Highly flexible and transparent film heaters based on polyimide films embedded with silver nanowires. RSC Adv. 5, 45836-45842. doi:10.1039/c5ra06529a

Huang, Y., Fuksman, L., and Zheng, J. (2018). Luminescence mechanisms of ultrasmall gold nanoparticles. Dalton Trans. 47, 6267-6273. doi:10.1039/ C8DT00420J

Huong Au, T., Thien Trinh, D., Bich Do, D., Phu Nguyen, D., Cong Tong, Q., and Diep Lai, N. (2018). Free-floating magnetic microstructures by mask photolithography. Phys. B Condens. Matter 532, 59-63. doi:10.1016/j.physb. 2017.03.032

Ingrosso, C., Fakhfouri, V., Striccoli, M., Agostiano, A., Voigt, A., Gruetzner, G., et al. (2007). An epoxy photoresist modified by luminescent nanocrystals for the fabrication of 3D high-aspect-ratio microstructures. Adv. Funct. Mater. 17, 2009-2017. doi:10.1002/adfm.200700098

Ingrosso, C., Martin, C., Llobera, A., Perez Murano, F., Innocenti, C., Sangregorio, C., et al. (2009). Magnetic nanocrystals modified epoxy photoresist for microfabrication of AFM probes. Proced. Chem. 1, 580-584. doi:10.1016/j. proche.2009.07.145

Ingrosso, C., Panniello, A. M., Comparelli, R., Curri, M. L., and Striccoli, M. (2010). Colloidal inorganic nanocrystal based nanocomposites: functional materials for micro and nanofabrication. Materials 3, 1316-1352. doi:10. 3390/ma3021316

Innocenzi, P., and Malfatti, L. (2018). Nanoparticles in mesoporous films, a happy marriage for materials science. J. Nanopart Res. 20, 167. doi:10.1007/s11051018-4251-1 
Iojoiu, C., Abadie, M. J. M., Harabagiu, V., Pinteala, M., and Simionescu, B. C. (2000). Synthesis and photocrosslinking of benzyl acrylate substituted polydimethylsiloxanes. Eur. Polym. J. 36, 2115-2123. doi:10.1016/S00143057(99)00287-6

Ishii, T., Nozawa, H., Tamamura, T., Tamamum, T., and Tamamura, T. (1997). A nano-composite resist system: a new approach to nanometer pattern fabrication. Microelectron. Eng. 35, 113-116. doi:10.1016/S0167-9317(96) 00167-0

Jain, S., Bharti, S., Bhullar, G. K., and Tripathi, S. K. (2020). I-III-VI core/shell QDs: synthesis, characterizations and applications. J. Lumin. 219, 116912. doi:10. 1016/j.jlumin.2019.116912

Jiang, N., Zhuo, X., and Wang, J. (2018). Active plasmonics: principles, structures, and applications. Chem. Rev. 118, 3054-3099. doi:10.1021/acs.chemrev. $7 \mathrm{~b} 00252$

Jiang, S., Hu, Y., Wu, H., Li, R., Zhang, Y., Chen, C., et al. (2020). Threedimensional multifunctional magnetically responsive liquid manipulator fabricated by femtosecond laser writing and soft transfer. Nano Lett. 20 (10), 7519-7529. doi:10.1021/acs.nanolett.0c02997

Jiguet, S., Bertsch, A., Hofmann, H., and Renaud, P. (2005). Conductive SU8 photoresist for microfabrication. Adv. Funct. Mater. 15, 1511-1516. doi:10. 1002/adfm.200400575

Jiguet, S., Bertsch, A., Hofmann, H., and Renaud, P. (2004). SU8-Silver photosensitive nanocomposite. Adv. Eng. Mater. 6, 719-724. doi:10.1002/ adem. 200400068

Jiguet, S., Bertsch, A., Judelewicz, M., Hofmann, H., and Renaud, P. (2006a). SU8 nanocomposite photoresist with low stress properties for microfabrication applications. Microelectron. Eng. 83, 1966-1970. doi:10.1016/j.mee.2006. 02.004

Jiguet, S., Judelewicz, M., Mischler, S., Bertch, A., and Renaud, P. (2006b). Effect of filler behavior on nanocomposite SU8 photoresist for moving micro-parts. Microelectron. Eng. 83, 1273-1276. doi:10.1016/j.mee.2006.01.068

Jiu, J., Araki, T., Wang, J., Nogi, M., Sugahara, T., Nagao, S., et al. (2014). Facile synthesis of very-long silver nanowires for transparent electrodes. J. Mater. Chem. A. 2, 6326-6330. doi:10.1039/C4TA00502C

Jordan, J., Jacob, K. I., Tannenbaum, R., Sharaf, M. A., and Jasiuk, I. (2005). Experimental trends in polymer nanocomposites-a review. Mater. Sci. Eng. A. 393, 1-11. doi:10.1016/j.msea.2004.09.044

Kuo, J.-C., Li, C.-S., and Yang, Y.-J. (2013). "Suspended magnetic polymer structures fabricated with exposure dose control," in The 8th annual IEEE international conference on nano/micro engineered and molecular systems, Suzhou, China, April 7-10, 2013, 779-782. doi:10.1109/NEMS.2013. 6559844

Kaboli, F., Ghazyani, N., Riahi, M., Zare-Behtash, H., Majles Ara, M. H., and Heydari, E. (2019). Upconverting nanoengineered surfaces: maskless photolithography for security applications. ACS Appl. Nano Mater. 2, 3590-3596. doi:10.1021/acsanm.9b00549

Kandpal, M., Sharan, C., Palaparthy, V., Tiwary, N., Poddar, P., and Rao, V. R. (2015). Spin-coatable, photopatternable magnetic nanocomposite thin films for MEMS device applications. RSC Adv. 5, 85741-85747. doi:10.1039/c5ra15706d

Kandpal, M., Sharan, C., Poddar, P., Prashanthi, K., Apte, P. R., and Ramgopal Rao, V. (2012). Photopatternable nano-composite (SU-8/ZnO) thin films for piezo-electric applications. Appl. Phys. Lett. 101, 104102. doi:10.1063/1.4748575

Kapat, K., Shubhra, Q. T., Zhou, M., and Leeuwenburgh, S. (2020). Piezoelectric nano-biomaterials for biomedicine and tissue regeneration. Adv. Funct. Mater. 30, 1909045. doi:10.1002/adfm.201909045

Kausar, A. (2020). Polydimethylsiloxane-based nanocomposite: present research scenario and emergent future trends. Polym. Technol. Mater. 59, 1148-1166. doi:10.1080/25740881.2020.1719149

Khosla, A., and Gray, B. L. (2010). Physical properties of polymers: preparation, micro-patterning and electrical characterization of functionalized carbonnanotube polydimethylsiloxane nanocomposite polymer. Macromol. Symp. 297, 210-218. doi:10.1002/masy.200900165

Khosla, A., and Gray, B. L. (2009). Preparation, characterization and micromolding of multi-walled carbon nanotube polydimethylsiloxane conducting nanocomposite polymer. Mater. Lett. 63, 1203-1206. doi:10. 1016/j.matlet.2009.02.043

Kim, H., Ge, J., Kim, J., Choi, S. E., Lee, H. H., Lee, H. H., et al. (2009). Structural colour printing using a magnetically tunable and lithographically fixable photonic crystal. Nat. Photon. 3, 534-540. doi:10.1038/nphoton. 2009.141

Kim, H., Renteria-Marquez, A., Islam, M. D., Chavez, L. A., Garcia Rosales, C. A., Ahsan, M. A., et al. (2019). Fabrication of bulk piezoelectric and dielectric batio3 ceramics using paste extrusion $3 \mathrm{~d}$ printing technique. J. Am. Ceram. Soc. 102, 3685-3694. doi:10.1111/jace.16242

Kim, J., Choi, S.-E., Lee, H., and Kwon, S. (2013). Magnetochromatic microactuators for a micropixellated color-changing surface. Adv. Mater. 25, 1415-1419. doi:10.1002/adma.201203810

Kim, J., Chung, S. E., Choi, S. E., Lee, H., Kim, J., and Kwon, S. (2011). Programming magnetic anisotropy in polymeric microactuators. Nat. Mater. 10, 747-752. doi:10.1038/nmat3090

Kim, K. K., Hong, S., Cho, H. M., Lee, J., Suh, Y. D., Ham, J., et al. (2015). Highly sensitive and stretchable multidimensional strain sensor with prestrained anisotropic metal nanowire percolation networks. Nano Lett. 15, 5240-5247. doi:10.1021/acs.nanolett.5b01505

Kim, K., Zhu, W., Qu, X., Aaronson, C., McCall, W. R., Chen, S., et al. (2014). 3D optical printing of piezoelectric nanoparticle-polymer composite materials. ACS nano 8, 9799-9806. doi:10.1021/nn503268f

Kim, S. D., Song, S. W., Oh, D. Y., Lee, A. C., Koo, J. W., Kang, T., et al. (2020). Microspinning: local surface mixing via rotation of magnetic microparticles for efficient small-volume bioassays. Micromachines 11, 175. doi:10.3390/ mil1020175

Kim, S. R., Kim, J. H., and Park, J. W. (2017). Wearable and transparent capacitive strain sensor with high sensitivity based on patterned Ag nanowire networks. ACS Appl. Mater. Inter. 9, 26407-26416. doi:10.1021/acsami.7b06474

Kimling, J., Maier, M., Okenve, B., Kotaidis, V., Ballot, H., and Plech, A. (2006). Turkevich method for gold nanoparticle synthesis revisited. J. Phys. Chem. B. 110, 15700-15707. doi:10.1021/jp061667w

Klein, F., Richter, B., Striebel, T., Franz, C. M., Freymann, G. v., Wegener, M., et al. (2011). Two-component polymer scaffolds for controlled three-dimensional cell culture. Adv. Mater. 23, 1341-1345. doi:10.1002/adma.201004060

Ko, Y., Kim, J., Kim, D., Yamauchi, Y., Kim, J. H., and You, J. (2017). A simple silver nanowire patterning method based on poly(ethylene glycol) photolithography and its application for soft electronics. Sci. Rep. 7, 2282. doi:10.1038/s41598-017-02511-8

Kong, W., Sun, T., Chen, B., Chen, X., Ai, F., Zhu, X., et al. (2017). A general strategy for ligand exchange on upconversion nanoparticles-SuppInfo. Inorg. Chem. 56, 872. doi:10.1021/acs.inorgchem.6b02479

Kuang, X., Roach, D. J., Hamel, C. M., Yu, K., and Qi, H. J. (2020). Materials, design, and fabrication of shape programmable polymers. Multifunct. Mater. 3, 032002. doi:10.1088/2399-7532/aba1d9

Kumar, S. K., Jouault, N., Benicewicz, B., and Neely, T. (2013). Nanocomposites with polymer grafted nanoparticles. Macromolecules 46, 3199-3214. doi:10. $1021 / \mathrm{ma} 4001385$

Kuo, J. C., Huang, H. W., Tung, S. W., and Yang, Y. J. (2014). A hydrogel-based intravascular microgripper manipulated using magnetic fields. Sensors Actuators, A. Phys. 211, 121-130. doi:10.1016/j.sna.2014.02.028

LaFratta, C., Fourkas, J., Baldacchini, T., and Farrer, R. (2007). Multiphoton fabrication. Angew. Chem. Int. Ed. 46, 6238-6258. doi:10.1002/anie. 200603995

Lee, A. C., Kim, J., Noh, J., Lee, H., and Kwon, S. (2020). "Optics and fluidics," in Engineering of micro/nano biosystems (Singapore: Springer), 197-234. doi:10. 1007/978-981-13-6549-2_5

Lee, E., Kim, H. J., Park, Y., Lee, S., Lee, S. Y., Ha, T., et al. (2019). Direct patterning of a carbon nanotube thin layer on a stretchable substrate. Micromachines 10 , 530-614. doi:10.3390/mi10080530

Lee, H., Kim, J., Kim, H., Kim, J., and Kwon, S. (2010). Colour-barcoded magnetic microparticles for multiplexed bioassays. Nat. Mater. 9, 745-749. doi:10.1038/ nmat 2815

Lee, J., Bisso, P. W., Srinivas, R. L., Kim, J. J., Swiston, A. J., and Doyle, P. S. (2014). Universal process-inert encoding architecture for polymer microparticles. Nat. Mater. 13, 524-529. doi:10.1038/nmat3938

Lee, P., Lee, J., Lee, H., Yeo, J., Hong, S., Nam, K. H., et al. (2012). Highly stretchable and highly conductive metal electrode by very long metal nanowire percolation network. Adv. Mater. 24, 3326-3332. doi:10.1002/adma.201200359

Lee, S., Lee, B., Kim, B. J., Park, J., Yoo, M., Bae, W. K., et al. (2009). Free-standing nanocomposite multilayers with various length scales, adjustable internal 
structures, and functionalities. J. Am. Chem. Soc. 131, 2579-2587. doi:10.1021/ ja8064478

Li, H., Chen, J., Zhang, J. J. J., Zhang, J. J. J., Zhao, G., and Wang, L. (2018). Photopatternable magnetic hollowbots by Nd-Fe-B nanocomposite for potential targeted drug delivery applications. Micromachines 9, 182. doi:10. 3390/mi9040182

Li, H., Flynn, T. J., Nation, J. C., Kershaw, J., Scott Stephens, L., and Trinkle, C. A. (2013). Photopatternable NdFeB polymer micromagnets for microfluidics and microrobotics applications. J. Micromech. Microeng. 23, 065002. doi:10.1088/ 0960-1317/23/6/065002

Li, L., Huang, Z., Wang, Y. H., and Brown, K. A. (2019a). Design of elastomer-CNT film photoactuators for nanolithography. Polymers 11, 314-319. doi:10.3390/ polym11020314

Li, X., Kundaliya, D., Tan, Z. J., Anc, M., and Fang, N. X. (2019b). Projection lithography patterned high-resolution quantum dots/thiol-ene photo-polymer pixels for color down conversion. Opt. Express 27, 30864. doi:10.1364/oe.27. 030864

Li, X., Kundaliya, D., Tan, Z. J., Anc, M., and Fang, N. X. (2019c). Projection lithography patterned high-resolution quantum dots/thiol-ene photo-polymer pixels for color down conversion. Opt. Express 27, 30864. doi:10.1364/oe.27. 030864

Li, Z., Wang, M., Zhang, X., Wang, D., Xu, W., and Yin, Y. (2019d). Magnetic assembly of nanocubes for orientation-dependent photonic responses. Nano Lett. 19, 6673-6680. doi:10.1021/acs.nanolett.9b02984

Li, Z., Yang, F., and Yin, Y. (2020). Smart materials by nanoscale magnetic assembly. Adv. Funct. Mater. 30, 1903467. doi:10.1002/adfm.201903467

Liao, C., Wuethrich, A., and Trau, M. (2020). A material odyssey for 3d nano/ microstructures: two photon polymerization based nanolithography in bioapplications. Appl. Mater. Today 19, 100635. doi:10.1016/j.apmt.2020. 100635

Ligon-Auer, S. C., Schwentenwein, M., Gorsche, C., Stampfl, J., and Liska, R. (2016). Toughening of photo-curable polymer networks: a review. Polym. Chem. 7, 257-286. doi:10.1039/c5py01631b

Lim, S. Y., Shen, W., and Gao, Z. (2015). Carbon quantum dots and their applications. Chem. Soc. Rev. 44, 362-381. doi:10.1039/c4cs00269e

Lio, G. E., Madrigal, J. B., Xu, X., Peng, Y., Pierini, S., Couteau, C., et al. (2019). Integration of nanoemitters onto photonic structures by guided evanescentwave nano-photopolymerization. J. Phys. Chem. C 123, 14669-14676. doi:10. 1021/acs.jpcc.9b03716

Liu, B., Zhan, C., Yao, X., Yan, S., and Ren, B. (2020). Nanobowtie arrays with tunable materials and geometries fabricated by holographic lithography. Nanoscale 12, 21401. doi:10.1039/D0NR05546H

Liu, C.-X. X., and Choi, J.-W. W. (2012). Precision patterning of conductive polymer nanocomposite using a laser-ablated thin film. J. Micromech. Microeng. 22, 045014. doi:10.1088/0960-1317/22/4/045014

Liu, R., Chen, H., Li, Z., Shi, F., and Liu, X. (2016). Extremely deep photopolymerization using upconversion particles as internal lamps. Polym. Chem. 7, 2457-2463. doi:10.1039/c6py00184j

Liu, S., and Han, M. Y. (2010). Silica-coated metal nanoparticles. Chem. Asian J. 5, 36-45. doi:10.1002/asia.200900228

Long, J., Xiong, W., Wei, C., Lu, C., Wang, R., Deng, C., et al. (2020). Directional assembly of $\mathrm{ZnO}$ nanowires via three-dimensional laser direct writing. Nano Lett. 20, 5159-5166. doi:10.1021/acs.nanolett.0c01378

Lu, A.-H., Salabas, E. L., and Schüth, F. (2007). Magnetic nanoparticles: synthesis, protection, functionalization, and application. Angew. Chem. Int. Ed. 46, 1222-1244. doi:10.1002/anie.200602866

Luo, C., Xu, C., Lv, L., Li, H., Huang, X., and Liu, W. (2020). Review of recent advances in inorganic photoresists. RSC Adv. 10, 8385-8395. doi:10.1039/ C9RA08977B

Ma, X., Zhu, X., You, F., Feng, J., Wang, M.-c., and Zhao, X. (2014). Preparation and optical polarization of Ag/epoxy composite films with aligned $\mathrm{Ag}$ nanowires. J. Alloys Compd. 592, 57-62. doi:10.1016/j.jallcom.2014.01.004

Mahapatra, S. K., Bogle, K. A., Dhole, S. D., and Bhoraskar, V. N. (2007). Synthesis of gold and silver nanoparticles by electron irradiation at $5-15 \mathrm{keV}$ energy. Nanotechnology 18, 1-6. doi:10.1088/0957-4484/18/13/135602

Mahmoudi, M., Sant, S., Wang, B., Laurent, S., and Sen, T. (2011). Superparamagnetic iron oxide nanoparticles (SPIONs): development, surface modification and applications in chemotherapy. Adv. Drug Deliv. Rev. 63, 24-46. doi:10.1016/j.addr.2010.05.006

Mai, H.-X., Zhang, Y.-W., Si, R., Yan, Z.-G., Sun, L.-D., You, L.-P., et al. (2006). High-quality sodium rare-earth fluoride nanocrystals: controlled synthesis and optical properties. J. Am. Chem. Soc. 128, 6426-6436. doi:10.1021/ja060212h

Maier, S. A., and Atwater, H. A. (2005). Plasmonics: localization and guiding of electromagnetic energy in metal/dielectric structures. J. Appl. Phys. 98, 011101. doi:10.1063/1.1951057

Majidian, M., Grimaldi, C., Pisoni, A., Forró, L., and Magrez, A. (2014). Electrical conduction of photo-patternable SU8-graphene composites. Carbon 80, 364-372. doi:10.1016/j.carbon.2014.08.075

Malekshahinezhad, K., Ahmadi-khaneghah, A., and Behniafar, H. (2020). Aminefunctionalized $\mathrm{TiO}_{2}$ nanoparticles covalently loaded into epoxy networks via thermal and microwave curing processes. Macromol. Res. 28, 567-572. doi:10. 1007/s13233-020-8067-3

Malfatti, L., Carboni, D., Pinna, A., Lasio, B., Marmiroli, B., and Innocenzi, P. (2016). In situ growth of $\mathrm{Ag}$ nanoparticles in graphene- $\mathrm{TiO}_{2}$ mesoporous films induced by hard X-ray. J. Sol-gel Sci. Technol. 79, 295-302. doi:10.1007/s10971016-4052-x

Marino, A., Almici, E., Migliorin, S., Tapeinos, C., Battaglini, M., Cappello, V., et al. (2019). Piezoelectric barium titanate nanostimulators for the treatment of glioblastoma multiforme. J. Colloid Interf. Sci. 538, 449-461. doi:10.1016/j. jcis.2018.12.014

Marino, A., Arai, S., Hou, Y., Sinibaldi, E., Pellegrino, M., Chang, Y.-T., et al. (2015a). Piezoelectric nanoparticle-assisted wireless neuronal stimulation. ACS nano 9, 7678-7689. doi:10.1021/acsnano.5b03162

Marino, A., Barsotti, J., De Vito, G., Filippeschi, C., Mazzolai, B., Piazza, V., et al. (2015b). Two-photon lithography of 3D nanocomposite piezoelectric scaffolds for cell stimulation. ACS Appl. Mater. Inter. 7, 25574-25579. doi:10.1021/ acsami.5b08764

Marino, A., Battaglini, M., De Pasquale, D., Degl'Innocenti, A., and Ciofani, G. (2018). Ultrasound-activated piezoelectric nanoparticles inhibit proliferation of breast cancer cells. Scientific Rep. 8, 1-13. doi:10.1038/s41598-018-24697-1

Marqués-Hueso, J., Abargues, R., Canet-Ferrer, J., Agouram, S. S., Valdés, J. L., Martínez-Pastor, J. P., et al. (2010). Au-pva nanocomposite negative resist for one-step three-dimensional e-beam lithography. Langmuir 26, 2825-2830. doi:10.1021/la902915n

Marques-Hueso, J., Abargues, R., Canet-Ferrer, J., Valdes, J. L., and MartinezPastor, J. (2010). Resist-based silver nanocomposites synthesized by lithographic methods. Microelectron. Eng. 87, 1147-1149. doi:10.1016/j.mee. 2009.10.043

Martínez, E. D., Bellino, M. G., and Soler-Illia, G. J. A. A. (2009). Patterned production of silver-mesoporous titania nanocomposite thin films using lithography-assisted metal reduction. ACS Appl. Mater. Inter. 1, 746-749. doi:10.1021/am900018j

Martínez, E. D., Brites, C. D. S., Carlos, L. D., García-Flores, A. F., Urbano, R. R., and Rettori, C. (2018a). Electrochromic switch devices mixing small- and largesized upconverting nanocrystals. Adv. Funct. Mater. 29, 1807758. doi:10.1002/ adfm. 201807758

Martínez, E. D., García Flores, A. F., Pastoriza, H., Urbano, R. R., and Rettori, C. (2018b). Electrothermal silver nanowire thin films for In-Situ observation of thermally-driven chemical processes. Sensors Actuators B Chem. 259, 475-483. doi:10.1016/j.snb.2017.12.021

Martínez, E. D., Granja, L., Bellino, M. G., and Soler-Illia, G. J. A. A. (2010). Electrical conductivity in patterned silver-mesoporous titania nanocomposite thin films: towards robust 3D nano-electrodes. Phys. Chem. Chem. Phys. 12, 14445-14448. doi:10.1039/c0cp00824a

Martínez, E. D., Lohr, J. H., Sirena, M., Sánchez, R. D., and Pastoriza, H. (2016). Silver nanowires in poly ( methyl methacrylate) as a conductive nanocomposite for microfabrication. Flex. Print. Electron. 1, 1-10. doi:10.1088/2058-8585/1/3/ 035003

Martínez, E. D., Urbano, R. R., and Rettori, C. (2019). Thermoplasmonic maskless lithography on upconverting nanocomposites assisted by gold nanostars. ACS Appl. Nano Mater. 2, 6889-6897. doi:10.1021/acsanm. $9 \mathrm{~b} 01355$

Martinez, V., Stauffer, F., Adagunodo, M. O., Forro, C., Vörös, J., and Larmagnac, A. (2015). Stretchable silver nanowire-elastomer composite microelectrodes 
with tailored electrical properties. ACS Appl. Mater. Inter. 7, 13467-13475. doi:10.1021/acsami.5b02508

Mayer, F., Richter, S., Hübner, P., Jabbour, T., and Wegener, M. (2017). 3D fluorescence-based security features by $3 \mathrm{~d}$ laser lithography. Adv. Mater. Technol. 2, 1700212. doi:10.1002/admt.201700212

Mayer, F., Richter, S., Westhauser, J., Blasco, E., Barner-Kowollik, C., and Wegener, M. (2019). Multimaterial 3d laser microprinting using an integrated microfluidic system. Sci. Adv. 5, eaau9160. doi:10.1126/ sciadv.aau9160

Merhari, L., Gonsalves, K. E., Hu, Y., He, W., Huang, W. S., Angelopoulos, M., et al. (2002). Nanocomposite resist systems for next generation lithography. Microelectron. Eng. 63, 391-403. doi:10.1016/S0167-9317(02)00554-3

Meyerbröker, N., and Zharnikov, M. (2013). Modification and patterning of nanometer-thin poly(ethylene glycol) films by electron irradiation. ACS Appl. Mater. Inter. 5, 5129-5138. doi:10.1021/am400991h

Min, Y.-S., Bae, E. J., Park, J. B., and Park, W. (2006). Direct photolithographic route to selective growth of single-walled carbon nanotubes using a modified photoresist with ferrocene. Nanotechnology 17, 116-123. doi:10.1088/09574484/17/1/019

Mionic, M., Jiguet, S., Judelewicz, M., Forró, L., and Magrez, A. (2009). Preparation and characterization of SU8-carbon nanotube composites. Phys. Status Solidi 246, 2461-2464. doi:10.1002/pssb.200982274

Mionić, M., Jiguet, S., Judelewicz, M., Karimi, A., Forró, L., and Magrez, A. (2010). Study of the mechanical response of carbon nanotubes-SU8 composites by nanoindentation. Phys. Status Solidi 247, 3072-3075. doi:10.1002/pssb. 201000305

Mionić, M., Pataky, K., Gaal, R., Magrez, A., Brugger, J., and Forró, L. (2012). Carbon nanotubes-SU8 composite for flexible conductive inkjet printable applications. J. Mater. Chem. 22, 14030. doi:10.1039/c2jm16547c

Moniruzzaman, M., Winey, K. I., April, R. V., Re, V., Recei, M., and May, V. (2006). Polymer nanocomposites containing carbon nanotubes. Macromolecules 39, 5194-5205. doi:10.1021/ma060733p

Murray, W. A., and Barnes, W. L. (2007). Plasmonic materials. Adv. Mater. 19, 3771-3782. doi:10.1002/adma.200700678

Nadort, A., Zhao, J., and Goldys, E. M. (2016). Lanthanide upconversion luminescence at the nanoscale: fundamentals and optical properties. Nanoscale 8, 13099-13130. doi:10.1039/C5NR08477F

Nakahara, T., Suzuki, J., Hosokawa, Y., Shimokawa, F., Kotera, H., and Suzuki, T. (2018). Fabrication of magnetically driven microvalve arrays using a photosensitive composite. Magnetochemistry 4, 7. doi:10.3390/ magnetochemistry 4010007

Nakahara, T., Ueda, Y., Miyagawa, H., Kotera, H., and Suzuki, T. (2020). Selfaligned fabrication process for active membrane in magnetically driven micropump using photosensitive composite. J. Micromech. Microeng. 30, 025006. doi:10.1088/1361-6439/ab6302

Neouze, M.-A., and Schubert, U. (2008). Surface modification and functionalization of metal and metal oxide nanoparticles by organic ligands. Monatsh Chem. 139, 183-195. doi:10.1007/s00706-007-0775-2

Nguyen, D. T. T., Del Guercio, O., Au, T. H., Trinh, D. T., Mai, N. P. T., and Lai, N. D. (2018). Optical lithography of three-dimensional magnetophotonic microdevices. Opt. Eng. 57, 1. doi:10.1117/1.OE.57.4.041406

Ozhikandathil, J., Khosla, A., and Packirisamy, M. (2015). Electrically conducting PDMS nanocomposite using in situ reduction of gold nanostructures and mechanical stimulation of carbon nanotubes and silver nanoparticles. ECS J. Solid State. Sci. Technol. 4, S3048-S3052. doi:10.1149/2.0091510jss

Palevicius, A., Ponelyte, S., Guobiene, A., Prosycevas, I., Puiso, J., and Sakalys, R. (2013). Design and fabrication of piezoelectric nanocomposite structures for microdevice applications. J. Micro/nanolith. MEMS MOEMS 12, 043004. doi:10.1117/1.jmm.12.4.043004

Palo, E., Lahtinen, S., Päkkilä, H., Salomäki, M., Soukka, T., and Lastusaari, M. (2018). Effective shielding of $\mathrm{NaYF}_{4}: \mathrm{Yb}^{3+}, \mathrm{Er}^{3+}$ upconverting nanoparticles in aqueous environments using layer-by-layer assembly. Langmuir 34, 7759-7766. doi:10.1021/acs.langmuir.8b00869

Park, J.-J., Prabhakaran, P., Jang, K. K., Lee, Y., Lee, J., Lee, K., et al. (2010). Photopatternable quantum dots forming quasi-ordered arrays. Nano Lett. 10, 2310-2317. doi:10.1021/nl101609s
Park, J., Joo, J., Soon, G. K., Jang, Y., and Hyeon, T. (2007). Synthesis of monodisperse spherical nanocrystals. Angew. Chem. Int. Ed. 46, 4630-4660. doi:10.1002/anie.200603148

Patel, K. D., Singh, R. K., and Kim, H. W. (2019). Carbon-based nanomaterials as an emerging platform for theranostics. Mater. Horiz. 6, 434-469. doi:10.1039/ c8mh00966j

Paul, D. R., and Robeson, L. M. (2008). Polymer nanotechnology: nanocomposites. Polymer 49, 3187-3204. doi:10.1016/j.polymer.2008.04.017

Paun, I. A., Calin, B. S., Mustaciosu, C. C., Mihailescu, M., Moldovan, A., Crisan, O., et al. (2019). 3D superparamagnetic scaffolds for bone mineralization under static magnetic field stimulation. Materials 12, 1-20. doi:10.3390/ma12172834

Paun, I. A., Mustaciosu, C. C., Mihailescu, M., Calin, B. S., and Sandu, A. M. (2020). Magnetically-driven 2D cells organization on superparamagnetic micromagnets fabricated by laser direct writing. Sci. Rep. 10, 1-12. doi:10. 1038/s41598-020-73414-4

Perry, A., Au, T. H., Trinh, D. T., Do, D. B., Buil, S., Quélin, X., et al. (2019). "Mask lithography of 2D fluorescent magneto-photonic microstructures for biomedical and quantum applications," in Colloidal Nanoparticles for Biomedical Applications XIV. Editors W. J. Parak and M. Osiński (SPIE). doi:10.1117/12.2509446

Persano, L., Camposeo, A., Di Benedetto, F., Stabile, R., Laera, A. M., Piscopiello, E., et al. (2012). CdS-polymer nanocomposites and light-emitting fibers by in situ electron-beam synthesis and lithography. Adv. Mater. 24, 5320-5326. doi:10. 1002/adma.201202440

Peters, C., Ergeneman, O., García, P. D., Müller, M., Pané, S., Nelson, B. J., et al. (2014). Superparamagnetic twist-type actuators with shape-independent magnetic properties and surface functionalization for advanced biomedical applications. Adv. Funct. Mater. 24, 5269-5276. doi:10.1002/adfm.201400596

Peters, C., Hoop, M., Pané, S., Nelson, B. J., and Hierold, C. (2016). Degradable magnetic composites for minimally invasive interventions: device fabrication, targeted drug delivery, and cytotoxicity tests. Adv. Mater. 28, 533-538. doi:10. 1002/adma.201503112

Pilot, R., Signorini, R., Durante, C., Orian, L., Bhamidipati, M., and Fabris, L. (2019). A review on surface-enhanced Raman scattering. Biosensors 9, 57. doi:10.3390/bios 9020057

Potts, J. R., Dreyer, D. R., Bielawski, C. W., and Ruoff, R. S. (2011). Graphenebased polymer nanocomposites. Polymer 52, 5-25. doi:10.1016/j.polymer.2010. 11.042

Pregibon, D. C., and Doyle, P. S. (2009). Optimization of encoded hydrogel particles for nucleic acid quantification. Anal. Chem. 81, 4873-4881. doi:10. $1021 /$ ac9005292

Pudlauskaite, J., Jankauskaite, V., Lazauskas, A., Prosyčevas, I., and Narmontas, P. (2013). Ag/DNQ-novolac-based nanocomposite films for controllable UV lithography morphological patterning. Colloid Polym. Sci. 291, 1787-1793. doi:10.1007/s00396-013-3008-8

Qin, D., Xia, Y., and Whitesides, G. M. (2010). Soft lithography for micro- and nanoscale patterning. Nat. Protoc. 5, 491-502. doi:10.1038/nprot.2009.234

Rahaman, M., Aldalbahi, A., Govindasami, P., Khanam, N. P., Bhandari, S., Feng, P., et al. (2017). A new insight in determining the percolation threshold of electrical conductivity for extrinsically conducting polymer composites through different sigmoidal models. Polymers 9, 1-17. doi:10.3390/polym9100527

Rasoulianboroujeni, M., Fahimipour, F., Shah, P., Khoshroo, K., Tahriri, M., Eslami, H., et al. (2019). Development of 3d-printed plga/ $/ \mathrm{TiO}_{2}$ nanocomposite scaffolds for bone tissue engineering applications. Mater. Sci. Eng. C 96, 105-113. doi:10.1016/j.msec.2018.10.077

Reichmanis, E., Nalamasu, O., Houlihan, F. M., and Novembre, A. E. (1999). Radiation chemistry of polymeric materials: novel chemistry and applications for microlithography. Polym. Int. 48, 1053-1059. doi:10.1002/(SICI)10970126(199910)48:10<1053::AID-PI268>3.0.CO;2-T

Reimann, S.M., and Manninen, M. (2002). Electronic structure of quantum dots. Rev. Mod. Phys. 74, 1283-1342. doi:10.1103/RevModPhys.74.1283

Reiss, P., Protière, M., and Li, L. (2009). Core/shell semiconductor nanocrystals. Small 5, 154-168. doi:10.1002/smll.200800841

Romanenko, O., Slepička, P., Malinsky, P., Cutroneo, M., Havránek, V., Stammers, J., et al. (2020). The influence of Au-nanoparticles presence in PDMS on microstructures creation by ion beam lithography. Surf. Interf. Anal. 52, 1040. doi:10.1002/sia.6821 
SadAbadi, H., Badilescu, S., Packirisamy, M., and Wüthrich, R. (2013). Integration of gold nanoparticles in PDMS microfluidics for lab-on-a-chip plasmonic biosensing of growth hormones. Biosens. Bioelectron. 44, 77-84. doi:10.1016/ j.bios.2013.01.016

Saifullah, M. S. M., Khan, M. Z. R., Hasko, D. G., Leong, E. S. P., Neo, X. L., Goh, E. T. L., et al. (2010). Spin-coatable $\mathrm{HfO}_{2}$ resist for optical and electron beam lithographies. J. Vac. Sci. Technol. B, Nanotechnol. Microelectron. Mater. Process. Meas. Phenom. 28, 90-95. doi:10.1116/1.3273536

Saifullah, M. S. M. (2009). Sub-10 nm direct patterning of oxides using an electron beam-a review. Scientific world 5, 1-21. doi:10.1142/s0219607709000403

Saifullah, M. S., Namatsu, H., Yamaguchi, T., Yamazaki, K., and Kurihara, K. (1999). Spin-coatable $\mathrm{Al}_{2} \mathrm{O}_{3}$ resists in electron-beam nanolithography. Jpn. J. Appl. Phys. 3678, 633. doi:10.1117/12.350248

Saifullah, M. S., Subramanian, K. R., Kang, D. J., Anderson, D., Huck, W. T., Jones, G. A., et al. (2005). Sub-10 nm high-aspect-ratio patterning of $\mathrm{ZnO}$ using an electron beam. Adv. Mater. 17, 1757-1761. doi:10.1002/adma. 200500484

Saifullah, M. S., Subramanian, K. R., Tapley, E., Kang, D. J., Welland, M. E., and Butler, M. (2003). Sub-10 nm electron beam nanolithography using spincoatable $\mathrm{TiO}_{2}$ resists. Nano Lett. 3, 1587-1591. doi:10.1021/nl034584p

Sakar, M. S., Steager, E. B., Kim, D. H., Kim, M. J., Pappas, G. J., and Kumar, V. (2010). Single cell manipulation using ferromagnetic composite microtransporters. Appl. Phys. Lett. 96, 043705. doi:10.1063/1.3293457

Sakhno, O., Stumpe, J., and Smirnova, T. (2011). Distributed feedback dye laser holographically induced in improved organic-inorganic photocurable nanocomposites. Appl. Phys. B 103, 907-916. doi:10.1007/s00340-011$4487-2$

Sakhno, O. V., Goldenberg, L. M., Stumpe, J., and Smirnova, T. N. (2009). Effective volume holographic structures based on organic-inorganic photopolymer nanocomposites. J. Opt. A: Pure Appl. Opt. 11, 024013. doi:10.1088/1464$4258 / 11 / 2 / 024013$

Schadler, L. S., Kumar, S. K., Benicewicz, B. C., Lewis, S. L., and Harton, S. E. (2007). Designed interfaces in polymer nanocomposites: a fundamental viewpoint. MRS Bull. 32, 335-340. doi:10.1557/mrs2007.232

Sengupta, R., Bhattacharya, M., Bandyopadhyay, S., and Bhowmick, A. K. (2011). A review on the mechanical and electrical properties of graphite and modified graphite reinforced polymer composites. Prog. Polym. Sci. 36, 638-670. doi:10. 1016/j.progpolymsci.2010.11.003

Shen, X., Zheng, Q., and Kim, J.-K. K. (2021). Rational design of twodimensional nanofillers for polymer nanocomposites toward multifunctional applications. Prog. Mater. Sci. 115, 100708. doi:10.1016/ j.pmatsci.2020.100708

Shin, K., Park, J. S., Han, J. H., Choi, Y., Chung, D. S., and Kim, S. H. (2017). Patterned transparent electrode with a continuous distribution of silver nanowires produced by an etching-free patterning method. Sci. Rep. 7, 1-10. doi:10.1038/srep40087

Shuai, X., Zhu, P., Zeng, W., Hu, Y., Liang, X., Zhang, Y., et al. (2017). Highly sensitive flexible pressure sensor based on silver nanowires-embedded polydimethylsiloxane electrode with microarray structure. ACS Appl. Mater. Inter. 9, 26314-26324. doi:10.1021/acsami.7b05753

Singh, A., Kulkarni, S. K., and Khan-Malek, C. (2011). Patterning of $\mathrm{SiO}_{2}$ nanoparticle-PMMA polymer composite microstructures based on soft lithographic techniques. Microelectron. Eng. 88, 939-944. doi:10.1016/j.mee. 2010.12.026

Smirnova, T. N., Kokhtych, L. M., Kutsenko, A. S., Sakhno, O. V., and Stumpe, J. (2009a). The fabrication of periodic polymer/silver nanoparticle structures: insitu reduction of silver nanoparticles from precursor spatially distributed in polymer using holographic exposure. Nanotechnology 20, 405301. doi:10.1088/ 0957-4484/20/40/405301

Smirnova, T. N., Sakhno, O. V., Stumpe, J., Kzianzou, V., and Schrader, S. (2011). Distributed feedback lasing in dye-doped nanocomposite holographic transmission gratings. J. Opt. 13, 035709. doi:10.1088/2040-8978/13/3/ 035709

Smirnova, T. N., Sakhno, O. V., Yezhov, P. V., Kokhtych, L. M., Goldenberg, L. M., and Stumpe, J. (2009b). Amplified spontaneous emission in polymer-CdSe/ ZnS-nanocrystal DFB structures produced by the holographic method. Nanotechnology 20, 245707. doi:10.1088/0957-4484/20/24/245707
Smith, M. J., Lin, C. H., Yu, S., and Tsukruk, V. V. (2019). Composite structures with emissive quantum dots for light enhancement. Adv. Opt. Mater. 7, 1801072. doi:10.1002/adom.201801072

Smith, M. M. J., Malak, S. T., Jung, J., Yoon, Y. J., Lin, C. H., Kim, S., et al. (2017). Robust, uniform, and highly emissive quantum dot-polymer films and patterns using thiol-ene chemistry. ACS Appl. Mater. Inter. 9, 17435-17448. doi:10. 1021/acsami.7b03366

Song, S. W., Jeong, Y., and Kwon, S. (2015). Photocurable polymer nanocomposites for magnetic, optical, and biological applications. IEEE J. Sel. Top. Quan. Electron. 21, 324-335. doi:10.1109/JSTQE.2014.2381491

Sperling, R. a., and Parak, W. J. (2010). Surface modification, functionalization and bioconjugation of colloidal inorganic nanoparticles. Phil. Trans. R. Soc. A. 368, 1333-1383. doi:10.1098/rsta.2009.0273

Srinivas, R. L., Chapin, S. C., and Doyle, P. S. (2011). Aptamer-functionalized microgel particles for protein detection. Anal. Chem. 83, 9138-9145. doi:10. $1021 / \mathrm{ac} 202335 \mathrm{u}$

Stöber, W., Fink, A., Bohn, E., and Stober, W. (1968). Controlled growth of monodisperse silica spheres in the micron size range. J. Colloid Interf. Sci. 26, 62-69. doi:10.1016/0021-9797(68)90272-5

Subramanian, K. R., Saifullah, M. S., Tapley, E., Kang, D. J., Welland, M. E., and Butler, M. (2004). Direct writing of $\mathrm{ZrO}_{2}$ on a sub- $10 \mathrm{~nm}$ scale using an electron beam. Nanotechnology 15, 158-162. doi:10.1088/0957-4484/ $15 / 1 / 031$

Suh, S. K., Chapin, S. C., Hatton, T. A., and Doyle, P. S. (2012). Synthesis of magnetic hydrogel microparticles for bioassays and tweezer manipulation in microwells. Microfluid Nanofluid 13, 665-674. doi:10.1007/s10404-0120977-8

Sun, P., Burton, A. R., and Lynch, J. P. (2018). "Spatial strain measurements using a strain-sensing grid patterned from nanocomposite films," in Sensors and smart structures technologies for civil, mechanical, and aerospace systems, Denver, CO, March 5-8, 2018 (Bellingham, WA: International Society for Optics and Photonics), 10598, 1059808

Sun, S., and Zeng, H. (2002). Size-controlled synthesis of magnetite nanoparticles. J. Am. Chem. Soc. 124, 8204-8205. doi:10.1021/ja026501x

Suter, M., Ergeneman, O., Zürcher, J., Moitzi, C., Pané, S., Rudin, T., et al. (2011a). A photopatternable superparamagnetic nanocomposite: material characterization and fabrication of microstructures. Sensors Actuators, B Chem. 156, 433-443. doi:10.1016/j.snb.2011.04.078

Suter, M., Ergeneman, O., Zürcher, J., Schmid, S., Camenzind, A., Nelson, B. J., et al. (2011b). Superparamagnetic photocurable nanocomposite for the fabrication of microcantilevers. J. Micromech. Microeng. 21, 025023. doi:10. 1088/0960-1317/21/2/025023

Suter, M., Zhang, L., Siringil, E. C., Peters, C., Luehmann, T., Ergeneman, O., et al. (2013). Superparamagnetic microrobots: fabrication by two-photon polymerization and biocompatibility. Biomed. Microdevices 15, 997-1003. doi:10.1007/s10544-013-9791-7

Tan, E. K., Shrestha, P. K., Pansare, A. V., Chakrabarti, S., Li, S., Chu, D., et al. (2019). Density modulation of embedded nanoparticles via spatial, temporal, and chemical control elements. Adv. Mater. 31, 1-7. doi:10.1002/adma. 201901802

Tandon, B., Blaker, J. J., and Cartmell, S. H. (2018). Piezoelectric materials as stimulatory biomedical materials and scaffolds for bone repair. Acta Biomater. 73, 1-20. doi:10.1016/j.actbio.2018.04.026

Tasoglu, S., Diller, E., Guven, S., Sitti, M., and Demirci, U. (2014). Untethered micro-robotic coding of three-dimensional material composition. Nat. Commun. 5, 3124. doi:10.1038/ncomms4124

Teo, B. M., Young, D. J., and Loh, X. J. (2016). Magnetic anisotropic particles: toward remotely actuated applications. Part. Part. Syst. Charact. 33, 709-728. doi:10.1002/ppsc.201600060

Tian, Z., Wang, Y., Chen, Y., Xu, B., Di, Z., and Mei, Y. (2020). Inorganic stimuliresponsive nanomembranes for small-scale Actuators and robots. Adv. Intell. Syst. 2, 1900092. doi:10.1002/aisy.201900092

Tierno, P. (2014). Recent advances in anisotropic magnetic colloids: realization, assembly and applications. Phys. Chem. Chem. Phys. 16, 23515-23528. doi:10. 1039/c4cp03099k

Tiwale, N., Subramanian, A., Kisslinger, K., Lu, M., Kim, J., Stein, A., et al. (2019). Advancing next generation nanolithography with infiltration synthesis of 
hybrid nanocomposite resists. J. Mater. Chem. C 7, 8803-8812. doi:10.1039/ c9tc02974e

Tjong, S. C. (2006). Structural and mechanical properties of polymer nanocomposites. Mater. Sci. Eng. R. Rep. 53, 73-197. doi:10.1016/j.mser. 2006.06.001

Tottori, S., Zhang, L., Qiu, F., Krawczyk, K. K., Franco-Obregón, A., and Nelson, B. J. (2012). Magnetic helical micromachines: fabrication, controlled swimming, and cargo transport. Adv. Mater. 24, 811-816. doi:10.1002/adma.201103818

Tseng, Y.-C., Peng, Q., Ocola, L. E., Czaplewski, D. A., Elam, J. W., and Darling, S. B. (2011). Enhanced polymeric lithography resists via sequential infiltration synthesis. J. Mater. Chem. 21, 11722-11725. doi:10.1039/cljm12461g

Tsubokawa, N. (2007). Surface grafting of polymers onto nanoparticles in a solvent-free dry-system and applications of polymer-grafted nanoparticles as novel functional hybrid materials. Polym. J. 39, 983-1000. doi:10.1295/polymj. PJ2007035

Turkevich, J., Stevenson, P. C., and Hillier, J. (1951). A study of the nucleation and growth processes in the synthesis of colloidal gold. Discuss. Faraday Soc. 11, 55. doi:10.1039/df9511100055

Ushiba, S., Shoji, S., Masui, K., Kono, J., and Kawata, S. (2014). Direct laser writing of 3D architectures of aligned carbon nanotubes. Adv. Mater. 26, 5653-5657. doi:10.1002/adma.201400783

Vaijayanthimala, V., and Chang, H.-C. (2009). Functionalized fluorescent nanodiamonds for biomedical applications. Nanomedicine 4, 47-55. doi:10. 2217/17435889.4.1.47

Valizadeh, A., Mikaeili, H., Samiei, M., Farkhani, S. M., Zarghami, N., Kouhi, M., et al. (2012). Quantum dots: synthesis, bioapplications, and toxicity. Nanoscale Res. Lett. 7, 480. doi:10.1186/1556-276X-7-480

Vaudreuil, S., Labzour, A., Sinha-Ray, S., Mabrouk, K. E., and Bousmina, M. (2007). Dispersion characteristics and properties of poly(methyl methacrylate)/ multi-walled carbon nanotubes nanocomposites. J. Nanosci. Nanotech. 7, 2349-2355. doi:10.1166/jnn.2007.419

Vieille, V., Pétrot, R., Stéphan, O., Delattre, G., Marchi, F., Verdier, M., et al. (2020). Fabrication and magnetic actuation of 3D-microprinted multifunctional hybrid microstructures. Adv. Mater. Technol. 5, 1-8. doi:10.1002/admt.202000535

Vieu, C., Carcenac, F., Pépin, A., Chen, Y., Mejias, M., Lebib, A., et al. (2000). Electron beam lithography: resolution limits and applications. Appl. Surf. Sci. 164, 111-117. doi:10.1016/s0169-4332(00)00352-4

Voicu, N. E., Saifullah, M. S., Subramanian, K. R., Welland, M. E., and Steiner, U. (2007). $\mathrm{TiO}_{2}$ patterning using electro-hydrodynamic lithography. Soft Matter 3, 554-557. doi:10.1039/b616538a

Vora, K. D., Shew, B. Y., Harvey, E. C., Hayes, J. P., and Peele, A. G. (2008). Sidewall slopes of SU-8 HARMST using deep x-ray lithography. J. Micromech. Microeng. 18, 035037. doi:10.1088/0960-1317/18/3/035037

Waldman, R. Z., Mandia, D. J., Yanguas-Gil, A., Martinson, A. B., Elam, J. W., and Darling, S. B. (2019). The chemical physics of sequential infiltration synthesis a thermodynamic and kinetic perspective. J. Chem. Phys. 151, 190901. doi:10. $1063 / 1.5128108$

Wang, F., Deng, R., and Liu, X. (2014). Preparation of core-shell $\mathrm{NaGdF}_{4}$ nanoparticles doped with luminescent lanthanide ions to be used as upconversion-based probes. Nat. Protoc. 9, 1634-1644. doi:10.1038/nprot.2014.111

Wang, F., Han, Y., Lim, C. S., Lu, Y., Wang, J., Xu, J., et al. (2010). Simultaneous phase and size control of upconversion nanocrystals through lanthanide doping. Nature 463, 1061-1065. doi:10.1038/nature08777

Wang, G., Hill, N. S., Zhu, D., Xiao, P., Coote, M. L., and Stenzel, M. H. (2019). Efficient photoinitiating system based on diaminoanthraquinone for $3 \mathrm{~d}$ printing of polymer/carbon nanotube nanocomposites under visible light. ACS Appl. Polym. Mater. 1, 1129-1135. doi:10.1021/acsapm. $9 \mathrm{~b} 00140$

Wang, J., Xia, H., Xu, B.-B., Niu, L.-G., Wu, D., Chen, Q.-D., et al. (2009). Remote manipulation of micronanomachines containing magnetic nanoparticles. Opt. Lett. 34, 581. doi:10.1364/OL.34.000581

Wang, Z., Wang, K., Liang, D., Yan, L., Ni, K., Huang, H., et al. (2020). Hybrid magnetic micropillar arrays for programmable actuation. Adv. Mater. 32, 2001879. doi:10.1002/adma.202001879

Watson, G. P., Aksyuk, V., Simon, M. E., Tennant, D. M., Cirelli, R. A., Mansfield, W. M., et al. (2006). Spatial light modulator for maskless optical projection lithography. J. Vac. Sci. Technol. B 24, 2852-2856. doi:10.1116/1.2387156
Webb, D. J., and Hatzakis, M. (1979). Metal methacrylates as sensitizers for poly methyl methacrylate electron resists. J. Vac. Sci. Technol. 16, 2008-2013. doi:10. $1116 / 1.570331$

White, S. I., Mutiso, R. M., Vora, P. M., Jahnke, D., Hsu, S., Kikkawa, J. M., et al. (2010). Electrical percolation behavior in silver nanowire-polystyrene composites: simulation and experiment. Adv. Funct. Mater. 20, 2709-2716. doi:10.1002/adfm.201000451

Woehrle, G. H., Brown, L. O., and Hutchison, J. E. (2005). Thiol-functionalized, $1.5 \mathrm{~nm}$ gold nanoparticles through ligand exchange reactions: scope and mechanism of ligand exchange. J. Am. Chem. Soc. 127, 2172-2183. doi:10. 1021/ja0457718

Wolosiuk, A., Tognalli, N. G., Martínez, E. D., Granada, M., Fuertes, M. C., Troiani, H., et al. (2014). Silver nanoparticle-mesoporous oxide nanocomposite thin films: a platform for spatially homogeneous SERS-active substrates with enhanced stability. ACS Appl. Mater. Inter. 6, 5263-5272. doi:10.1021/ am500631f

Wu, H., Fahy, W. P., Kim, S., Kim, H., Zhao, N., Pilato, L., et al. (2020). Recent developments in polymers/polymer nanocomposites for additive manufacturing. Prog. Mater. Sci. 111, 100638. doi:10.1016/j.pmatsci.2020.100638

Wu, W., He, Q., and Jiang, C. (2008). Magnetic iron oxide nanoparticles: synthesis and surface functionalization strategies. Nanoscale Res. Lett. 3, 397-415. doi:10. 1007/s11671-008-9174-9

Wu, Z., Guo, C., Liang, S., Zhang, H., Wang, L., Sun, H., et al. (2012). A pluronic F127 coating strategy to produce stable up-conversion $\mathrm{NaYF}_{4}: \mathrm{Yb}, \mathrm{Er}(\mathrm{Tm})$ nanoparticles in culture media for bioimaging. J. Mater. Chem. 22, 18596-18602. doi:10.1039/c2jm33626j

Xi, S., Shi, T., Liu, D., Xu, L., Long, H., Lai, W., et al. (2013). Integration of carbon nanotubes to three-dimensional C-MEMS for glucose sensors. Sensors Actuators A. Phys. 198, 15-20. doi:10.1016/j.sna.2013.04.004

Xia, H., Wang, J., Tian, Y., Chen, Q. D., Du, X. B., Zhang, Y. L., et al. (2010). Ferrofluids for fabrication of remotely controllable micro-nanomachines by two-photon polymerization. Adv. Mater. 22, 3204-3207. doi:10.1002/adma. 201000542

Xiong, W., Liu, Y., Jiang, L. J. L., Zhou, Y. S., Li, D. W., Jiang, L. J. L., et al. (2016). Laser-Directed assembly of aligned carbon nanotubes in three dimensions for multifunctional device fabrication. Adv. Mater. 28, 2002-2009. doi:10.1002/ adma.201505516

Xu, B.-B., Zhang, Y.-L., Zhang, R., Wang, L., Xiao, X.-Z., Xia, H., et al. (2013). Programmable assembly of cdte quantum dots into microstructures by femtosecond laser direct writing. J. Mater. Chem. C 1, 4699-4704. doi:10. $1039 / \mathrm{c} 3 \mathrm{tc} 30666 \mathrm{f}$

$\mathrm{Xu}$, J., and Wong, C. (2007). High dielectric constant su8 composite photoresist for embedded capacitors. J. Appl. Polym. Sci. 103, 1523-1528. doi:10.1002/app. 24957

Xu, J., Zhou, J., Chen, Y., Yang, P., and Lin, J. (2020a). Lanthanide-activated nanoconstructs for optical multiplexing. Coord. Chem. Rev. 415, 213328. doi:10. 1016/j.ccr.2020.213328

Xu, X., Broussier, A., Ritacco, T., Nahra, M., Geoffray, F., Issa, A., et al. (2020b). Towards the integration of nanoemitters by direct laser writing on optical glass waveguides. Photon. Res. 8, 1541-1550. doi:10.1364/prj.392706

Yang, C. G., Cheng, L., Ye, W. Q., Zheng, D. H., and Xu, Z. R. (2020a). Preparation of encoded bar-like core-shell microparticles on a microfluidic chip. Colloids Surf. A Physicochem. Eng. Asp. 588, 124373. doi:10.1016/j. colsurfa.2019.124373

Yang, J., Lee, J. Y., and Ying, J. Y. (2011). Phase transfer and its applications in nanotechnology. Chem. Soc. Rev. 40, 1672-1696. doi:10.1039/B916790K

Yang, T. Q., Peng, B., Shan, B. Q., Zong, Y. X., Jiang, J. G., Wu, P., et al. (2020b). Origin of the photoluminescence of metal nanoclusters: from metal-centered emission to ligand-centered emission. Nanomaterials 10, 261. doi:10.3390/ nano10020261

Yang, Y., Peng, S., Qi, F., Zan, J., Liu, G., Zhao, Z., et al. (2020c). Graphene-assisted barium titanate improves piezoelectric performance of biopolymer scaffold. Mater. Sci. Eng. C 116, 111195. doi:10.1016/j.msec.2020.111195

Yasa, I. C., Tabak, A. F., Yasa, O., Ceylan, H., and Sitti, M. (2019). 3D-printed microrobotic transporters with recapitulated stem cell niche for programmable and active cell delivery. Adv. Funct. Mater. 29, 1808992. doi:10.1002/adfm. 201808992 
Yoon, J., and Park, W. (2020). Microsized 3D hydrogel printing system using microfluidic maskless lithography and single axis stepper motor. Biochip J. 14, 317. doi:10.1007/s13206-020-4310-4

Yu, H., Liu, J., Zhao, Y.-Y., Jin, F., Dong, X.-Z., Zhao, Z.-S., et al. (2019a). Biocompatible three-dimensional hydrogel cell scaffold fabricated by sodium hyaluronate and chitosan assisted two-photon polymerization. ACS Appl. Bio Mater. 2, 3077-3083. doi:10.1021/acsabm.9b00384

Yu, H., Peng, Y., Yang, Y., and Li, Z. Y. (2019b). Plasmon-enhanced light-matter interactions and applications. Npj Comput. Mater. 5, 1-14. doi:10.1038/s41524-019-0184-1

Yu, Z., Wang, C.-F., Ling, L., Chen, L., and Chen, S. (2012). Triphase microfluidicdirected self-assembly: anisotropic colloidal photonic crystal supraparticles and multicolor patterns made easy. Angew. Chem. 124, 2425-2428. doi:10.1002/ ange.201107126

Zeng, X., Vanga, S. K., Poh, E. T., Shi, Y., Sow, C. H., Bettiol, A. A., et al. (2020). Photolithographic fabrication of upconversion barcodes for multiplexed molecular detection. Adv. Opt. Mater. 8, 2001168. doi:10.1002/adom.202001168

Zhang, J., Ye, S., Liu, H., Chen, X., Chen, X., Li, B., et al. (2020). 3d printed piezoelectric bnnts nanocomposites with tunable interface and microarchitectures for self-powered conformal sensors. Nano Energy 77, 105300. doi:10.1016/j.nanoen.2020.105300
Zhao, Q., Zhao, M., Qiu, J., Lai, W. Y., Pang, H., and Huang, W. (2017). One dimensional silver-based nanomaterials: preparations and electrochemical applications. Small 13, 1-18. doi:10.1002/smll.201701091

Zhao, Y., Shum, H. C., Chen, H., Adams, L. L., Gu, Z., and Weitz, D. A. (2011). Microfluidic generation of multifunctional quantum dot barcode particles. J. Am. Chem. Soc. 133, 8790-8793. doi:10.1021/ja200729w

Zhou, L., Fu, J., and He, Y. (2020). A review of 3D printing technologies for soft polymer materials. Adv. Funct. Mater. 30, 2000187. doi:10.1002/adfm.202000187

Conflict of Interest: The authors declare that the research was conducted in the absence of any commercial or financial relationships that could be construed as a potential conflict of interest.

Copyright (c) 2021 Martínez, Prado, Gonzalez, Anguiano, Tosi, Salazar Alarcón and Pastoriza. This is an open-access article distributed under the terms of the Creative Commons Attribution License (CC BY). The use, distribution or reproduction in other forums is permitted, provided the original author(s) and the copyright owner(s) are credited and that the original publication in this journal is cited, in accordance with accepted academic practice. No use, distribution or reproduction is permitted which does not comply with these terms. 


\section{APPENDIX}

\section{Lithographic Methods}

In this appendix we will briefly describe different lithographic methods employed in the experimental works discussed. As mentioned, lithography is the transfer of a predefined pattern to a surface covered by a thin PR film. After development, some regions of the substrate remain covered while others are exposed for the following deposition of materials or the etching of the substrate. The latter can proceed either by means of a suitable chemical solution (wet etching) or by using an accelerated plasma (dry etching). The etching reaction proceeds differently for the substrate and the resist. Selectivity is calculated as the quotient between the etch rate of the material to be removed and the protecting resist. Alternatively, other materials can be deposited on the uncovered parts. The resist, also covered with the deposited material, can then be removed or "lifted-off."

Based on the specific type of radiation used for structuring the resist, different methods can be grouped: Photo-lithography relies on a photo-curing (negative-tone) or photo-degrading (positivetone) resist. Different photon wavelengths can be used, but the most common platforms use UV light. Other techniques rely on accelerated charged particles, instead of photons, to modify the solubility of the resist, or to directly remove it. Examples include EBL and ion projection lithography. For the first, a focused beam is controlled with a computer while the latter uses a patterned mask. In photo-lithography methods, three main photon energy ranges are commonly used: UV, $\mathrm{x}$-ray and IR. UV irradiation is the most widespread, and encompasses regular UV $(365 \mathrm{~nm}$ i-line, $405 \mathrm{~nm}$ h-line, $436 \mathrm{~nm}$ g-line), deep UV (190-250 nm) and extreme UV $(<100 \mathrm{~nm})$. The spatial resolution of photolithography is limited by diffraction, which in turn depends on the wavelength. For i, $g$ and $h \mathrm{UV}$ lines the resolution lie in the order of a few microns. The selective irradiation of the resist is usually carried out with an opaque patterned mask and homogeneous illumination through a mask-aligner. Maskless methods using UV light include stereolithography (Wu et al., 2020) and projection lithography (Dinh et al., 2019). The former relies on layer-by-layer photo-curing of a photopolymer, while the latter relies on a DMD or a spatial light modulator (SLM) (Watson et al., 2006) to generate the desired pattern. Holographic lithography, on the other hand, uses interference patterns generated through the engineering of coherent illumination to generate periodic structures in relatively wide surfaces (Liu et al., 2020).
$\mathrm{X}$-rays are much more energetic than UV photons and, thus, have a higher penetration depth in the resist. This makes XRL better for thick resist applications, generating vertical walls even for thicknesses in the order of millimeters (Vora et al., 2008). IR lithography, on the other hand, relies mostly on multi-photon absorption (MPA). In contrast to $x$-ray and UV irradiation, MPA requires very high photon densities. Therefore, only direct writing with one or several focused fs-pulsed-laser beams is possible. MPA techniques are specially suitable for complex and precise 3D structuring of resists (LaFratta et al., 2007). By far, the most widespread technique of this kind is TPL. 3D features as small as $100 \mathrm{~nm}$ can be achieved with this technique (Carlotti and Mattoli, 2019; Fourkas, 2020; Liao et al., 2020). Another less common but quite interesting technique is LOPA, which is similar to stereolithography but relies on a low absorption band of the resist to enhance the penetration depth. For the case of SU-8, a $532 \mathrm{~nm}$ CW laser is used (Nguyen et al., 2018). Interestingly, the resulting nano-structures are comparable to those obtained by MPA techniques (Do et al., 2013).

Regarding charged particle methods, EBL is the most popular technique. It relies on a focused beam of accelerated electrons which forms the desired pattern on the resist through a predefined scan of the surface. Its main advantage is the attainable resolution. For instance, while photo-lithography has to deal with the diffraction limit of photons, electrons can be used to generate features below $\sim 10 \mathrm{~nm}$ (Vieu et al., 2000). Its main drawback, on the other hand, is the susceptibility to charge building on the exposed surfaces. This may impair the resolution, due to beam repulsion from the surface, effectively limiting the technique to conductive materials.

Finally, the use of microfluidics for maskless lithography is a research field of continuous interest. The reader is referred to the review by Tian et al. (Tian et al., 2020) which discuss, in particular, the fabrication of complex 3D microparticles by microfluidic lithography. A combined system including a vertical step motor was recently explored by Yoon and coworkers. The authors presented a micro 3D printing system which combines a microfluidic channel connecting a twodimensional particle generation system, and a single-axis stepper motor to control the thickness of each layer. Zinc oxide NPs being transparent, biocompatible, and capable of absorbing UV light, were added to the premixed photocurable solution allowing the fabrication of robust three dimensional micro-patterned particles (Yoon and Park, 2020). 


\section{NOMENCLATURE}

$\phi$ filling fraction

ALD atomic layer deposition

BIS N, N'-Methylenebisacrylamide

BNNT boron nitride nanotube

BTNP barium titanate nanoparticle

CNT carbon nanotube

CPN cyclopentanone

DFB distributed feedback

DLW direct laser writing

DMD digital micromirror device

DNQ diazonaphthoquinone

EBL electron beam lithography

GBL gamma (c)-butyrolactone

HSQ hydrogen silsesquioxane

IR infrared

LOPA ultra-low one-photon absorption

MEMS microelectro-mechanical system

MPA multi-photon absorption

MPL multi-photon lithography

MSM magnetic soft material

MSMP magnetic shape memory polymer

MWCNT multi-wall carbon nanotube

NCM nanocomposite material

NCPR nanocomposite photoresist

NF nanofiller

NIR near-infrared

NP nanoparticle
NS nanostar

NW nanowire

PC photonic crystal

PDMS polydimethyl siloxane

PEG poly(ethylene glycol)

PEGDA poly(ethylene glycol) diacrylate

PETA pentaerythritol triacrylate

PGMEA propylene glycol methyl ether acetate

PLA polylactic acid

PMMA poly(methyl methacrylate)

PR photoresist

PSD particle size distribution

PTFE polytetrafluoroethylene

PVA polyvinyl alcohol

PVDF poly(vinylidene fluoride)

QD quantum dot

RGO reduced graphene oxide

SEM scanning electron microscope

SPION superparamagnetic iron oxide nanoparticle

SWCNT single-wall carbon nanotube

TMA trimethylaluminum

TMPETA trimethylolpropane ethoxylate triacrylate

TMSPM 3-(trimethoxysilyl)propyl methacrylate

TOP trioctylphosphine

TOPO trioctylphosphine oxide

TPL two-photon lithography

UCNP upconversion nanoparticle

UV ultraviolet

XRL x-ray lithography 